\title{
Oligocyclopentadienyl Transition Metal Complexes
}

Cristina G. de Azevedo, ${ }^{* 1}$ K. Peter C. Vollhardt*

Center for New Directions in Organic Synthesis, Department of Chemistry, University of California at Berkeley and the Chemical Sciences Division, Lawrence Berkeley National Laboratory, Berkeley, California 94720-1460, USA

Fax: 510643 5208; E-mail: vollhard@cchem.berkeley.edu

\begin{abstract}
Synthesis, characterization, and reactivity studies of oligocyclopentadienyl transition metal complexes, namely those of fulvalene, tercyclopentadienyl, quatercyclopentadienyl, and pentacyclopentadienyl(cyclopentadienyl) are the subject of this account. Thermal-, photo-, and redox chemistries of homo- and heteropolynuclear complexes are described.
\end{abstract}

Key words: fulvalene, heterodinuclear fulvalene, tercyclopentadienyl, quatercyclopentadienyl, pentacyclopentadienyl.

1. Introduction

2. Fulvalene Complexes

2.1. Homodinuclear Fulvalene Metal Carbonyls

2.1.1. Synthesis and structural characterization

2.1.2. Reactivity

2.1.3. Conclusions

2.2. Heterodinuclear Fulvalene Metal Complexes

2.2.1. Synthesis

2.2.2. Reactivity

2.2.3. Conclusions

3. Tercyclopentadienyl Metal Complexes

3.1. Synthesis and structural characterization

3.2. Reactivity

3.2.1. Anionic charge transfer

3.2.2. Radical electron transfer

3.2.3. Methyl transfer

3.2.4. Some tantalizing photochemical experiments

3.2.5. Conclusions

4. Quatercyclopentadienyl Metal Complexes

5. Penta(cyclopentadienyl)cyclopentadienyl Metal Complexes

5.1. Synthesis and structural characterization

5.2. Reactivity

5.3. Conclusions

6. Outlook

\section{Introduction}

The design and construction of "tailored" linked oligocyclopentadienyl ( $\mathrm{Cp}$ ) ring assemblies with defined topology may provide a family of ligands that can function as ideal templates on which to bind metal centers. The reason for the interest in such systems stems in part from the suggestion that polynuclear species may act as suitable models for the interaction of organic 
molecules with surfaces ${ }^{2}$ and would constitute attractive molecules with which to explore the influence of their rigidly held arrays in organic substrate activation, intrachain ligand migration, electron transfer, and ultimately, synergistic catalysis.

These oligoCp ligands combine: i) the thermodynamic robustness offered by the $\mathrm{Cp}$ fragment ${ }^{3}$ which is among the most strongly bonded ligands in organometallic chemistry, with bond strengths to metals typically estimated at $90-100 \mathrm{kcal} / \mathrm{mol}^{; \mathrm{e}, \mathrm{f}}$ ii) the fully conjugated nature of the ligand $\pi$-system which may permit rapid through ligand electron transfer; ${ }^{4,5,6}$ and iii) sufficient proximity of the $\mathrm{Cp}$ moieties to allow for adjacent metal-metal bonds.

There are at least two important reasons for the notion that $\mathrm{Cp}$ polynuclear systems might exhibit properties quite different from those of their mononuclear (and those not directly attached oligonuclear ${ }^{6,7} \mathrm{Cp}$ analogs. First, in the metal-metal bonded configuration, the linked $\mathrm{Cp}$ rings are forced to bend away from overall planarity. Indeed, the distance between the ring centroids in a planar bicyclopentadienyl, or fulvalene, linked ligand has been estimated to be about $4 \AA{ }^{8}$ whereas most M-M bonds in fulvalene systems are less than $3.5 \AA$ (Table 1). This bending of the Fv ligand may cause strain which in turn may translate into unique reactivity. ${ }^{9}$ Second, the conjugated $\pi$ system of the Fv ligand provides a mechanism of electronic communication between the metal centers, ${ }^{9 a}$ regardless of whether there is a metal-metal bond present or not and of whether the metals are oriented cis or trans with respect to the bridging ligand, thus facilitating potential synergism.

Table 1. Some Reprensentative M-M Distances $(\AA)$ and "Dihedral" Fulvalene Angles, $\theta\left({ }^{\circ}\right)$, in Fulvalenedimetals and Comparison with Selected CpM Dimers

\begin{tabular}{llcl}
\hline Compound & $\mathrm{M}-\mathrm{M}, \AA$ & $\theta\left(^{\circ}\right)$ & Ref. \\
\hline $\mathrm{Fv}_{2} \mathrm{Fe}_{2}$ & 3.984 & 2.6 & 10 \\
{$\left[\mathrm{Fv}_{2} \mathrm{~V}_{2}(\mathrm{NCMe})_{2}{ }^{2+}\right]\left[\mathrm{PF}_{6}{ }^{-}\right]_{2}$} & 3.329 & 13.6 & 11 \\
$\mathrm{FvMO}_{2}(\mathrm{CO})_{6}$ & 3.371 & 15.3 & 12 \\
$\mathrm{FvW}_{2}(\mathrm{CO})_{6}$ & 3.347 & 16.1 & 13 \\
$\mathrm{FvRu}_{2}(\mathrm{CO})_{4}$ & 2.821 & 28.5 & $14 \mathrm{a}$ \\
$\mathrm{FvRu}_{2}(\mathrm{CO})_{2}(\mu-\mathrm{CO})\left(\mu-\eta^{2}-\mathrm{C}_{2} \mathrm{H}_{2}\right)$ & 2.719 & 31.6 & $14 \mathrm{~d}$ \\
$\mathrm{FvCr}_{2}(\mathrm{CO})_{6}$ & 3.471 & 13.0 & 15 \\
{$\left[\mathrm{CpCr}(\mathrm{CO})_{3}\right]_{2}$} & 3.281 & - & $16 \mathrm{a}$ \\
{$\left[\mathrm{CpMo}(\mathrm{CO})_{3}\right]_{2}$} & 3.235 & - & $16 \mathrm{~b}$ \\
{$\left[\mathrm{CpW}(\mathrm{CO})_{3}\right]_{2}$} & 3.221 & - & $16 \mathrm{~b}$ \\
{$\left[\mathrm{CpRu}(\mathrm{CO})_{2}\right]_{2}$} & 2.735 & - & $16 \mathrm{c}$ \\
\hline
\end{tabular}

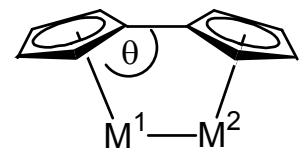

Among the possible oligoCp ligands, it is the simplest fulvalene (Fv) that has attracted most attention and the chemistry of dinuclear organometallic complexes containing this ligand is a topic of continuing interest. The fulvalene system is flexible and can accommodate structures with homo- and heteronuclear metal-metal bonds, additional bridging ligands, cis or trans geometry, sandwich, and cluster arrays, ${ }^{4,5 a, b, 6,17}$ providing complexes with a range of metal-metal distances and different degrees of electronic communication between the metals. Fulvalene complexes also offer the opportunity to compare the properties of analogous mono- and dinuclear $\mathrm{Cp}$-systems in order to test the potential cooperative interaction of two metal centers with a substrate. 
About ten years ago, we were stimulated by the emerging rich chemistry of fulvalene complexes ${ }^{14,18}$ to extend the ligand by successive attachment of $\mathrm{Cp}$ rings, giving rise to terCp, quaterCp, and higher oligoCp ligands. These can be viewed as cyclopentadienylmetal analogs of the corresponding fulvalene dimetals and as such constitute attractive molecules with which to explore the basic chemical potential of metal arrays rigidly held in "unnatural" configurations. ${ }^{19}$ The oligoCp ligands would allow the binding of additional metals and the formation of "super" half-sandwich oligocyclopentadienyl transition metal complexes. At the outset of this work halfsandwich oligoCp complexes were unknown, in contrast to the analogous and extensively investigated sandwich oligometallocenes. ${ }^{4-6,20}$

This account will provide a selective update on our studies of oligocyclopentadienylmetals, focusing on work accomplished since $1990 .{ }^{18}$ Some of the older results are included when it was necessary to provide coherence to the story, but the reader is encouraged to peruse ref. 18 as an introduction. We will begin with the simplest ligand, fulvalene, its attachment to homo- and then heterodinuclear fragments and the chemistry arising from these compounds. We will then move on to the larger systems, comprised of three and four "linearly" linked CpM units and the regio- and stereochemical intricacies associated with their construction. The report ends with the current "record" of our efforts, the assembly of penta(cyclopentadienyl)cyclopentadienylmanganese tricarbonyl. The emphasis throughout will be on the synthetic aspects of the targets.

\section{Fulvalene Complexes}

\subsection{Homonuclear Fulvalene Metal Carbonyls}

\subsubsection{Synthesis and structural characterization}

Our entry into this field occurred in 1983, when it was still in its infancy, with our report ${ }^{14 a, b}$ of an effective synthetic variant into the class of half-sandwich fulvalene systems. It was based on the discovery that dihydrofulvalene, $\mathbf{1}$, is relatively stable when pure and can therefore be converted in the presence of metal carbonyls, "M(CO)" at elevated temperatures to a number of fulvalene homodinuclear compounds (Table 2).

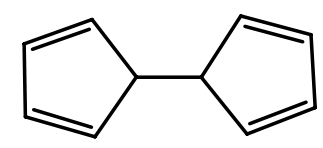

1

Table 2. Synthesis of Fulvalenedimetal Complexes from 1

\begin{tabular}{llllll}
\hline Complex & "M(CO)” & $\mathrm{M}$ & $\mathrm{M}$ ' & Yield & ref. \\
\hline $\mathrm{FvCo}_{2}(\mathrm{CO})_{4}, \mathbf{2}$ & $\mathrm{Co}_{2}(\mathrm{CO})_{8}$ & $\mathrm{Co}$ & $\mathrm{Co}$ & 80 & $14 \mathrm{~b}$ \\
$\mathrm{FvRu}_{2}(\mathrm{CO})_{4}, \mathbf{3}$ & $\mathrm{Ru}_{3}(\mathrm{CO})_{12}$ & $\mathrm{Ru}$ & $\mathrm{Ru}$ & 78 & $14 \mathrm{~b}$ \\
$\mathrm{FvCr}_{2}(\mathrm{CO})_{6}, \mathbf{4}$ & $\mathrm{Cr}(\mathrm{NCEt})_{3}(\mathrm{CO})_{3}$ & $\mathrm{Cr}$ & $\mathrm{Cr}$ & 71 & $15^{\mathrm{a}}$ \\
$\mathrm{FvMo}_{2}(\mathrm{CO})_{6} \mathbf{5}$ & $\mathrm{Mo}(\mathrm{CO})_{6}$ & $\mathrm{Mo}$ & $\mathrm{Mo}$ & 60 & $14 \mathrm{~b}$ \\
$\mathrm{FvW}_{2}(\mathrm{CO})_{6}, \mathbf{6}$ & $\mathrm{W}(\mathrm{NCEt})_{3}(\mathrm{CO})_{3}$ & $\mathrm{~W}$ & $\mathrm{~W}$ & 72 & $14 \mathrm{~b}$ \\
$\mathrm{Fv}\left[\mathrm{Ru}(\mathrm{CO})_{2}\right]\left[\mathrm{Mo}(\mathrm{CO})_{3}\right], 7$ & $\mathrm{Ru}_{3}(\mathrm{CO})_{12}+\mathrm{Mo}(\mathrm{CO})_{6}$ & $\mathrm{Ru}$ & $\mathrm{Mo}$ & 42 & $14 \mathrm{~b}$ \\
\hline
\end{tabular}

${ }^{\mathrm{a}}$ Via fulvalene dianion. 
Complexes 2, 3, and 5 were prepared by reaction with commercially available $\mathrm{Co}_{2}(\mathrm{CO})_{8}$, $\mathrm{Ru}_{3}(\mathrm{CO})_{12}$, and $\mathrm{Mo}(\mathrm{CO})_{6}$, respectively. Efficient syntheses of complexes 4 and $\mathbf{6}$ required the readily accessible propionitrile complexes $\mathrm{Cr}(\mathrm{NCEt})_{3}(\mathrm{CO})_{3}$ and $\mathrm{W}(\mathrm{NCEt})_{3}(\mathrm{CO})_{3}$, respectively. The corresponding $\mathrm{Cr}$ and $\mathrm{W}$ hexacarbonyls are insufficiently labile and the tris(acetonitrile) complexes too insoluble to react with dihydrofulvalene before it polymerizes. Attempts to prepare the iron analog of $\mathbf{3}^{21}$ under these conditions were unsuccessful. The heterodinuclear 7 was the first of its kind.

Most of the fulvalene compounds were found to be more stable than the analogous cyclopentadienyl complexes; they are air stable as solids and oxidize only slowly (over a period of many hours) in solutions protected from light. Their structural characterization (Table 1) shows that they all have a longer metal-metal bond than their $\mathrm{Cp}$ analogs. To accommodate such bonds, there is a bend from planarity in the ligand, the "dihedral" angle $\theta$ between the two Cp planes generally increasing as the bond length decreases, with a range of 2.6 to $31.6^{\circ}$.

\subsubsection{Reactivity}

Of the simple homodinuclear fulvalenes in Tables 1 and 2, the best scrutinized to date are $\mathbf{3}, \mathbf{5}$, and 6, as described in the following sections. All of these investigations began with the basic aim to establish ligand mobility and substitutional lability under thermal and/or photochemical conditions. Such chemistry is fundamental in the development of new potentially catalytic reactions on the dinuclear frame provided by fulvalene dimetals. A number of surprises were in store for us as these projects got underway, as the systems frequently deviated not only quantitatively, but, more importantly, qualitatively from the known chemistry of their CpMdimeric relatives.

\section{Homodinuclear Mo and W organometallic zwitterions}

Depending on reaction conditions and the electronic and steric properties of $\mathrm{PR}_{3}, \mathrm{Cp}_{2} \mathrm{Mo}_{2}(\mathrm{CO})_{6}$ may yield phosphine substituted Mo-Mo bonded dimers $\mathrm{Cp}_{2} \mathrm{Mo}_{2}(\mathrm{CO})_{6-\mathrm{x}}\left(\mathrm{PR}_{3}\right)_{\mathrm{x}}(\mathrm{x}=1,2)^{22}$ or disproportionation products $\left[\mathrm{CpMo}(\mathrm{CO})_{2}\left(\mathrm{PR}_{3}\right)_{2}\right]^{+}\left[\mathrm{CpMo}(\mathrm{CO})_{3}\right]^{-23}$. The latter are favored when electron-rich, sterically undemanding, and/or chelating phosphines are used.

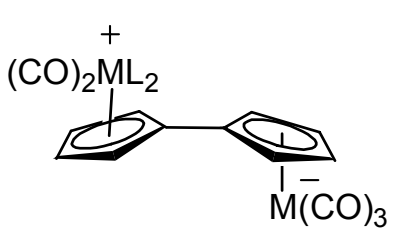

8a, $M=M o, L=P_{3}$ 9a, $M=W, L=\mathrm{PMe}_{3}$

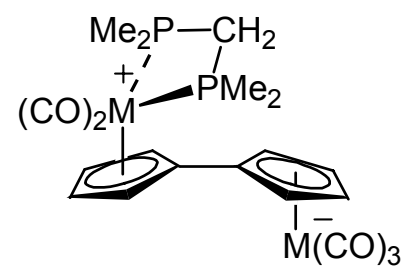

8b, $M=M o$

$9 b, M=W$

\section{Scheme 1}

With this behavior in mind, it was very surprising that treatment of 5 or 6 with $\mathrm{PPh}_{3}$, $\mathrm{Ph}_{2} \mathrm{PCH}_{2} \mathrm{PPh}_{2}$, or $\mathrm{Ph}_{2} \mathrm{PCH}_{2} \mathrm{CH}_{2} \mathrm{PPh}_{2}$, under thermal or photochemical conditions, gave no isolable products. However, when the reaction was performed with more basic phosphines, such as $\mathrm{PMe}_{3}$ or $\mathrm{Me}_{2} \mathrm{PCH}_{2} \mathrm{PMe}_{2}(\mathrm{dmpm}), \mathrm{FvM}_{2}(\mathrm{CO})_{5} \mathrm{~L}_{2} \mathbf{8 a}, \mathbf{b}$, and $\mathbf{9 a}$, b were obtained (Scheme 1). ${ }^{24}$ 
Complex $\mathbf{8 b}$ was structurally characterized by X-ray diffraction. The molecule consists of two Mo centers bonded to an essentially planar Fv ligand in a trans manner; both rings are planar and the dihedral angle between the two rings is $5^{\circ}$. Although conjugated, the molecule prefers the charge localized $\eta^{5}: \eta^{5}-F_{V}$ structure rather than the alternative $\eta^{6}: \eta^{4}-F v$ form, which would also give each metal 18 valence electrons (Scheme 2). Both $\mathrm{M}(\mathrm{CO})_{2} \mathrm{~L}_{2}\left(\right.$ diene) ${ }^{25}$ and $\mathrm{M}(\mathrm{CO})_{3}\left(\eta^{6}\right.$ fulvene $)^{26}$ complexes $\left(\mathrm{L}=\mathrm{PR}_{3} ; \mathrm{M}=\mathrm{Cr}\right.$, Mo, W) are well known.

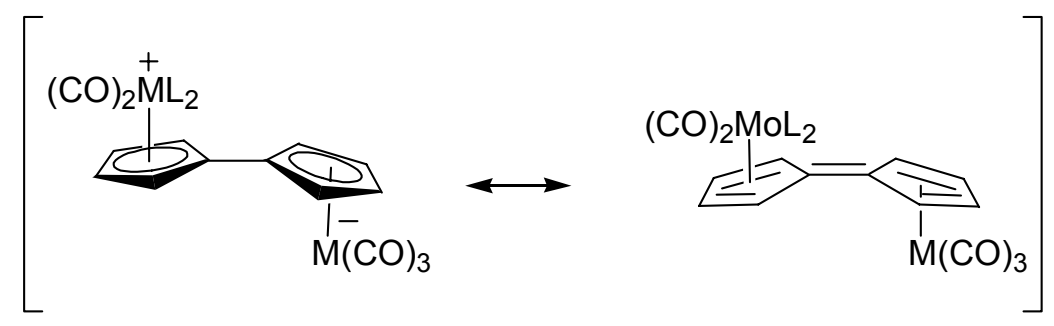

Scheme 2

These two alternatives can be viewed conceptually as either resonance structures or as (rapidly) equilibrating species. The possible contribution (in resonance terms) or availability (when viewed as equilibrating structures) of a fulvalene-diene form is of special importance for the reactivity to be described later. The mechanism proposed for the above reactions is a direct nucleophilic attack of the phosphine that causes heterolytic cleavage of M-M bond to generate a zwitterionic intermediate, as shown in Scheme 3. The relief of strain induced in $\mathbf{5}$ and $\mathbf{6}$ by the presence of the bent Fv ligand should enhance such reactivity towards nucleophiles. The cationic half of the resulting intermediate may then undergo substitution by the second phosphine unit to give the final products.
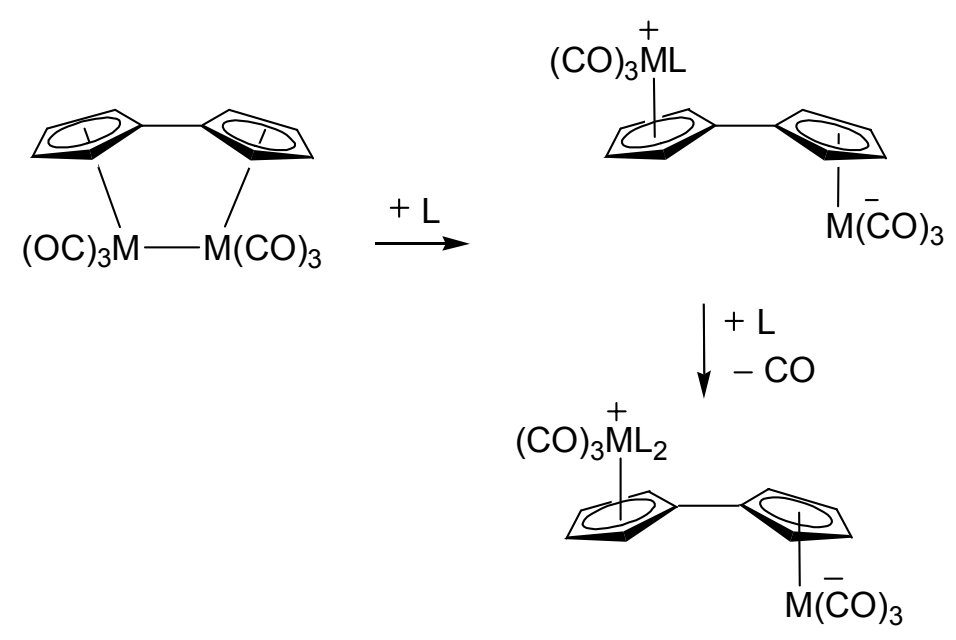

\section{Scheme 3}

The chemistry of $\mathbf{8}$ and $\mathbf{9}$ is consistent with the dipolar nature of zwitterions which induces dual reactivity: electrophiles add at the anionic end, nucleophiles at the cationic one. Some of the reactions performed are summarized in Scheme 4. 


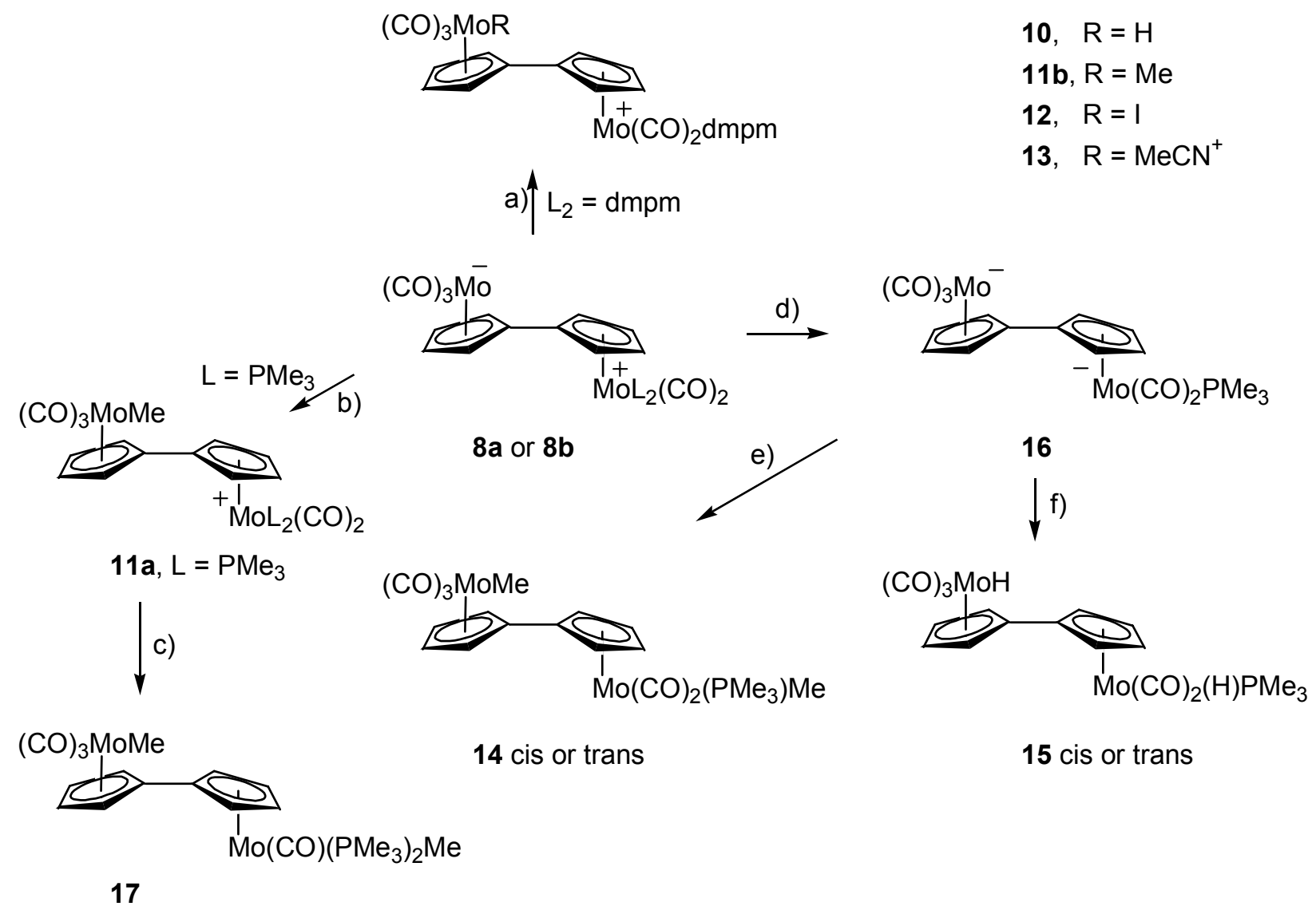

Scheme 4 a) $\mathbf{8 b}+\mathrm{HBF}_{4} \mathrm{Et}_{2} \mathrm{O} \rightarrow \mathbf{1 0} ; \mathbf{8 b}+\mathrm{CF}_{3} \mathrm{SO}_{3} \mathrm{Me} \rightarrow \mathbf{1 1 b} ; \mathbf{8 b}+\mathrm{I}_{2} \rightarrow \mathbf{1 2} ; \mathbf{8 b}+\mathrm{AgBF}_{4} \rightarrow \mathbf{1 3}$. b) $\mathrm{MeI}$. c) $\mathrm{LiAlH}_{4}$. d) $\mathrm{Na} / \mathrm{Hg}$. e) $\mathrm{MeI}$. f) $\mathrm{CF}_{3} \mathrm{COOH}$.

Thus, $8 \mathbf{b}$ reacted with $\mathrm{HBF}_{4} \mathrm{Et}_{2} \mathrm{O}, \mathrm{CF}_{3} \mathrm{SO}_{3} \mathrm{Me}, \mathrm{I}_{2}$, and $\mathrm{AgBF}_{4}$ to afford compounds of general formula $\left[\mathrm{FvMo}_{2}(\mathrm{CO})_{5}(\mathrm{dmpm})(\mathrm{R})\right]^{+}\left(\mathrm{R}=\mathrm{H}, \quad \mathbf{1 0} ; \mathrm{Me}, \mathbf{1 1 b} ; \mathrm{I}, \quad \mathbf{1 2} ; \mathrm{MeCN}^{+}, \quad \mathbf{1 3}\right)$. $\mathrm{FvMo}_{2}(\mathrm{CO})_{5}\left(\mathrm{PMe}_{3}\right)_{2}$ (8a) was unreactive toward $\mathrm{NaBH}_{4}$ (as anticipated on the basis of the reported inertness of $\left[\mathrm{CpMo}(\mathrm{CO})_{2}\left(\mathrm{PPh}_{3}\right)_{2}\right]^{+}$toward $\left.\mathrm{NaBH}_{4}{ }^{27}\right)$ but transformed with $\mathrm{LiAlH}_{4}$ to yield the anion $\left[\mathrm{FvMo}_{2}(\mathrm{CO})_{4}\left(\mathrm{PMe}_{3}\right)_{2} \mathrm{Me}\right]^{-}$. A reaction of $\mathbf{8 a}$ with nucleophiles is exemplified by the reduction of coordinated $\mathrm{CO}$ to $\mathrm{Me}$, performed by $\mathrm{LiAlH}_{4}$ at the cationic center of $\mathrm{FvMo}_{2}(\mathrm{CO})_{5}\left(\mathrm{PMe}_{3}\right)_{2}{ }^{+}$to give $\mathrm{FvMo}_{2}(\mathrm{CO})_{4}\left(\mathrm{PMe}_{3}\right)_{2} \mathrm{Me}_{2}(\mathbf{1 7})$. In analogy to the behavior of $\mathrm{FvW}_{2}(\mathrm{CO})_{6} \mathrm{H}_{2}$ (vide infra), irradiation of $\mathrm{FvMo}_{2}(\mathrm{CO})_{5}\left(\mathrm{PMe}_{3}\right) \mathrm{H}_{2} \quad$ (15), [and $\left.\mathrm{FvMo}_{2}(\mathrm{CO})_{4}\left(\mathrm{PMe}_{3}\right) \mathrm{H}_{2}\right]$, led to $\mathrm{H}_{2}$ elimination and gave Mo-Mo-bonded complexes $\mathrm{FvMo}_{2}(\mathrm{CO})_{5}\left(\mathrm{PMe}_{3}\right)(\mathbf{1 8})$, [and $\left.\mathrm{FvMo}_{2}(\mathrm{CO})_{4}\left(\mathrm{PMe}_{3}\right)_{2}(\mathbf{1 9})\right]$ (Scheme 5).

When treated with an excess of $\mathrm{PMe}_{3}, \mathbf{8 a}$ and $\mathbf{8 b}$ underwent surprising decomplexation to form $\mathrm{Mo}(\mathrm{CO})_{3}\left(\mathrm{PMe}_{3}\right)_{3}$ and $\mathrm{FvMo}(\mathrm{CO})_{2} \mathrm{~L}_{2}(\mathbf{2 5}, \mathbf{2 6})$ in which only one $\mathrm{Cp}$ moiety of the $\mathrm{Fv}$ ligand was complexed to Mo. 


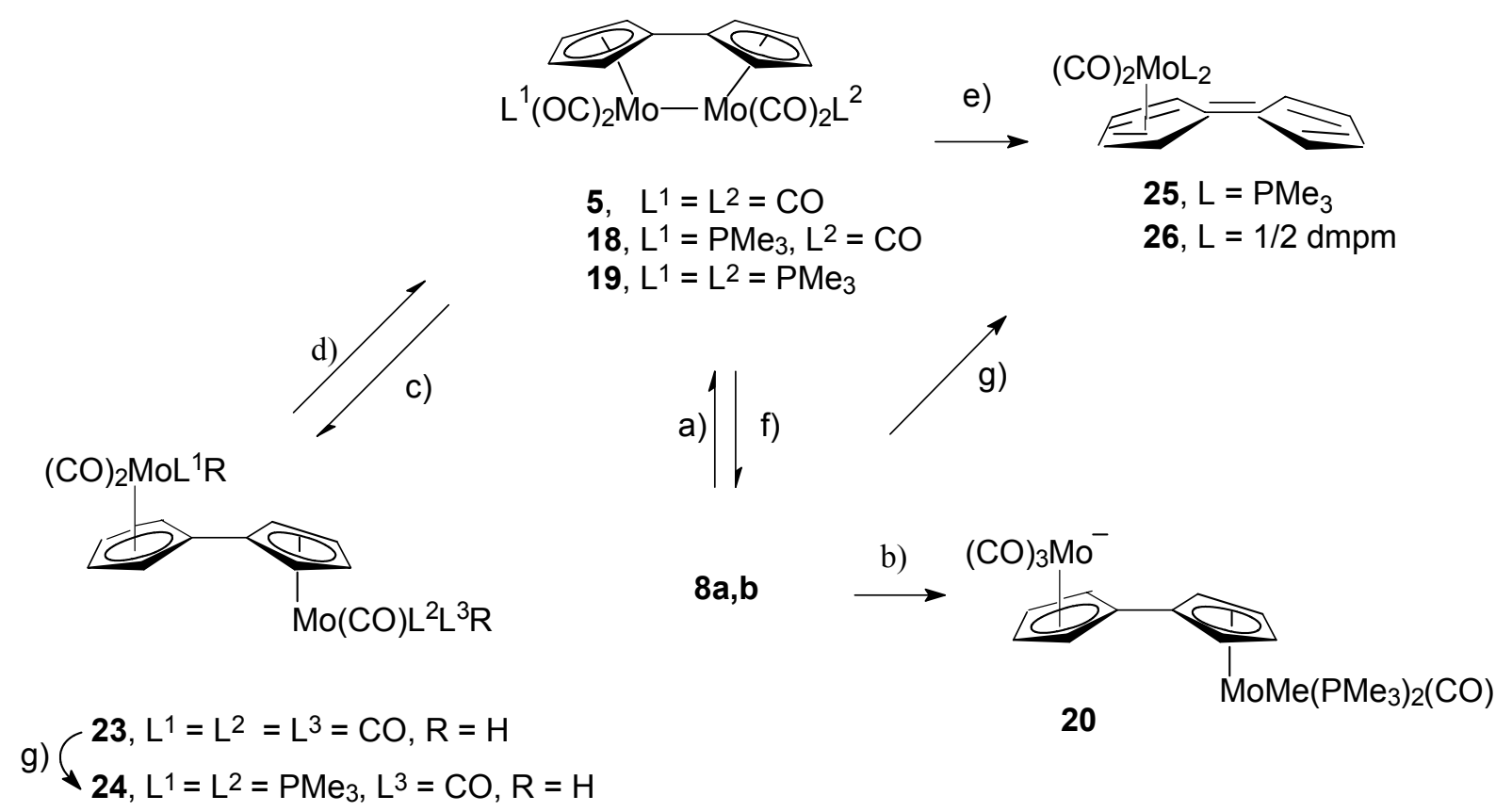

Scheme 5 a) a. $\mathbf{8 a}+\mathrm{Na} / \mathrm{Hg}$, b. $\mathrm{CF}_{3} \mathrm{COOH}$, c. hv $\rightarrow$ 18. b) $\mathbf{8 a}+\mathrm{LiAlH}_{4}$. c) a. $\mathbf{5}+\mathrm{Na} / \mathrm{Hg}$, b. $\mathrm{CF}_{3} \mathrm{COOH} \rightarrow$ 23. d) $24+\mathrm{h} v \rightarrow$ 19. e) $5+\mathrm{PMe}_{3}$ (excess) $\rightarrow$ 25; $5+$ dmpm $\rightarrow$ 26. f) $5+\mathrm{PMe}_{3}$. g) $\mathrm{PMe}_{3}$.

No reaction occurred when 19 was treated with an excess of $\mathrm{PMe}_{3}$, proving that $\mathbf{1 9}$ is not an intermediate in the formation of $\mathbf{8 a}$ from 5. The latter reaction is facile even in the dark, indicating that initial homolysis of the M-M bond is not required. Compounds $\mathbf{2 5}$ and $\mathbf{2 6}$ can be made directly from $\mathbf{5}$ by demetallation, a process that can be reversed by the addition of metal carbonyls. The former constituted the first examples of ring slippage in a fulvalene system and opened up the way to a designed synthesis of heterodinuclear complexes (Section 2.2.1.). Spectral data indicated a geometry reflecting both contributing resonance forms $\mathbf{2 7}$ and $\mathbf{2 8}$ (Scheme 6). Evidence in support of the structure proposed was provided by the X-ray structural analysis of the $\mathrm{Ru}$ analog, obtained upon treatment of $\mathbf{3}$ with a large excess of $\mathrm{PMe}_{3} .{ }^{14 \mathrm{~d}}$

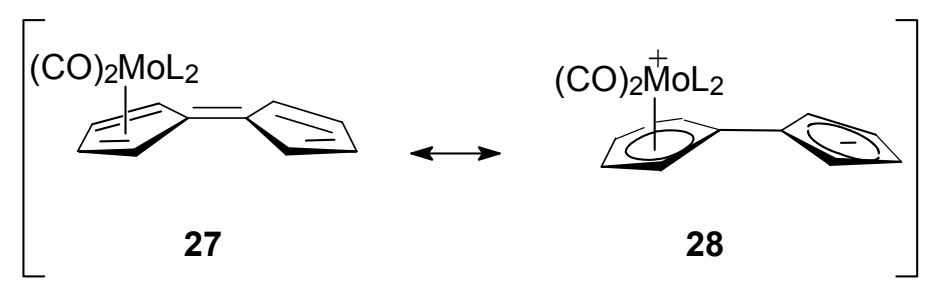

\section{Scheme 6}

The reactions between $\mathbf{8 a}, \mathbf{b}$ and $\mathrm{PMe}_{3}$ came as a surprise, since the anionic site should not be expected to react with $\mathrm{PMe}_{3}$ for electronic reasons and the cationic site should be rendered unreactive for steric reasons. A possible mechanism ${ }^{24 a}$ is depicted in Scheme 7 and involves hapticity changes in 8a that render it subject to nucleophilic attack. When exposed to $\mathrm{Mo}(\mathrm{CO})_{3}(\mathrm{NCMe})_{3}, \mathrm{FvMo}(\mathrm{CO})_{2}\left(\mathrm{PMe}_{3}\right)_{2}(\mathbf{2 5})$ cleanly regenerated $\mathrm{FvMo}_{2}(\mathrm{CO})_{5}\left(\mathrm{PMe}_{3}\right)_{2}(\mathbf{8 a})$. 


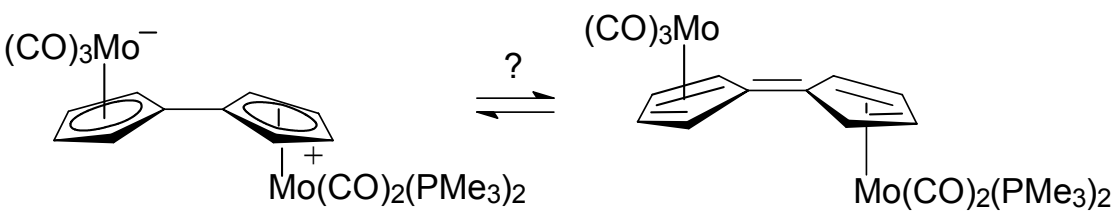

$8 \mathbf{a}$
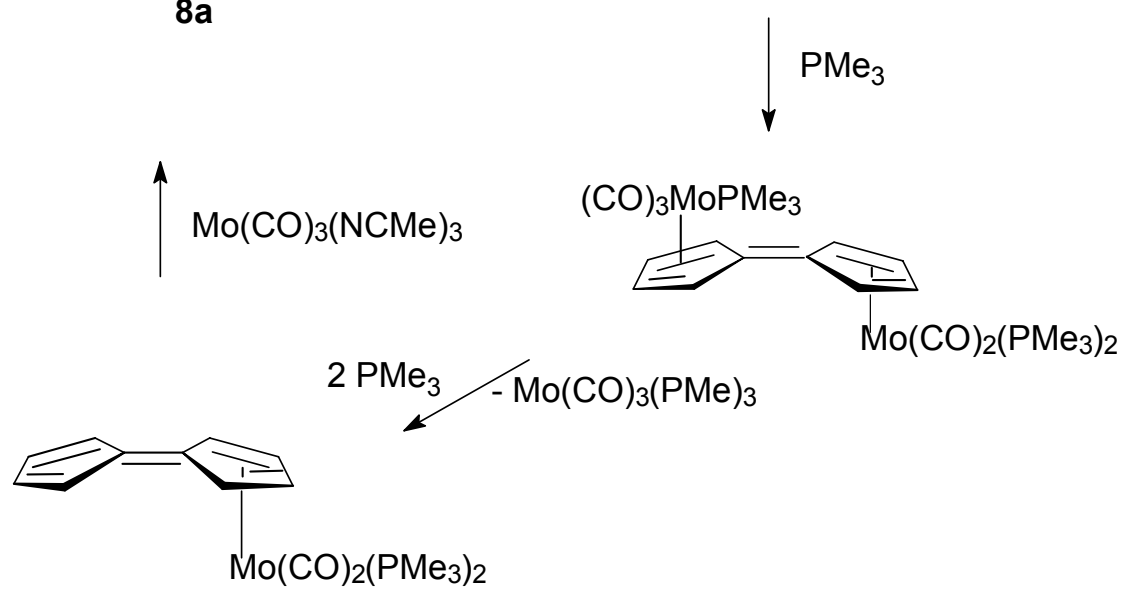

25

Scheme 7

Photo- and thermal reactivity of $\mathrm{FvM}_{2}(\mathrm{CO})_{6}, \mathrm{M}=\mathrm{Mo}, \mathrm{W}$

Photolysis of $\mathrm{FvMo}_{2}(\mathrm{CO})_{6}(\mathbf{5})$ in the presence of alkynes afforded mono- and bis(alkyne) complexes $\mathrm{FvMo}_{2}(\mathrm{CO})_{4}(\mathrm{RC} \equiv \mathrm{CR})$ 30-32 and $\mathrm{FvMo}_{2}(\mathrm{CO})_{3}(\mathrm{RC} \equiv \mathrm{CR})_{2} 33$ and 34, respectively, as in Scheme 8. Spectroscopic evidence indicated that the former bears as a ligand a $\mu-\eta^{2}$-alkyne and that this ligand is mobile around the Mo-Mo bond in a rapid fluxional process. ${ }^{12}$

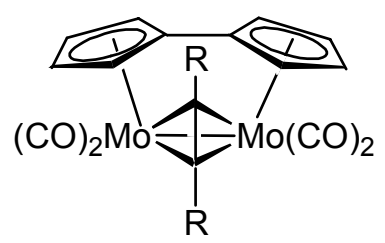

30, $\mathrm{R}=\mathrm{H}$

31, $\mathrm{R}=\mathrm{Ph}$

32, $\mathrm{R}=\mathrm{CO}_{2} \mathrm{Me}$

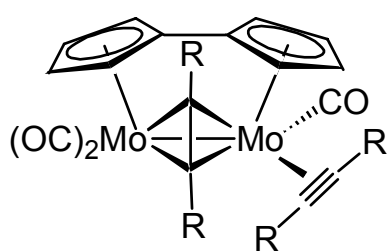

33, $\mathrm{R}=\mathrm{Ph}$

34, $\mathrm{R}=\mathrm{CO}_{2} \mathrm{Me}$

\section{Scheme 8}

The bis(alkyne) systems contained uncoupled alkynes, as determined by an X-ray diffraction study of 34. This result is unusual in light of the frequent occurrence of alkyne coupling at a binuclear center. ${ }^{28}$ Several unsuccessful attempts were made to induce such coupling in $\mathbf{3 3}$ and 34. It is difficult to find a rationale for this departure from the chemistry of the analogous $\mathrm{Cp}$ compounds. Perhaps a bridging metallacycle requires a relatively short metal-metal distance, which might be prevented in $\mathbf{3 3}$ and $\mathbf{3 4}$ by the resulting strain energy in the fulvalene ligand. 
These results should be compared to those obtained in the photochemical reactions of $\mathrm{FvW}_{2}(\mathrm{CO})_{6}(\mathbf{6})$ with alkynes. ${ }^{29}$ Here, single and double alkyne photosubstitution was also observed in the presence of diphenylethyne to afford complexes $\mathbf{3 5}$ and 36, whose structures were proposed based on spectroscopic data (Scheme 9). It is interesting to note that in $\mathbf{3 5}$ the alkyne functions as a 2e ligand, stopping short of conversion to the $4 \mathrm{e}$ ligand system analogous to 30-32.

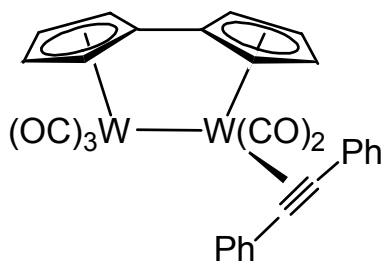

35

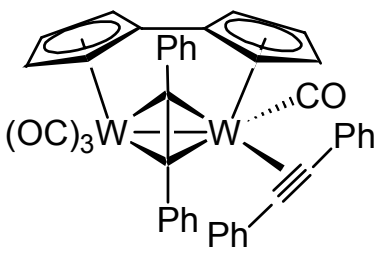

36

\section{Scheme 9}

In related work, in collaboration with Amouri's group in Paris, the complex formed from $\mathbf{5}$ and $\mathrm{MeC} \equiv \mathrm{CCH}_{2} \mathrm{OMe}, \quad \mathrm{FvMo}_{2}(\mathrm{CO})_{4}\left(\mu, \eta^{2}-\eta^{2}-\mathrm{MeC} \equiv \mathrm{CCH}_{2} \mathrm{OMe}\right)$, afforded on protonation the carbenium ion $\left[\mathrm{FvMo}_{2}(\mathrm{CO})_{4}\left(\mu, \eta^{2}-\eta^{3}-\mathrm{MeC} \equiv \mathrm{CCH}_{2}\right)\right] \mathrm{BF}_{4}$ in which the fluxional process of the alkyne ligand already noted in the systems 30-32 is superimposed on another involving reversible complexation of the cationic center to either metal. ${ }^{30}$

Formation of dihydride, dialkyl, and carbene complexes from the dianions $\left[\mathrm{FvM}_{2}(\mathrm{CO})_{6}\right]^{2-}, \mathrm{M}$ =Mo, $\boldsymbol{W}$

The metal-metal bonded complexes $\mathrm{FvM}_{2}(\mathrm{CO})_{6}(\mathrm{M}=\mathrm{Cr}$, Mo, W) undergo facile two-electron electrochemical reductive cleavage of the metal-metal bonds (vide infra). This result suggested that a dianion should be readily accessible from $\mathbf{5}$ and provide a useful starting material for further functionalization as already indicated in Scheme 5. Indeed, the reported procedure for preparing $\mathrm{Na}\left[\mathrm{Cp}(\mathrm{CO})_{3} \mathrm{Mo}\right]$ from $\mathrm{Cp}_{2} \mathrm{Mo}_{2}(\mathrm{CO})_{6}$ and $\mathrm{Na} / \mathrm{Hg}^{31}$ was applied to the synthesis of the dianion $\left[\mathrm{FvMo}_{2}(\mathrm{CO})_{6}\right]^{2-}\left[\mathrm{Na}^{+}\right]_{2}$, and the dilithium salt was conveniently prepared from lithium triethylborohydride. These species are rapidly air-oxidized to 5 . $\mathrm{Li}_{2}\left[\mathrm{FvMo}_{2}(\mathrm{CO})_{6}\right]$ was protonated instantaneously by trifluoroacetic acid in $\mathrm{THF}$ at $20^{\circ} \mathrm{C}$ to give the dihydride $\mathrm{FvMo}_{2}(\mathrm{CO})_{6} \mathrm{H}_{2}, 37$ (Scheme 10). It underwent ready intramolecular elimination of dihydrogen, a reaction of interest as a model for the desorption of $\mathrm{H}_{2}$ from metal surfaces.

Addition of primary alkyl, allyl, and benzyl halides to $\left[\mathrm{Cp}(\mathrm{CO})_{3} \mathrm{Mo}\right]^{-}$has been known to afford the corresponding substituted compounds $\mathrm{CpMo}(\mathrm{CO})_{3} \mathrm{R}^{31}$ Not surprisingly, subjecting $\mathrm{Li}_{2}\left[\mathrm{FvMo}_{2}(\mathrm{CO})_{6}\right]$ to various haloalkanes produced the alkylated derivatives $\mathrm{FvMo}_{2}(\mathrm{CO})_{6} \mathrm{R}_{2}$. In analogy to the methyl complex $\mathrm{Cp}(\mathrm{CO})_{3} \mathrm{MoMe}^{35 \mathrm{a}, \mathrm{b}} \mathrm{FvMo}_{2}(\mathrm{CO})_{6}(\mathrm{Me})_{2}(\mathbf{3 8})$ was observed to decompose photochemically to yield 5 and large quantities of methane (Scheme 10). On the basis of labeling experiments, it appears that the departing methyl group abstracts hydrogen from the cyclopentadienyl ring. The mechanism of $\mathrm{H}_{2}$ evolution from 37 may follow that proposed for the corresponding $\mathrm{Cr}$ analog ${ }^{9 b}$ involving both metals (as suggested by kinetic experiments), but was not conclusively established. 

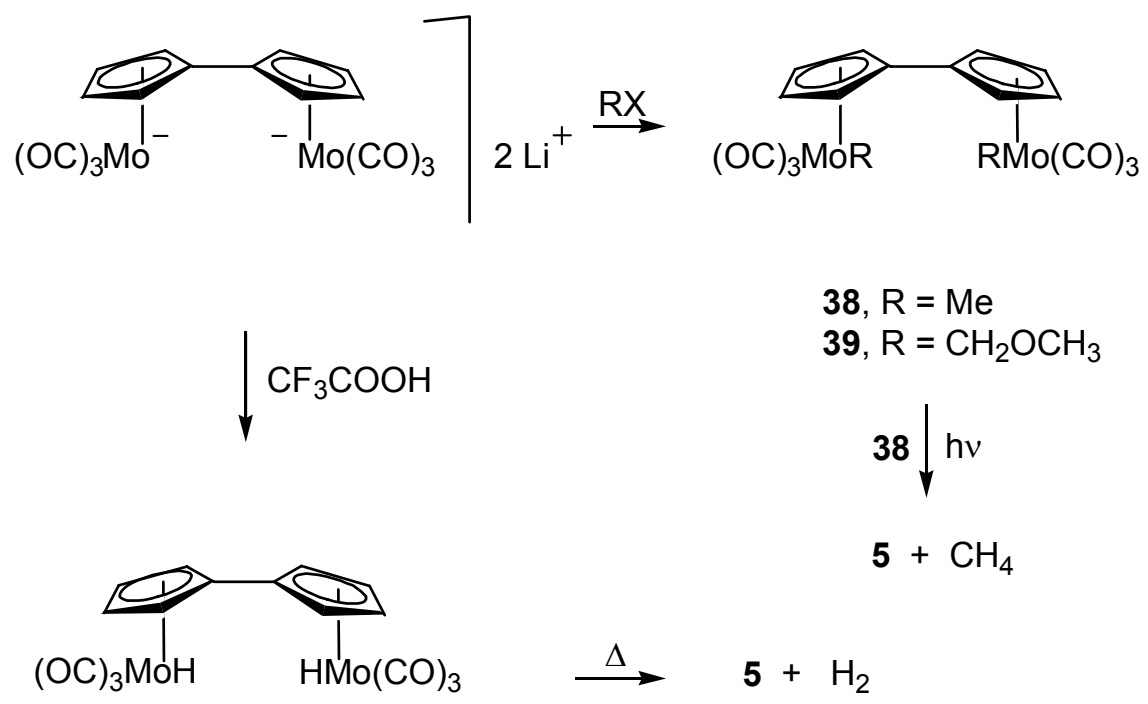

37

\section{Scheme 10}

Treatment of $\mathrm{Fv}(\mathrm{Mo})_{2}(\mathrm{CO})_{6}\left(\mathrm{CH}_{2} \mathrm{OMe}\right)_{2}$ (39) with $\mathrm{HBF}_{4} \mathrm{Et}_{2} \mathrm{O}$ at $-20{ }^{\circ} \mathrm{C}\left(\mathrm{CD}_{2} \mathrm{Cl}_{2}\right)$ produced $\mathrm{FvMo}_{2}(\mathrm{CO})_{6}\left(\mathrm{CH}_{2} \mathrm{OMe}\right)\left(=\mathrm{CH}_{2}\right)^{+}(\mathbf{4 0})$, as determined by NMR spectroscopy. Warming to $0{ }^{\circ} \mathrm{C}$ gave the carbene-coupling product $\mathrm{FvMo}_{2}(\mathrm{CO})_{6}\left(\mathrm{C}_{2} \mathrm{H}_{4}\right)^{2+}, \mathbf{4 2}$, (Scheme 11). The possible intermediate bis(carbene) $\mathrm{FvMo}_{2}(\mathrm{CO})_{6}\left(=\mathrm{CH}_{2}\right)_{2}{ }^{2+}$ (41) was not detected. Compound 42 decomposed on further warming with the evolution of ethene. The sequence in Scheme 11 can be viewed as a binuclear model for carbene coupling on surfaces. ${ }^{2}$

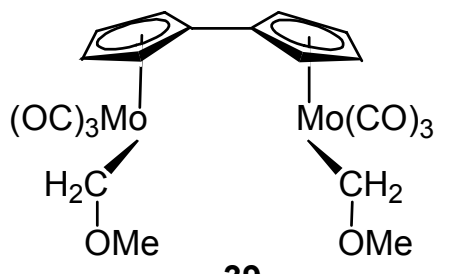

39

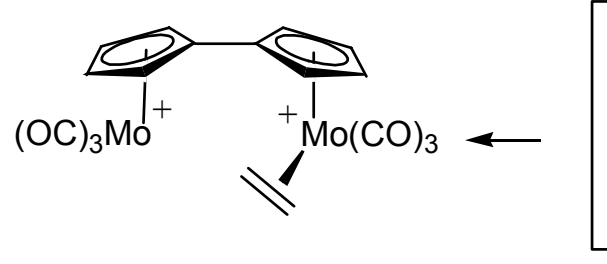

42

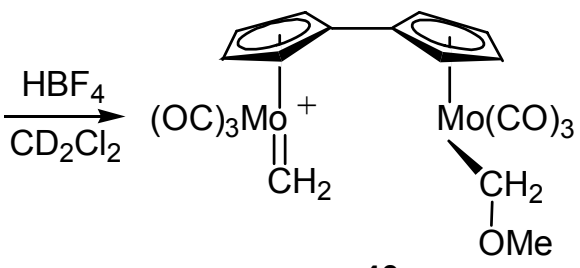

40

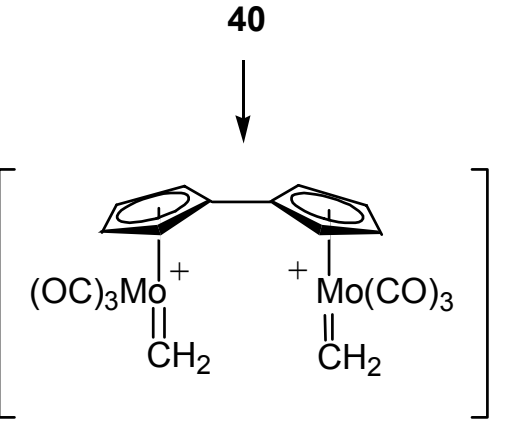

41

\section{Scheme 11}

The facile alkylations depicted in Scheme 11 suggested that it might be possible to synthesize the novel dimetallacycles of the type 43 by the reaction of $\left[\mathrm{FvMo}_{2}(\mathrm{CO})_{6}{ }^{2-}\right]$ with dihaloalkanes. To our delight, instead, exposure to $\mathrm{I}\left(\mathrm{CH}_{2}\right)_{3} \mathrm{I}$ gave a metal-metal bonded 1-oxacyclopent-2- 
ylidene complex, 44 (Scheme 12). An X-ray diffraction analysis showed that the Fischer-type carbene ligand was terminally bound. However, this complex exhibited fluxional behavior via a bridging carbene species, the first such process observed. Thermolysis $\left(100^{\circ} \mathrm{C}\right)$ led to efficient generation of propene and $\mathbf{5}$ by an unprecedent retro-ene reaction on a dinuclear matrix. ${ }^{12}$

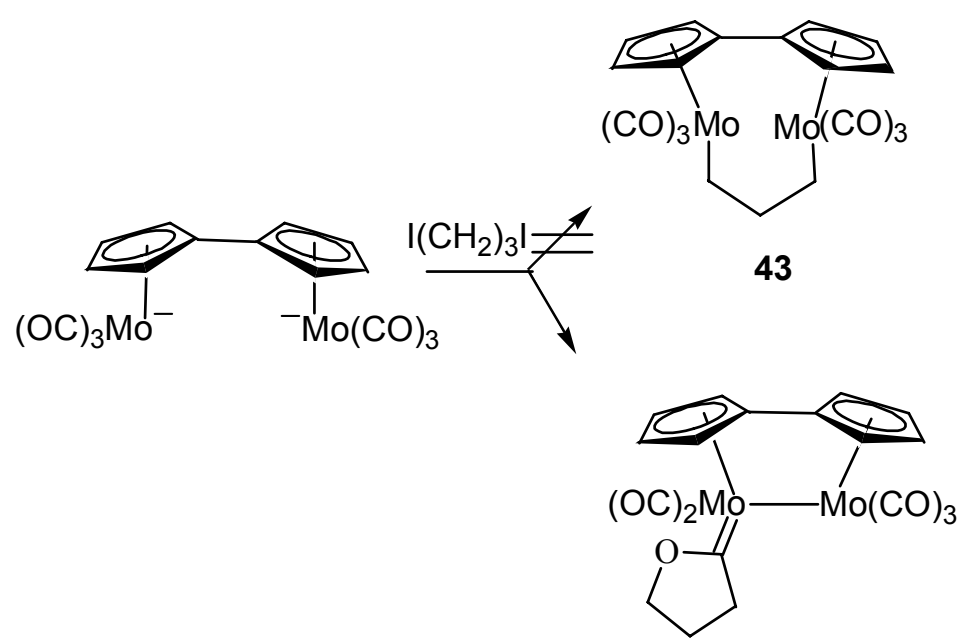

44

\section{Scheme 12}

As its Mo analog, $\mathrm{FvW}_{2}(\mathrm{CO})_{6}(6)$ underwent reduction by $\mathrm{LiEt}_{3} \mathrm{BH}$ or $\mathrm{Na} / \mathrm{Hg}$ to form the $\mathrm{Li}^{+}$and $\mathrm{Na}^{+}$salts of the corresponding dianion. An X-ray crystallographic analysis of $\left[\mathrm{Et}_{4} \mathrm{~N}\right]_{2}\left[\mathrm{FvW}_{2}(\mathrm{CO})_{6}\right]$ showed it to contain a planar $\mathrm{Fv}$ ring system bonded to the two metal centers in trans fashion, ${ }^{24 a}$ as observed in analogous $\mathrm{FvM}_{2}$ systems lacking $\mathrm{M}-\mathrm{M}$ bonds ${ }^{5 \mathrm{a}, 9 \mathrm{~b}, 12,17 \mathrm{f}, \mathrm{h}, 32,33}$ (with the exception of those endowed with addition M-M bridges). ${ }^{34}$ $\left[\mathrm{FvW}_{2}(\mathrm{CO})_{6}\right]^{2-}$ exhibited chemistry that is similar to but also occasionally quite different from that of the Mo relative. Thus, it attacked a number of electrophiles to yield the neutral disubstituted compounds $\mathrm{FvW}_{2}(\mathrm{CO})_{6} \mathrm{R}_{2}\left(\mathrm{R}=\mathrm{H}, \mathrm{Me}, \mathrm{Et}, \mathrm{CH}_{2} \mathrm{OMe}, \sigma-\mathrm{C}_{3} \mathrm{H}_{5}, \mathrm{CH}_{2} \mathrm{Ph}\right)$.

Photolysis of $\mathrm{FvW}_{2}(\mathrm{CO})_{6} \mathrm{Me}_{2}$ yielded methane gas and $\mathrm{FvW}_{2}(\mathrm{CO})_{6} \cdot{ }^{24 \mathrm{a}}$ This reactivity parallels that of $\mathrm{FvMo}_{2}(\mathrm{CO})_{6} \mathrm{Me}_{2}$ (Scheme 10), ${ }^{12} \mathrm{CpMo}(\mathrm{CO})_{3} \mathrm{Me},{ }^{35}$ and $\mathrm{CpW}(\mathrm{CO})_{3} \mathrm{Me}^{35}$ The source of the fourth $\mathrm{H}$ (necessary for $\mathrm{CH}_{4}$ ) in the $\mathrm{W}$ system is a second methyl group, and it differs, in a puzzling way, from that for $\mathrm{FvMo}_{2}(\mathrm{CO})_{6} \mathrm{Me}_{2}$ and $\mathrm{CpMo}(\mathrm{CO})_{3} \mathrm{Me}$ (the source of the hydrogen being mostly the ring systems) and $\mathrm{CpW}(\mathrm{CO})_{3} \mathrm{Me}$ (solvent).

In contrast to Scheme $12, \mathrm{FvW}_{2}(\mathrm{CO})_{6}{ }^{2-}$ and 1,3-iodopropane provided only the bis(3-iodopropyl) complex, $\mathrm{FvW}_{2}(\mathrm{CO})_{6}\left(\mathrm{CH}_{2} \mathrm{CH}_{2} \mathrm{CH}_{2} \mathrm{I}\right)_{2}$. The absence of Fischer-type carbenes in the case of the $\mathrm{W}$ compound may be due to less facile $\mathrm{CO}$ insertion into $\mathrm{W}$-alkyl bonds. On the other hand, the $\mathrm{W}$ analog of 39, upon treatment with $\mathrm{HBF}_{4} \mathrm{Et}_{2} \mathrm{O}$, reproduced the chemistry depicted in Scheme $11 .{ }^{24 a}$

The dihydride complexes $\mathrm{FvM}_{2}(\mathrm{CO})_{6} \mathrm{H}_{2}(\mathrm{M}=\mathrm{Cr}$, Mo, W) are plausible, although not observed, intermediates in the reactions of metal carbonyl precursors with dihydrofulvalene to provide the corresponding metal-metal-bonded complexes $\mathrm{FvM}_{2}(\mathrm{CO})_{6}$ (Table 2). ${ }^{9 b, 14 b, 15} \mathrm{FvCr}_{2}(\mathrm{CO})_{6} \mathrm{H}_{2}$ and $\mathrm{FvMo}_{2}(\mathrm{CO})_{6} \mathrm{H}_{2}$ could be prepared from the corresponding dianions by protonation and were 
indeed readily decomposed to $\mathbf{4}$ and $\mathbf{5}$, respectively, and $\mathrm{H}_{2}$ at $20^{\circ} \mathrm{C} .{ }^{9 b, 12}$ On the other hand (and as expected for $\mathrm{W}$ ), the dihydride $\mathbf{4 5}$ turned out to be considerably more stable and therefore subject of further investigation. ${ }^{24 a}$ Its ${ }^{1} \mathrm{H}$ NMR spectrum established the presence of two terminal hydride ligands. This notion was also supported by its reactions with $\mathrm{CCl}_{4}, \mathrm{CHBr}_{3}$, and $\mathrm{I}_{2}$ to yield the corresponding dihalide complexes (Scheme 13).
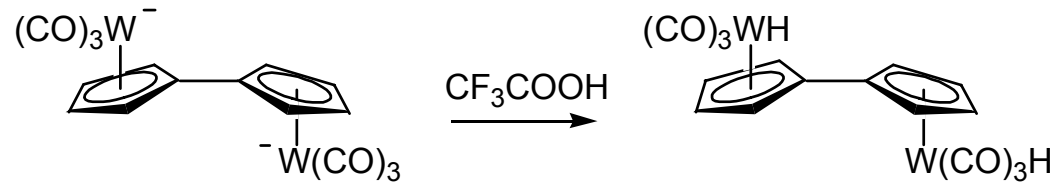

45

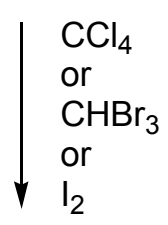

\section{Scheme 13}

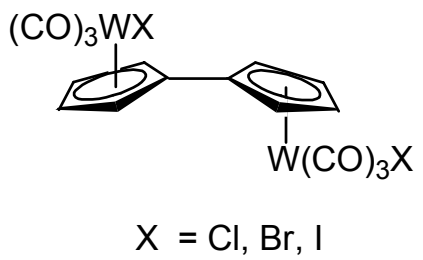

The $\mathrm{p} K_{\mathrm{a}}$ values for the two consecutive deprotonations of $\mathbf{4 5}$ were determined as 14.0 and 16.6 by equilibrium measurements in acetonitrile. Thermolysis (and photolysis) yielded $\mathrm{FvW}_{2}(\mathrm{CO})_{6}$ (6) and $\mathrm{H}_{2}$. Kinetic measurements in ether solvents suggested the intervention of a radical chain, perhaps obviating a concerted binuclear elimination reaction under these conditions. ${ }^{9 b}$ Pure $\mathbf{4 5}$ was inert with respect to $\mathrm{H}_{2}$ elimination on the time scale and at the temperature that is employed for the synthesis of 6 from dihydrofulvalene and $\mathrm{W}(\mathrm{CO})_{3}(\mathrm{NCEt})_{3}$. Under the latter conditions, however, it is likely that radical initiators are present that may well facilitate the extrusion of $\mathrm{H}_{2}$. The questions posed by these results are now being addressed by more detailed studies of the hydrogenation of $\mathbf{5}$ and $\mathbf{6}$.

Unlike $\mathrm{Cp}_{2} \mathrm{~W}_{2}(\mathrm{CO})_{6}, \mathrm{FvW}_{2}(\mathrm{CO})_{6}(\mathbf{6})$ underwent protonation of the $\mathrm{W}-\mathrm{W}$ bond by $\mathrm{HBF}_{4} \mathrm{Et}_{2} \mathrm{O}$ in acetonitrile to the bridging hydride $\left[\mathrm{FvW}_{2}(\mathrm{CO})_{6}(\mu-\mathrm{H})\right]^{+}(\mathbf{4 6})$. The $\mathrm{W}-\mathrm{W}$ bond in $\mathrm{FvW}_{2}(\mathrm{CO})_{6}$ appears therefore more basic than that of $\mathrm{Cp}_{2} \mathrm{~W}_{2}(\mathrm{CO})_{6}$, perhaps due to the strain energy contained in 6. However, there are other factors that may contribute to the basicity of $\mathrm{Fv}(\mathrm{M}-\mathrm{M})$ bonds and this result cannot be generalized. ${ }^{9 b, 36}$

The studies concerning cationic complexes derived from $\mathrm{FvW}_{2}(\mathrm{CO})_{6}$ and the dihydride $\mathrm{FvW}_{2}(\mathrm{CO})_{6} \mathrm{H}_{2}$ are summarized in Scheme 14. ${ }^{24 \mathrm{a}}$ Treatment of 46 with excess of $\mathrm{HBF}_{4} \mathrm{Et}_{2} \mathrm{O}$ in $\mathrm{CD}_{3} \mathrm{CN}$ afforded the monohydride $\left[\mathrm{FvW}_{2}(\mathrm{CO})_{6}(\mathrm{H})\left(\mathrm{NCCD}_{3}\right)\right]^{+}(47)$. Double hydride abstraction from $\mathrm{FvW}_{2}(\mathrm{CO})_{6} \mathrm{H}_{2}$ occurred instantaneously when 2 equiv. of $\mathrm{Ph}_{3} \mathrm{CPF}_{6}$ were added, yielding $\left[\mathrm{FvW}_{2}(\mathrm{CO})_{6}(\mathrm{NCMe})_{2}\right]\left[\mathrm{PF}_{6}\right]_{2}(\mathbf{4 8})$. This product was also accessible from the bridging dihydride 46 and 1 equiv. of $\mathrm{Ph}_{3} \mathrm{C}^{+}$. The removal of the hydride from 46 (with a great $\mathrm{H}^{+}$character) as $\mathrm{H}^{-}$ 


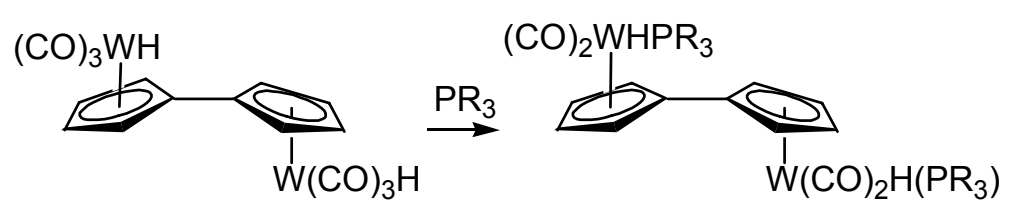

45

49, $\mathrm{R}=\mathrm{Me}$

50, $\mathrm{PR}_{3}=\mathrm{PMe}_{2} \mathrm{Ph}$

51, $\mathrm{R}=\mathrm{OMe}$

$\downarrow \mathrm{Ph}_{3} \mathrm{C}^{+}$

2 BuLi

2 R'X

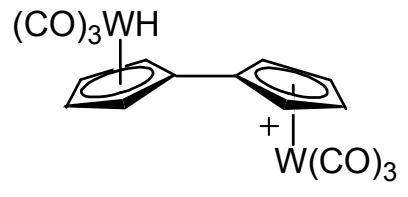

$(\mathrm{CO})_{2} \mathrm{WR}^{\prime} \mathrm{PR}_{3}$

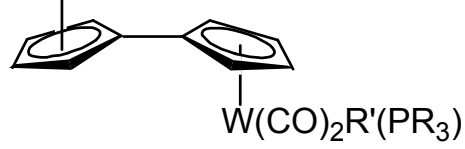

52, $\mathrm{R}^{\prime}=\mathrm{Me}$

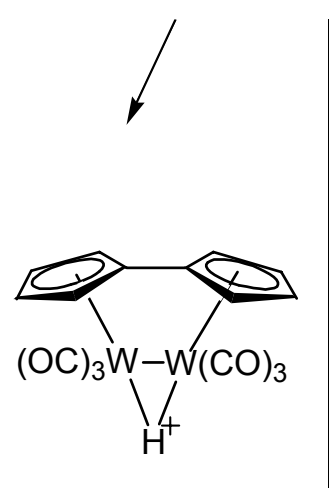

$\bigvee$ NCMe

53, $\mathrm{R}^{\prime}=\mathrm{CH}_{2} \mathrm{Ph}$

54, $\mathrm{R}^{\prime}=\mathrm{CH}_{2} \mathrm{OMe}$

$\mathrm{Ph}_{3} \mathrm{C}^{+}$

46

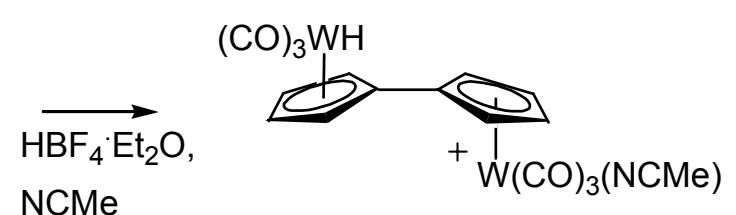

47

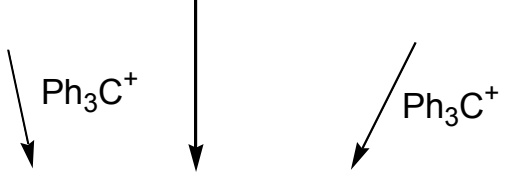

$(\mathrm{CO})_{3} \stackrel{+}{\mathrm{W}}(\mathrm{NCMe})$

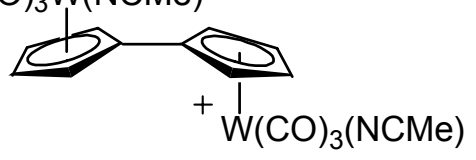

48

\section{Scheme 14}

by $\mathrm{Ph}_{3} \mathrm{C}^{+}$, requires an electronic rearrangement in the molecule, which can be one of the reasons for the high kinetic barrier observed. Simultaneously, the electrostatic repulsion between the two cationic reagents does not favor the reaction. ${ }^{37}$

Although, as already pointed out (Scheme 1), the $\mathrm{M}-\mathrm{M}$ bonded $\mathrm{FvM}_{2}(\mathrm{CO})_{6}$ species $\left(\mathrm{M}=\mathrm{Mo},{ }^{12}\right.$ $\mathrm{W}^{22}$ ) are less prone to enter into thermal or photochemical substitution reactions by phosphines 
than are their $\mathrm{Cp}_{2} \mathrm{M}_{2}(\mathrm{CO})_{6}$ analogs, the dihydride 45 underwent ready substitution of $\mathrm{CO}$ for phosphines, affording 49, 50, and $\mathbf{5 1}$ in a near 1:1 mixture of cis and trans configurations at the metal centers. Deprotonation of these species, followed by dialkylation, gave the corresponding dialkyl complexes 52-54 (Scheme 14).

\section{Thermally reversible photoisomerization of $\mathrm{FvRu_{2 }}(\mathrm{CO})_{4}$}

Like its $\mathrm{Cp}$ analog $\left[\mathrm{CpRu}(\mathrm{CO})_{2}\right]_{2},{ }^{38} \mathrm{FvRu}_{2}(\mathrm{CO})_{4}(\mathbf{3})$ is fairly inert to thermal ligand substitution. In contrast to the $\mathrm{Cp}$-metal dimer, which undergoes $\mathrm{CO}$ loss and metal-metal bond homolysis upon irradiation, ${ }^{39}$ photolysis of $\mathbf{3}$ (350 nm or sun light) led to the formation of the complex ( $\mu_{2}$ $\left.\eta^{1}: \eta^{5}-\mathrm{C}_{5} \mathrm{H}_{5}\right)_{2} \mathrm{Ru}_{2}(\mathrm{CO})_{4}(\mathbf{5 5}) .{ }^{14 a, 40}$ An X-ray structural determination of the latter revealed that both the Ru-Ru bond and the central $\mathrm{C}-\mathrm{C}$ bond in the Fv ligand of $\mathbf{3}$ had been cleaved and that a remarkable binuclear oxidative addition to a $\mathrm{C}_{s p 2}-\mathrm{C}_{s p 2}$ bond had occurred (Scheme 15). A number of $\mu^{2}-\eta^{1}: \eta^{5}-\mathrm{Cp}$ complexes are known, mostly derived by (formal) $\mathrm{C}-\mathrm{H}$ activation of a metal bound $\eta^{5}-\mathrm{Cp}$ unit. ${ }^{32 \mathrm{a}, 40,41}$ For 55, this moiety was generated by insertion of a bimetallic fragment into a C-C bond, a rare transformation. ${ }^{42}$ The quantum yield for this process $(0.15)$ was unaffected by the presence of $\mathrm{CCl}_{4}$, and chlorinated products were not detected. The "electronic window" for successful photoisomerization is narrow, as $\mathbf{5 9}$ and $\mathbf{6 0}$ (prepared from $\mathbf{3}$ and the respective phosphine at $120^{\circ} \mathrm{C}$ ) did not enter this pathway, nor do any other $\mathrm{FvM}_{2}$ complexes. However, $\mathbf{6 1}$ (to give 56) and fulvalene substituted derivatives of $\mathbf{3}$ and $\mathbf{6 1}$ were similarly reactive. In the presence of alkynes, 3 or $\mathbf{5 5}$ (or a mixture of the two) eventually underwent photosubstitution of $\mathrm{CO}$ to furnish the new (for $\mathrm{FvM}_{2}$ ) bridging alkyne complexes 57. Loss of $\mathrm{CO}$ was also effected by higher energy UV light $(300 \mathrm{~nm})$ which transformed $3(\mathbf{5 5})$ into cluster $\mathbf{5 8}$, topologically readily derived from $\mathbf{3}$ and $\mathbf{5 5}$ by formal decarbonylative coupling.

Equally remarkable to the photoprocess $\mathbf{3} \rightarrow \mathbf{5 5}$ was the finding of clean thermal reversal ( $>65$ $\left.\mathrm{C}^{\circ}\right) \mathbf{5 5} \rightarrow \mathbf{3}$ (and $\mathbf{5 6} \rightarrow \mathbf{6 1}$ ) with the release of $29.8 \mathrm{kcal} \mathrm{mol}^{-1}$ of energy. Thus, the system constitutes a relatively efficient and energy rich light energy storage cycle. The conversion of $\mu^{2}-\eta^{1}: \eta^{5}-\mathrm{Cp}$ complexes to fulvalene dimetals has precedence in the literature. ${ }^{40,43}$ 


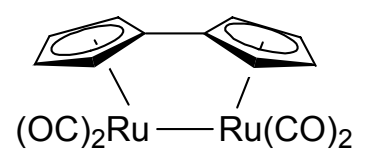

3

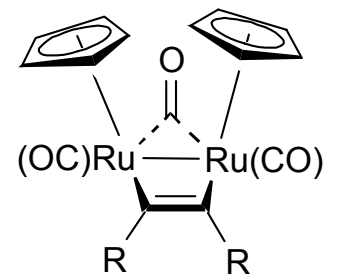

57

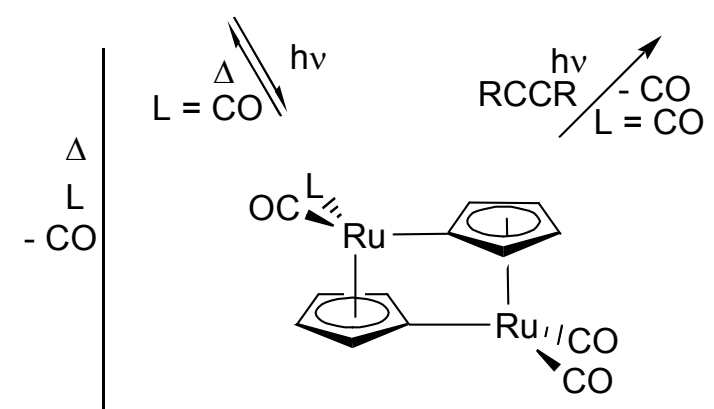

55, $\mathrm{L}=\mathrm{CO}$

56, $\mathrm{L}=\mathrm{P}(\mathrm{OMe})_{3}$

61,

$\mathrm{h} v / \mathrm{S}_{\Delta}$
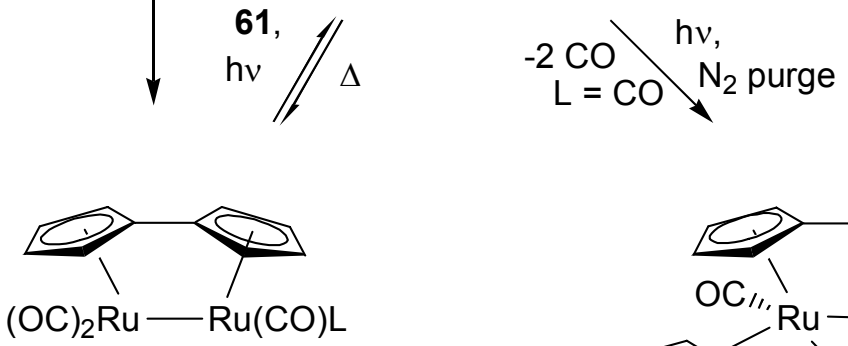

59, $\mathrm{L}=\mathrm{PEt}_{3}$

60, $\mathrm{L}=\mathrm{PMe}_{3}$

61, $\mathrm{L}=\mathrm{P}(\mathrm{OMe})_{3}$

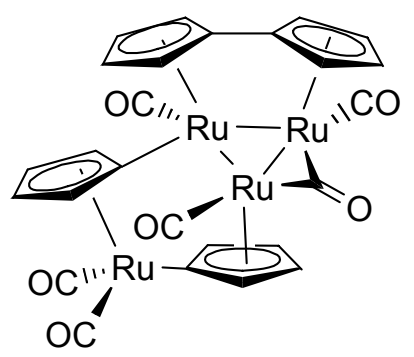

58

\section{Scheme 15}

An extensive series of mechanistic experiments was executed. Thus, a crossover experiment involving $\mathbf{3}$ and $\mathbf{3}-\boldsymbol{d}_{\mathbf{8}}$, in conjunction with clean first order kinetics for the thermal reversal of $\mathbf{5 5}$, pinpointed the intramolecular character of these isomerization. Moreover, using $\mathrm{P}(\mathrm{OMe})_{3}$ as a means to label one of the Ru atoms and tert-butyl as a stereo-and regiomarker of the Fv moiety showed that the basic connectivity of the $\mathrm{FvM}_{2}$ core stayed intact during the photochemicalthermal sequence (as, for example, in Scheme 16). All of the evidence points to concerted mechanisms, as shown in Scheme 17, presumably involving different electronic states (ground state versus excited state) for the individual species in the manifold, and analogous to those proposed by Green for the molybdenocene dimer manifold $66 \quad 67^{43,44}$ 


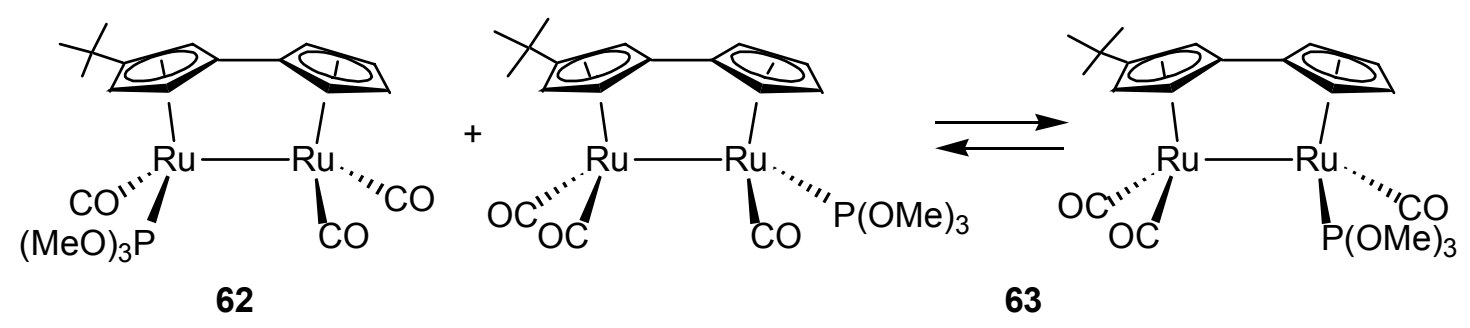

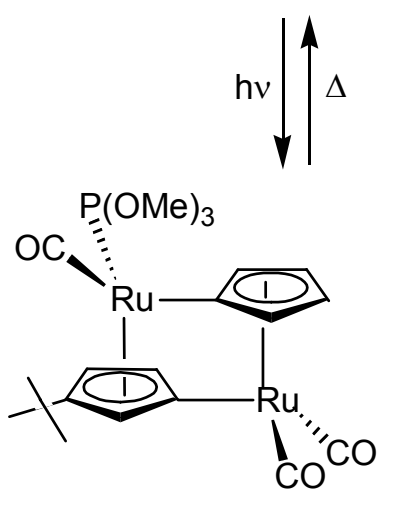

64 $\mathrm{h} v \downarrow \Delta$

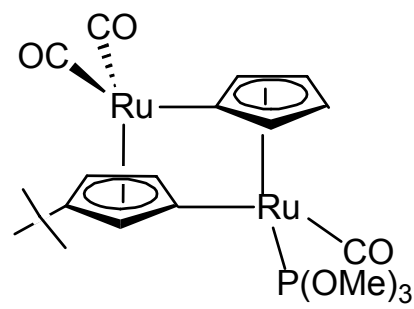

65

\section{Scheme 16}
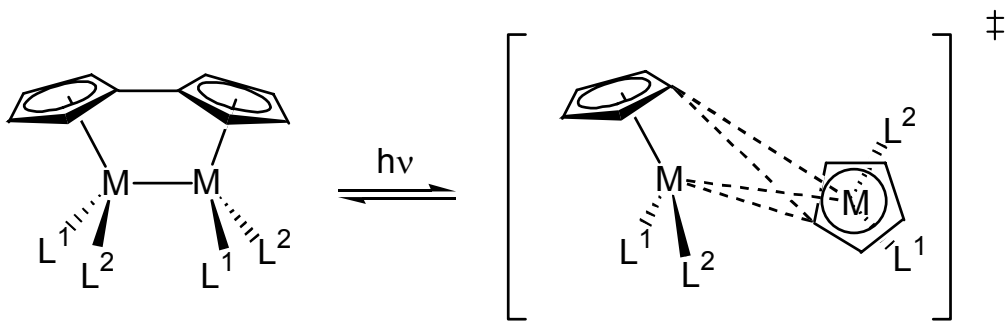

3, $M=R u, L^{1}=L^{2}=C O$

66, $M=M o, L^{1}=C p, L^{2}=H$

$\Delta \|$

55, $M=R u, L^{1}=L^{2}=C O$

67, $M=M o, L^{1}=C p, L^{2}=H$

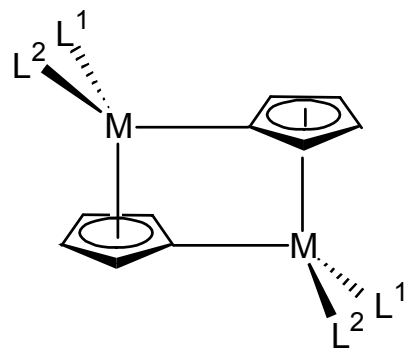

Scheme 17 


\subsubsection{Conclusions}

The resemblance between $\mathrm{Cp}$ and $\mathrm{Fv}$ ligands often produces similar chemistry, for example, in substitution reactions, which is not surprising considering the analogous microenvironment around the individual metal centers. Numerous ligand substitution reactions and functional group manipulations that are typical of $\mathrm{Cp}$-bonded metal centers can be faithfully reproduced at the two metal centers that are attached to the Fv ligand. However, there are also qualitative and quantitative differences in reactivity, and these are, of course, the ones for which we were looking.

For example, the $\mathrm{p} K_{\mathrm{a}}$ measurements showed that the metal hydride acidities decreased in the order $\mathrm{FvW}_{2}(\mathrm{CO})_{6} \mathrm{H}_{2}(14.0)>\mathrm{CpW}(\mathrm{CO})_{3} \mathrm{H}(16.1)>\left[\mathrm{FvW}_{2}(\mathrm{CO})_{6} \mathrm{H}\right]^{-}(16.6)$. The acidity of the metal hydride, located between that of $\mathrm{FvW}_{2}(\mathrm{CO})_{6} \mathrm{H}_{2}$ and $\left[\mathrm{FvW}_{2}(\mathrm{CO})_{6} \mathrm{H}\right]^{-}$, shows that there is electronic communication between the two metal centers, through the Fv ligand.

The metal-metal bond cleavage reactions of $\mathrm{FvM}_{2}(\mathrm{CO})_{6}(\mathrm{M}=\mathrm{Mo}, \mathrm{W})$ leading to the respective zwitterionic species seem to be facilitated by the relief of strain of the Fv ligand. The decomplexation reactions observed for the zwitterionic compounds are favored by the capacity of the Fv ligand system to undergo gradual ring slippage to accommodate reduced hapticity bonding modes; this versatility is not available for a mono $\mathrm{Cp}$ ligand. Similar strain arguments can be made for the relative ease of protonation of $\mathrm{FvW}_{2}(\mathrm{CO})_{6}$. Conversely, increased strain may be responsible for the relative reluctance of $\mathrm{FvM}_{2}$ to support alkyne couplings to tightly bridging metallacycles. On the other hand, the observation of bridging alkynes 57, contrasting the bonding pattern in $\mathbf{3 5}$, points to subtle stereoelectronic effects that still need to be unraveled.

Most striking is the unprecedented photo- and thermal chemistry of $\mathrm{FvRu}_{2}(\mathrm{CO})_{4}$ in which both the electronic and structural peculiarities of the molecular frame, albeit still not completely understood, must play a fundamental role.

\subsection{Heterodinuclear Fulvalene Metal Complexes}

Heterometallic clusters elicit great fascination, because of the presence of potentially uniquely reactive polar M-M bonds and the possibility of synergistic or, at least, cooperative activation of separate functionalities and reagents. ${ }^{45}$ It is therefore not surprising that we were interested in the Fv variety of such systems from the very beginning of our studies, ${ }^{14 b}$ an effort that went hand in hand with the development of ever simpler methods to construct the $\mathrm{Cp}-\mathrm{Cp}$ bond to provide chemoselective access to such systems. The inherent synthetic challenge has been appreciated by others. ${ }^{46}$

\subsubsection{Synthesis}

We have reported ${ }^{47}$ three synthetic strategies for the construction of heterobimetallic fulvalene complexes. The first is based on the remetallation of the previously described monometallic ring slippage products 25 and $\mathbf{6 8}$ of $\mathrm{FvMo}_{2}(\mathrm{CO})_{6}$ (Scheme 5) and $\mathrm{FvRu}_{2}(\mathrm{CO})_{4}$, respectively, and has 
the Fv ligand already in place. ${ }^{47 a}$ The second utilizes a stepwise assembly of the Fv frame, exploiting the nucleophilic property of $\mathrm{Cp}$ anion to attach a masked $\mathrm{Cp}$ ring. ${ }^{47 \mathrm{a}, \mathrm{b}}$ The third and most direct approach makes use of the discovery that $\mathrm{Cp}$ anion (as such or in stannylated form) undergoes $\mathrm{Pd}$ catalyzed coupling with readily available ${ }^{48}$ iodocyclopentadienylmetal complexes. ${ }^{47 \mathrm{c}}$

Scheme 18 exemplifies the first approach giving rise to a number of novel heterodinuclear organometallic zwitterions. The addition of $\mathrm{M}(\mathrm{CO})_{3}(\mathrm{NCMe})_{3}(\mathrm{M}=\mathrm{Cr}, \mathrm{Mo}, \mathrm{W})$ to a THF solution of 25 or 68 gave the mixed metal complexes 8a and 69-72 in essentially quantitative yields. $^{47 a}$ Metal-metal bonded molybdenum-iron and -zirconium complexes $\mathbf{7 3}$ and $\mathbf{7 4}$ were obtained by reduction of $\mathbf{2 5}$ followed by the addition of the respective transition metal chlorides. The "slipped" approach to $\mathrm{Fv}\left[\mathrm{Ru}(\mathrm{CO})_{2}\right]\left[\mathrm{Mo}(\mathrm{CO})_{3}\right]($ Table 2$)$ provided a high yielding entry into this system, and this route afforded also the mixed metal complexes of Ru-Fe (75) and the earlylate metal combination $\mathrm{Ru}-\mathrm{Ti}$ (76). ${ }^{49}$ 


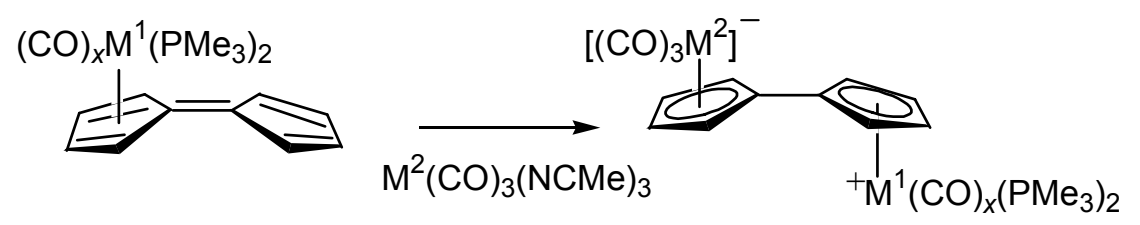
25, $\mathrm{M}^{1}=$ Mo, $x=2$
8a, $M^{1}=M^{2}=$ Mo, $x=2$
68, $\mathrm{M}^{1}=\mathrm{Ru}, x=1$
69, $M^{1}=$ Mo, $M^{2}=\mathrm{Cr}, x=2$
70, $\mathrm{M}^{1}=\mathrm{Ru}, \mathrm{M}^{2}=\mathrm{Cr}, x=1$
71, $M^{1}=\mathrm{Ru}, \mathrm{M}^{2}=\mathrm{Mo}, x=1$
72, $M^{1}=\mathrm{Ru}, \mathrm{M}^{2}=\mathrm{W}, x=1$
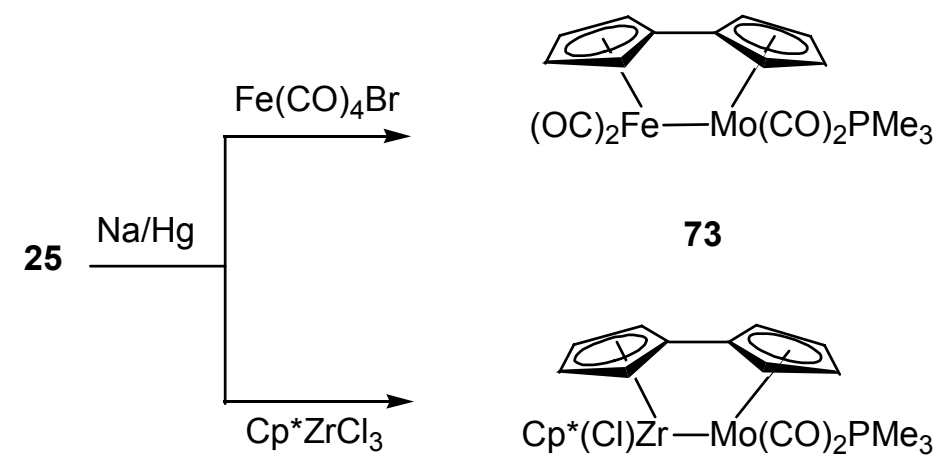

73

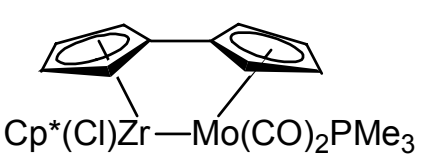

74
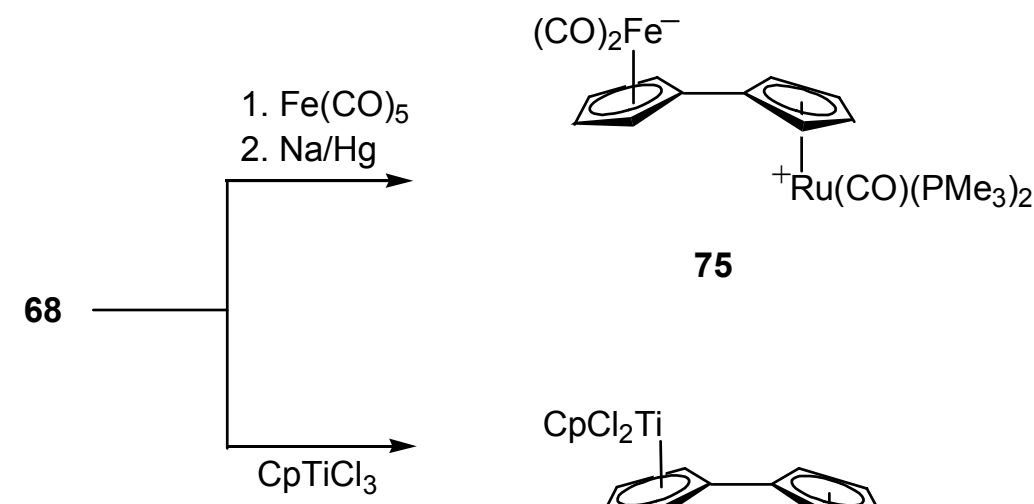

75

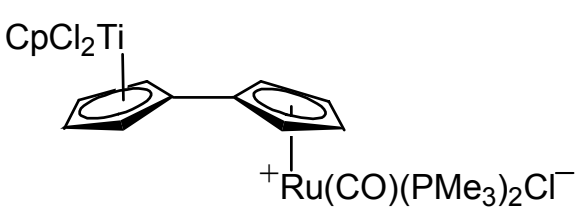

76

\section{Scheme 18}

The second strategy to heterodinuclear fulvalene systems took advantage of purely organic synthetic methodology to append a 3-oxo-1-cyclopentenyl unit to $\mathrm{Cp}$ anion. In the first generation of the execution of this route, a cumbersome stepwise sequence was employed, which consisted of reaction of $\mathrm{Cp}$ anion with dimethyl butanedioate, one carbon homologation of the resulting keto ester, metallation of the $\mathrm{Cp}$, and intramolecular aldol condensation to give $\mathbf{7 8}$ or 79 in 10 and 13\% overall yield, respectively. ${ }^{47 a}$ A tremendous boost in efficiency was realized 
when we discovered that $\mathrm{Cp}$ anion underwent Michael addition-elimination to 3-alkoxy- (or 3halo-) cyclopentenones to furnish the enolate 77 quantitatively (Scheme 19). The latter could then be treated with a metalating reagent to introduce a (first) metal into the eventual Fv frame selectively. Elaboration of the cyclopentenone substituent to give the second $\mathrm{Cp}$ unit was accomplished by reduction with $\mathrm{LiAlH}_{4}$, followed by catalytic dehydration with ptoluenesulfonic acid, giving cyclopentadiene complexes of the type $\mathbf{8 0}$ and $\mathbf{8 1}$.

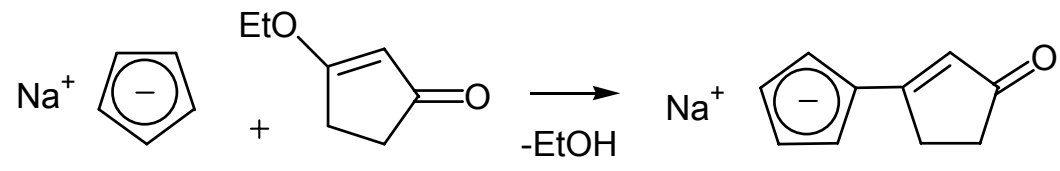

77

1. $\mathrm{ML}_{x}$

2. $\mathrm{CH}_{3} \mathrm{I}$
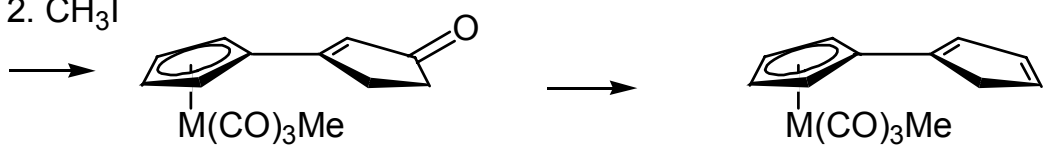

78, $M=M o$

$80, M=M o$

79, $M=W$

$81, M=W$

\section{Scheme 19}

Their versatility is illustrated for $\mathbf{8 1}$ by the preparation of a variety of heterobimetallic complexes, both with or without metal-metal bonds (Scheme 20). ${ }^{47 \mathrm{~b}}$ Cyclopentadiene complex 80 presents a parallel chemistry. ${ }^{50}$

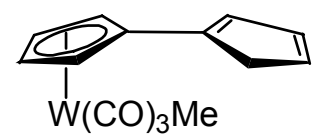

81
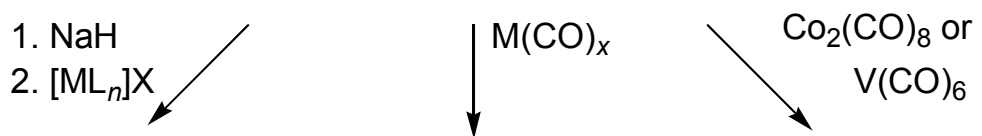

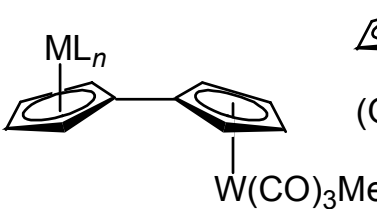

82-88

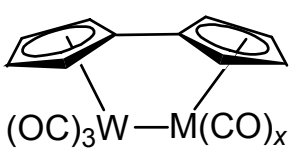

89-92

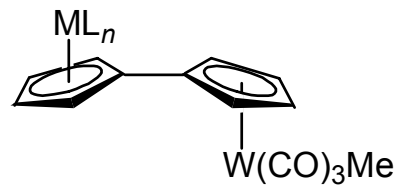

93,94 


\begin{tabular}{llcc} 
Reagent & \multicolumn{1}{c}{$\mathrm{ML}_{n}$} & Compound & Yield (\%) \\
& & & \\
{$\left[\mathrm{Rh}(\mathrm{CO})_{2} \mathrm{Cl}\right]_{2}$} & $\mathrm{Rh}(\mathrm{CO})_{2}$ & $\mathbf{8 2}$ & 73 \\
{$\left[\mathrm{Rh}\left(\mathrm{C}_{2} \mathrm{H}_{4}\right)_{2} \mathrm{Cl}\right]_{2}$} & $\mathrm{Rh}\left(\mathrm{C}_{2} \mathrm{H}_{4}\right)_{2}$ & $\mathbf{8 3}$ & 64 \\
$\mathrm{Ir}(\mathrm{CO})_{3} \mathrm{Cl}$ & $\mathrm{Ir}(\mathrm{CO})_{2}$ & $\mathbf{8 4}$ & 25 \\
{$\left[\mathrm{Mn}(\mathrm{CO})_{4} \mathrm{Br}\right]_{2}$} & $\mathrm{Mn}(\mathrm{CO})_{3}$ & $\mathbf{8 5}$ & 71 \\
$\left.\mathrm{Re}(\mathrm{CO})_{3}(\mathrm{THF}) \mathrm{Br}\right]_{2}$ & $\mathrm{Re}(\mathrm{CO})_{3}$ & $\mathbf{8 6}$ & 64 \\
$\mathrm{Mo}(\mathrm{CO})_{3}(\mathrm{MeCN})_{3}, \mathrm{MeI}$ & $\mathrm{Mo}(\mathrm{CO})_{3} \mathrm{Me}$ & $\mathbf{8 7}$ & 44 \\
$\mathrm{Cp} \mathrm{ZrCl}_{3}$ & $\mathrm{Cp} \mathrm{ZrCl}_{2}$ & $\mathbf{8 8}$ & 20 \\
& & & \\
$\mathrm{Fe}(\mathrm{CO})_{5}$ & $\mathrm{Fe}(\mathrm{CO})_{2}$ & $\mathbf{8 9}$ & 68 \\
$\mathrm{Ru}{ }_{3}(\mathrm{CO})_{12}$ & $\mathrm{Ru}(\mathrm{CO})_{2}$ & $\mathbf{9 0}$ & 46 \\
$\mathrm{Mo}(\mathrm{CO})_{3}(\mathrm{MeCN})_{3}$ & $\mathrm{Mo}(\mathrm{CO})_{3}$ & $\mathbf{9 1}$ & 39 \\
$\mathrm{Cr}(\mathrm{CO})_{3}(\mathrm{MeCN})_{3}$ & $\mathrm{Cr}(\mathrm{CO})_{3}$ & $\mathbf{9 2}$ & 48 \\
$\mathrm{Co}_{2}(\mathrm{CO})_{8}$ & $\mathrm{Co}(\mathrm{CO})_{2}$ & $\mathbf{9 3}$ & 63 \\
$\mathrm{~V}(\mathrm{CO})_{6}$ & $\mathrm{~V}(\mathrm{CO})_{4}$ & $\mathbf{9 4}$ & 30
\end{tabular}

\section{Scheme 20}

A third and latest approach is the most direct and is based on the discovery that Heck type coupling of trialkylstannylcyclopentadienes with iodocyclopentadienylmetals ${ }^{48}$ occurs readily ${ }^{47 \mathrm{c}}$ to generate $81(89 \%)$ and the corresponding $\mathrm{Mn}(\mathrm{CO})_{3}(61 \%)$ and $\mathrm{Fe}(\mathrm{CO})_{2} \mathrm{CH}_{3}(50 \%)$ analogs. This method appears to be quite general and a particularly powerful application is presented in Section 5.

\subsubsection{Reactivity}

With reasonably efficient preparations of heterodinuclear complexes in hand, some forays have been made into the investigation of their chemistry, all of which have been quite rewarding. Some selected examples follow next.

\section{The unique reactivity of $F v M o R u(C O)_{5}$ with alkynes}

In light of the remarkable photobehavior of 3 (Scheme 15), we decided to look into the ruthenium based system $\mathrm{FvMoRu}(\mathrm{CO})_{5}, 7{ }^{14 \mathrm{~b}}$ While this compound did not (visibly) enter into the photoisomerization manifold traversed by $\mathbf{3}$, in the presence of alkynes it underwent selective photo substitution at the Mo center only (Scheme 21). ${ }^{51}$ Thus, irradiation in the presence of diphenylethyne gave $\mathbf{9 5}$ and traces of 96, the latter presumably being a precursor to the former, as 95 readily carbonylated to 96 . The analogous 97-99 were prepared in the same way, whereas 103a, $\mathbf{b}$ were derived by protodesilylation of $98 \mathbf{a}, \mathbf{b}$ at $-78^{\circ} \mathrm{C}$. The rotamers $\mathbf{a}$ and $\mathbf{b}$ underwent thermal equilibration on the NMR time scale and could not be isolated separately. The unusual end-on, parallel (and symmetrical) configuration of the two-electron donating alkynes in 96 and 99 contrasts the perpendicular arrangement in the four-electron donating alkyne complexes of the type 95 (Scheme 21). In addition to alkyne rotation, 95 and 97 exhibited a fluxional process that equilibrates the two halves of the respective Cp ligands $\left({ }^{1} \mathrm{H}\right.$ NMR), presumably via a species containing doubly bridging carbonyls and a symmetrically positioned terminal alkyne ligand. 
The role of the ruthenium was changed from that of a spectator to that of an active participant in the case of terminal alkynes $\mathbf{1 0 3}$ which (already at $-40{ }^{\circ} \mathrm{C}$ !) were subject to alkyne-alkenylidene isomerization to $\mathbf{1 0 0}$ with remarkable facility. ${ }^{52-54}$ Indeed $\mathbf{1 0 0}$ and $\mathbf{1 0 1}$ could be prepared directly from 7 and the respective terminal alkynes. They exist as equilibrating mixtures of isomers, established by an NMR study of the parent vinylidene $\mathbf{1 0 2}$ to be due to vinylidene rotation, possibly proceeding through a non- or semibridging isomer. The first demonstration of the existence of the latter was provided by an X-ray structural analysis of 104, obtained by (reversible) carbonylation of $\mathbf{1 0 0}$. To date there seems to be only one other example of such a species, ${ }^{54 \mathrm{a}}$ much better known for other bridging ligands, such as $\mathrm{CO}$ and CS. All of this chemistry is very different from that of the corresponding homodinuclear analogs $\mathbf{3}$ and $\mathbf{5}$ (Schemes 15 and 8, respectively), a remarkable demonstration of heterodinuclear diversity.

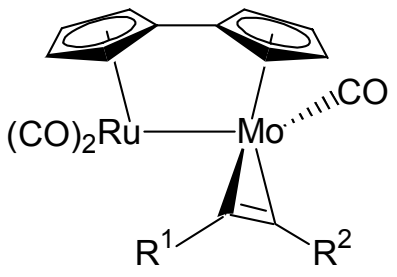

95, $\quad \mathrm{R}^{1}=\mathrm{R}^{2}=\mathrm{Ph}$

97, $\mathrm{R}^{1}=\mathrm{R}^{2}=4-\mathrm{MeC}_{6} \mathrm{H}_{4}$

98a, $R^{1}=\mathrm{SiMe}_{3}, \mathrm{R}_{2}=\mathrm{Ph}$

98b, $\mathrm{R}^{1}=\mathrm{Ph}, \mathrm{R}^{2}=\mathrm{SiMe}_{3}$

103a, $R^{1}=H, R^{2}=P h$

103b, $R^{1}=P h, R^{2}=H$

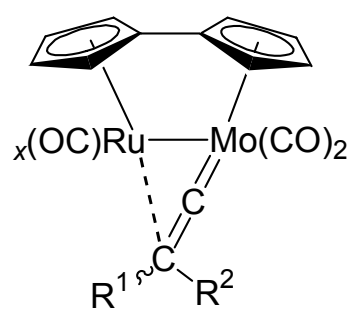

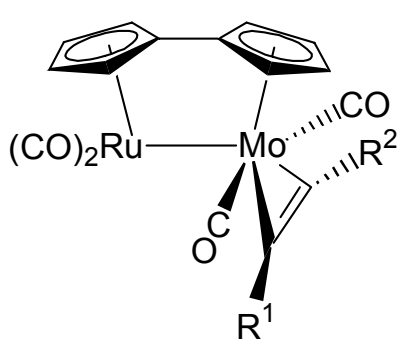

96, $\mathrm{R}^{1}=\mathrm{R}^{2}=\mathrm{Ph}$

99, $\mathrm{R}^{1}=\mathrm{SiMe}_{3}, \mathrm{R}^{2}=\mathrm{Ph}$

100, $\mathrm{R}^{1}=\mathrm{Ph}, \mathrm{R}^{2}=\mathrm{H}, x=1$

101, $\mathrm{R}^{1}=\mathrm{SiMe}_{3}, \mathrm{R}^{2}=\mathrm{H}, x=1$

102, $\mathrm{R}^{1}=\mathrm{R}^{2}=\mathrm{H}, x=1$

104, $\mathrm{R}^{1}=\mathrm{Ph}, \mathrm{R}^{2}=\mathrm{H}, x=2$

\section{Scheme 21}

In this vein, the oxidation of 95 with $\mathrm{O}_{2}$ gave the molybdenum-oxo species $\mathbf{1 0 5}$, which could then be converted back to $\mathrm{FvMoRu}(\mathrm{CO})_{5} 7$ under moderate pressures of carbon monoxide. ${ }^{29,51}$ The sequence shown in Scheme 22 can be viewed as a stepwise model for the catalytic oxidation of $\mathrm{CO}$ by $\mathrm{O}_{2}$ to give $\mathrm{CO}_{2}$, and it seems to strengthen the notion that synergistic effects can be observed in heterobimetallic fulvalene compounds. Interestingly, $\mathbf{1 0 5}$ also polymerizes alkynes catalytically, ${ }^{29}$ a process that is now under renewed scrutiny. 


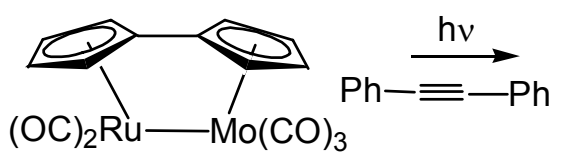

7

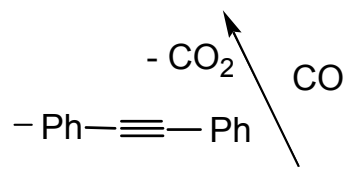

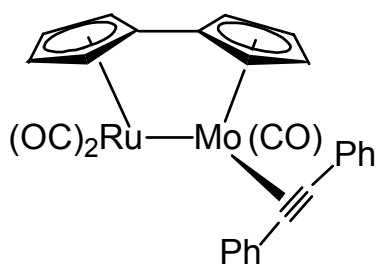

95

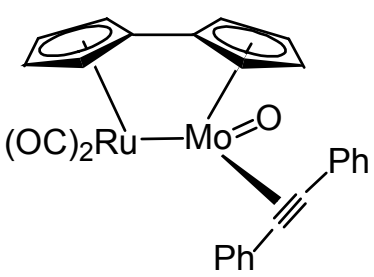

105

Scheme 22

Photo- and thermal reactivity of $\left.\mathrm{Fv} / \mathrm{W}(\mathrm{CO})_{3} \mathrm{Me}\right]\left[\mathrm{Rh}(\mathrm{CO})_{2}\right]$

A second example constitutes the photochemistry of $\mathrm{Fv}\left[\mathrm{W}(\mathrm{CO})_{3} \mathrm{Me}\right]\left[\mathrm{Rh}(\mathrm{CO})_{2}\right] \mathbf{8 2}^{47 \mathrm{~b}}$ and its molybdenum analog, chosen in part as a model system on which to probe potential alkyl group migrations, because of the possibility of $\mathrm{W}-\mathrm{Me} \mathrm{C}-\mathrm{H}$ activation by the neighboring $\mathrm{CpRh}(\mathrm{CO})_{2}$, and finally for the pragmatic reason that the relevant behavior of the respective CpM units in 82 had been well investigated. ${ }^{56}$ In the event, ${ }^{55} \mathbf{8 2}$ underwent photodercarbonylation to the M-M bonded 106, which further rearranged by methyl migration to 107 (Scheme 23). 


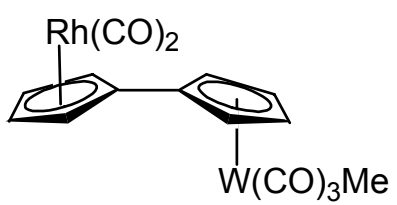

82

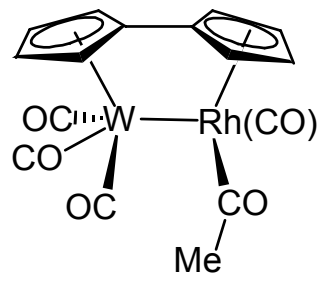

108

$$
\underset{\Delta, \mathrm{CO}}{\rightleftharpoons}
$$

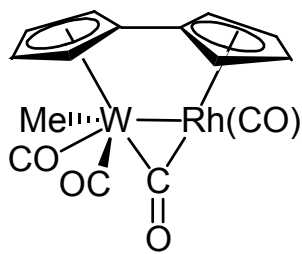

106

$\Delta$

$$
\frac{\Delta,-\mathrm{CO}}{\mathrm{CO}}
$$

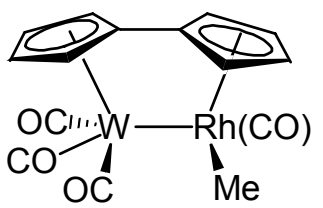

107

\section{Scheme 23}

The same final product could be obtained directly from 82 on heating to $110{ }^{\circ} \mathrm{C}$. That the thermal process was mechanistically distinct from the photochemical variant was indicated by the ready, reversible carbonylation of $\mathbf{1 0 7}$ to $\mathbf{1 0 8}$, suggesting the latter as an intermediate in the absence of light. This notion was supported by the chemistry of the (presumed) Mo analog of 82, which, on attempted synthesis from 80 (Schemes 19 and 20), spontaneously rearranged at ambient temperatures to the Mo version of $\mathbf{1 0 8}$ (similarly subject to thermal decarbonylation to the framework present in 107). The heterodinuclear complex 108 exhibits an unusually long WRh bond of 2.990 (1) $\AA$.

The mechanisms of these processes could be elucidated in greater detail using matrix isolation photochemical techniques and ${ }^{13} \mathrm{C}$ labeling experiments. The key conclusions are that: 1 . Complex 82 is selectively photodecarbonylated at the W center to presumably furnish $\mathbf{1 0 6}$ by (possibly direct) addition to the $\mathrm{Rh}=\mathrm{C}=\mathrm{O}$ bond; 2. Complex $\mathbf{1 0 7}$ thermally transforms to $\mathbf{1 0 8}$ by likely regioisomeric retrocycloaddition to $\mathrm{Fv}\left[\mathrm{W}(\mathrm{CO})_{3} \mathrm{Me}\right] \mathrm{Rh}(\mathrm{CO})$ which continues by insertion into the W-Me bond; 3. the thermal generation of $\mathbf{1 0 7}$ from 82 involves decarbonylation at $\mathrm{Rh}$ (in stark contrast to 1.) through the intermediacy of 108 ; 4. a plausible mechanistic scheme connecting 82 with 108 has as its key feature the well known equilibration of the $\mathrm{CpW}(\mathrm{CO})_{3} \mathrm{Me}$ unit with its $\mathrm{CpW}(\mathrm{CO})_{2} \mathrm{COCH}_{3}$ isomer, providing the necessary coordinative unsaturation to allow M-M bond formation and eventual acetyl transfer. 
In an attempt to effect $\mathrm{CO}$ insertion in $\mathbf{1 0 7}$ in the presence of an external ligand other than $\mathrm{CO}$ (which results in 108; Scheme 23), the complex was treated with $\mathrm{PMe}_{3}$. Interestingly, the (now familiar) zwitterion chemistry depicted in Scheme 24 occurred, providing first 109, then 111. Similarly, 108 gave 110 and 112. The latter was reacted with $\mathrm{Mo}(\mathrm{CO})_{3}(\mathrm{NCEt})_{3}$ to give zwitterionic 113.
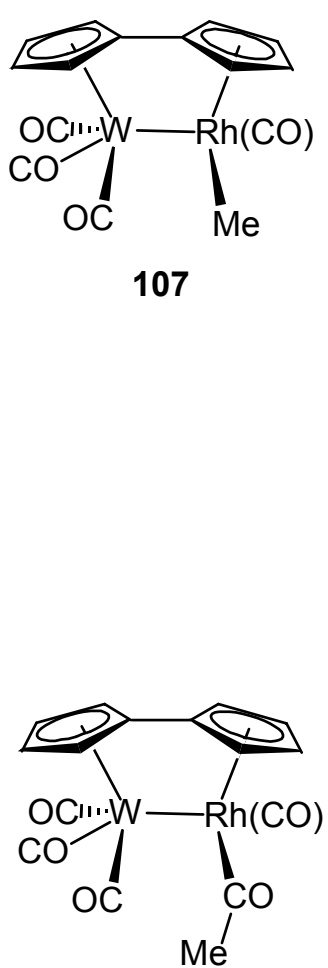

108
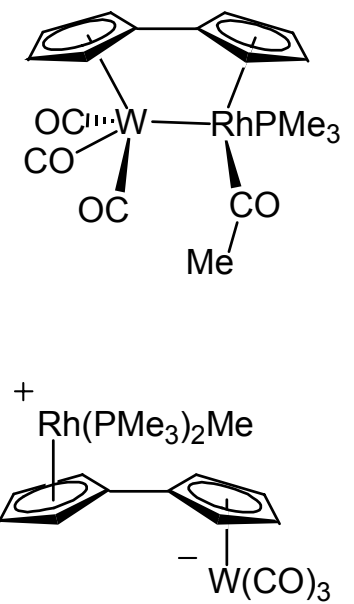

109
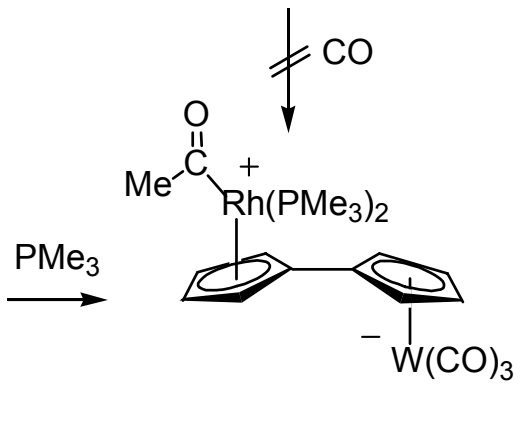

110
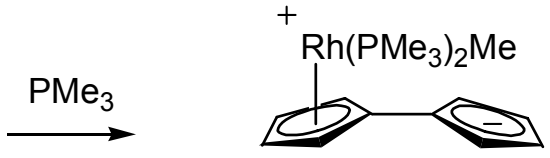

111

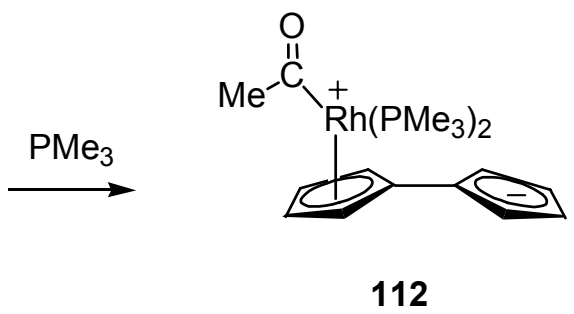

$\mathrm{Mo}(\mathrm{CO})_{3}(\mathrm{NCEt})_{3}$

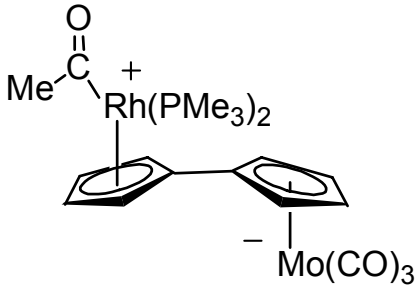

113

Scheme 24 


\section{Redox chemistry}

A third project in which heterodinuclear Fv complexes played an important role was executed in collaboration with the group of Astruc at Bordeaux, ${ }^{4 a}$ significantly expanding on earlier work with Bard in Austin. ${ }^{57}$ The latter established the electrochemistry of 3-7 as reflecting the relative ease of reductive cleavage of the $\mathrm{M}-\mathrm{M}$ bond by $2 \mathrm{e}$ processes and probed the mechanism of reoxidation of the dianions. With Astruc (and Delville), we became interested in whether the communication through the Fv bridge would allow for specific metal "recognition" in heterodinuclear systems. Thus, the electrochemistry of heterobimetallic complexes $\mathrm{FvWFe}(\mathrm{CO})_{5} 89$ and $\mathrm{FvWRu}(\mathrm{CO})_{5} 90$ was investigated. The former was reduced in two successive one-electron steps (slow-fast), and this behavior was synthetically exploited by using the one-electron transfer agent $\mathrm{CpFe}\left(\mathrm{C}_{6} \mathrm{Me}_{6}\right)$ to prepare the tetranuclear dimer 114 by selective metal reduction, dimerization, and trapping by methyl iodide (Scheme 25).

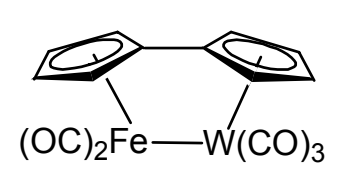

89

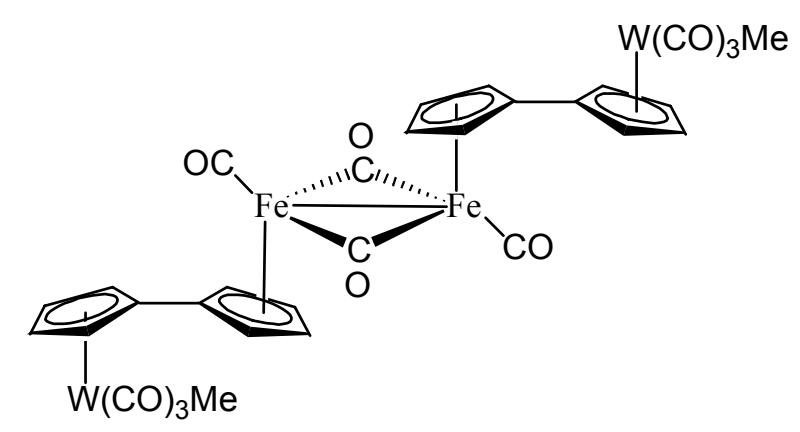

114
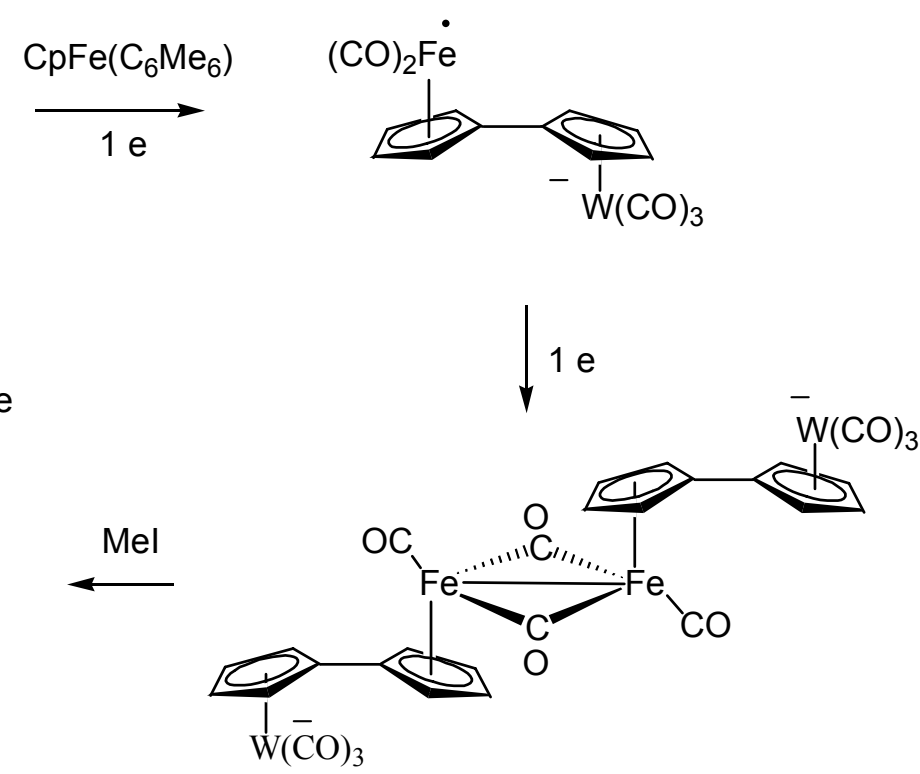

Scheme 25

In contrast, complex $\mathbf{9 0}$ reduced slowly in a two-electron step [or, preparatively, using $\left.\mathrm{CpFe}\left(\mathrm{C}_{6} \mathrm{Me}_{6}\right)\right]$ to the dianion. Upon reoxidation (anode or with $\mathrm{Cp}_{2} \mathrm{Fe}^{+} \mathrm{PF}_{6}{ }^{-}$), selective metal coupling occurred to eventually allow the isolation of 115 (Scheme 26). 


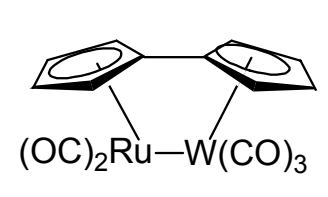

90

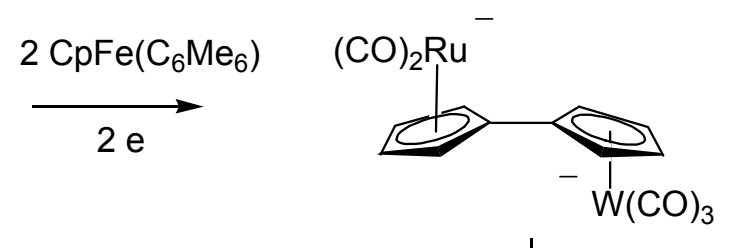

$\downarrow-1 e$

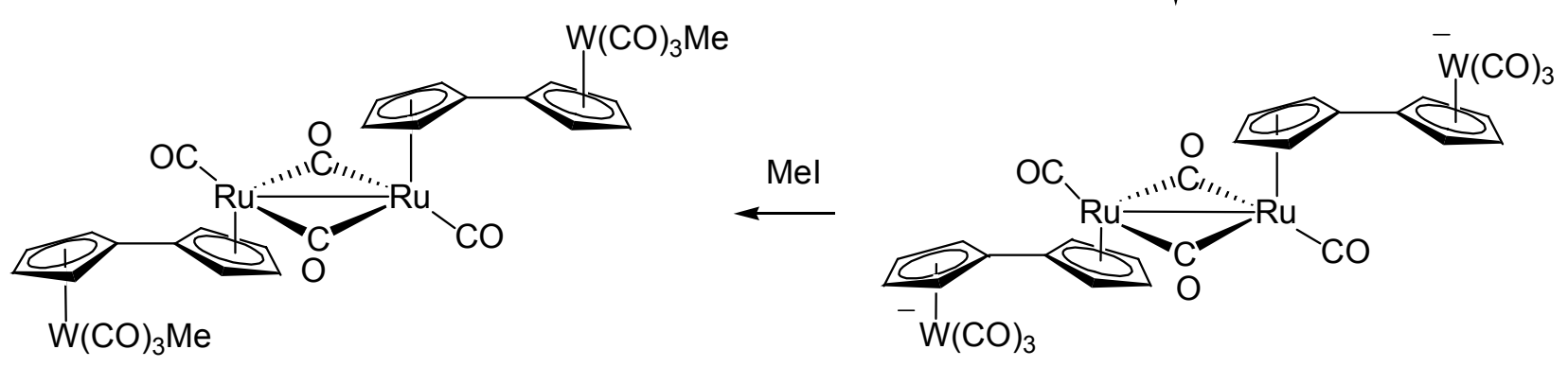

115

\section{Scheme 26}

This redox behavior led to an investigation of the use of electrocatalysis to effect metal-specific ligand substitution. ${ }^{59}$ It was found that reduction of $\mathbf{8 9}$ with a catalytic amount of $\mathrm{CpFe}\left(\mathrm{C}_{6} \mathrm{Me}_{6}\right)$ in the presence of excess $\mathrm{P}(\mathrm{OMe})_{3}$ or $\mathrm{PMe}_{3}$ led to the formation of the zwitterions $\mathrm{Fv}\left[\mathrm{W}(\mathrm{CO})_{3}{ }^{-}\right.$ ]$\left[\mathrm{Fe}(\mathrm{CO}) \mathrm{PR}_{3}{ }^{+}\right](\mathrm{R}=\mathrm{Me}, \mathrm{OMe})$.

Interestingly, 90 displayed unique behavior with different reducing agents, as the monosubstituted zwitterion $\mathrm{Fv}\left[\mathrm{W}(\mathrm{CO})_{3}{ }_{3}\right]\left[\mathrm{Ru}(\mathrm{CO})_{2}\left(\mathrm{PMe}_{3}\right)^{+}\right]$was obtained when $\mathrm{CpFe}\left(\mathrm{C}_{6} \mathrm{Me}_{6}\right)$ was used, while the disubstituted complex $\mathrm{Fv}\left[\mathrm{W}(\mathrm{CO})_{3}{ }^{-}\right]\left[\mathrm{Ru}(\mathrm{CO})\left(\mathrm{PMe}_{3}\right)_{2}{ }^{+}\right]$was formed when $\mathrm{Cp} * \mathrm{Fe}\left(\mathrm{C}_{6} \mathrm{Me}_{6}\right)$ was the catalyst. This electrocatalytic process was generalized to include the homobimetallic species $\mathrm{FvMo}_{2}(\mathrm{CO})_{6}(\mathbf{5})$ and $\mathrm{FvW}_{2}(\mathrm{CO})_{6}(\mathbf{6})$, allowing the preparation of previously reported zwitterions $\mathrm{Fv}\left[\mathrm{M}(\mathrm{CO})_{3}{ }_{3}\right]\left[\mathrm{M}(\mathrm{CO})_{2} \mathrm{PMe}_{3}{ }^{+}\right](\mathrm{M}=\mathrm{Mo}$, W) under milder conditions, completely obviating the occurrence of ring slippage (Section 2.1.2.). Zwitterions of this type may have applications in nonlinear optics. ${ }^{60}$

\subsubsection{Conclusions}

The heterodinuclear fulvalene complexes described above differ in photo- and thermal reactivity from comparable homonuclear analogs. Thus, under the same conditions, 7 reacted quite differently from its homodinuclear analogs $\mathbf{3}$ and $\mathbf{5}$ in the presence of alkynes. Moreover, none of the fulvalene dimetals investigated so far have effected C-C bond formations with alkynes, such as those typically observed with CpM dimers. It is curious why this should be so, and further experimentation is in order.

With respect to the chemistry of $\mathbf{8 2}$ (and its Mo analog), distinct metal-specific decarbonylation pathways were uncovered, in addition to a unique methyl migration process from $\mathrm{W}$ to $\mathrm{Rh}$. 
Fundamentally, such ligand migrations along a metal chain are important prerequisites for the attainment of synergistic (or at least cooperative) catalysis. ${ }^{61}$

Finally, specific metal selectivity was observed in the reactions of $\mathbf{1 0 7}$ and $\mathbf{1 0 8}$ with phosphines and in the reductive couplings of 89 and 90 to give 114 and 115, respectively. In both cases kinetic and thermodynamic factors may play a role, details that need to be worked out in the future.

\section{Tercyclopentadienyl Metal Complexes}

\subsection{Synthesis and structural characterization}

Armed with the considerable knowledge of $\mathrm{FvM}_{2}$ complexes exemplified in the previous sections, about a decade ago we embarked on expanding the Fv motif to incorporate cyclopentadienologs, i.e. cyclopentadienyl substituted Fv systems, the first member of the series being tercyclopentadienyl (terCp). The "unnatural" topology of three metals held in close proximity by the tightly bound $\pi$ ligand seemed to promise rich chemistry. ${ }^{62}$

On the basis of the transformations described in Schemes 19 and 20, two routes to these systems were developed. The first starts with fulvalene dianion and exploits the deactivating nature of the first vinyligous alkanoylation with 3-chlorocyclopentenane on the resulting fulvalene frame to achieve selective monosubstitution (Scheme 27). Deprotonation in situ provided the two regioisomeric 3-oxocyclopentenylated fulvalene dianions which were worked up in two ways: either metallation followed by oxidative $M-M$ bond formation to give 116 and 117, or metallation followed by methylation to furnish 118. Chromatography at this stage separated components a from b. The appended cyclopentenone was then elaborated as described in Schemes 19 and 20 to result in $\mathbf{1 2 1} \mathbf{- 1 2 8}$. 


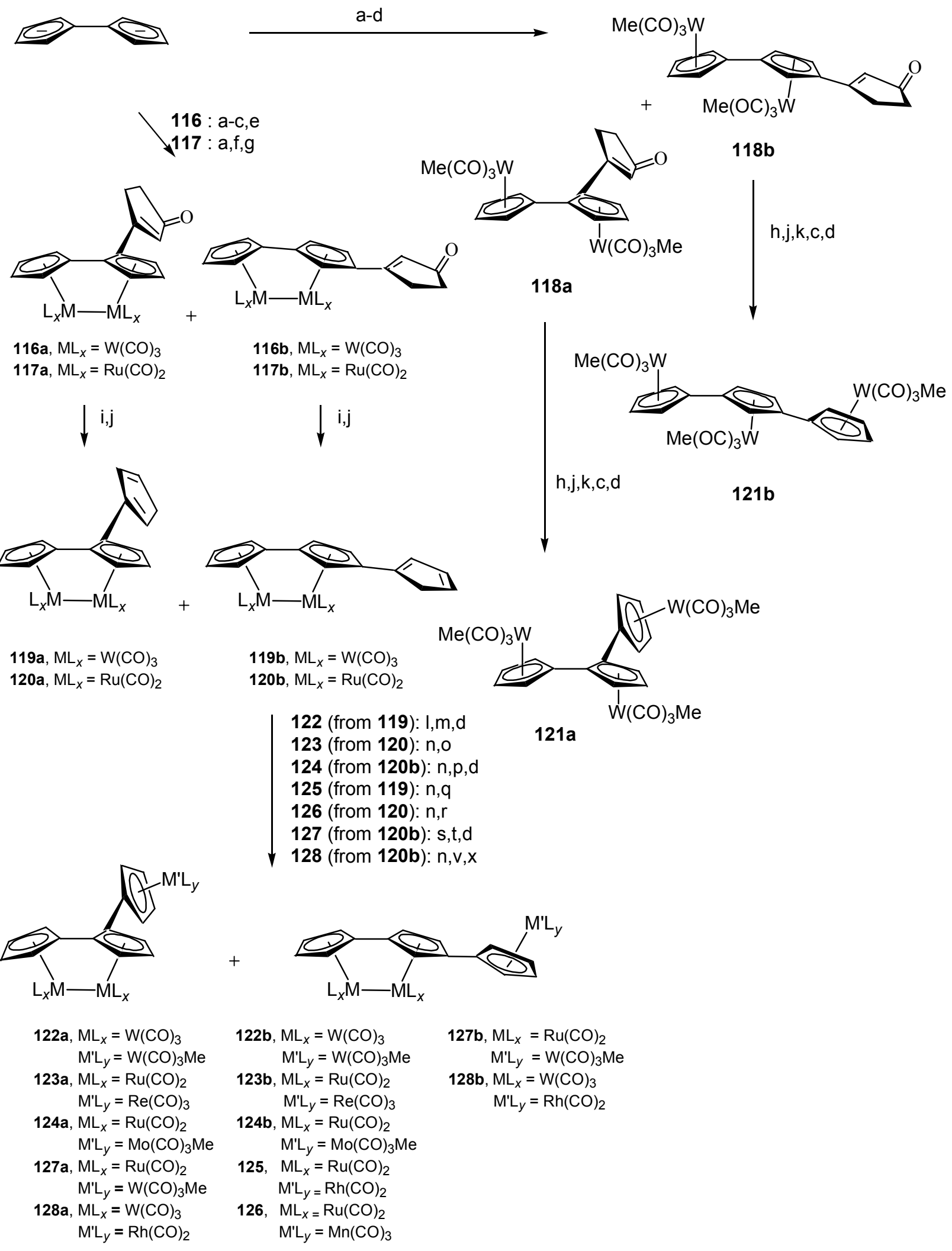

Scheme 27 a) 3-Chloro-2-cyclopentenone, THF, $-78^{\circ} \mathrm{C}, 5 \mathrm{~min}$; b) $\mathrm{BuLi},-78{ }^{\circ} \mathrm{C}$ to $23{ }^{\circ} \mathrm{C}$; c) $\left[\mathrm{W}(\mathrm{NCEt})_{3}(\mathrm{CO})_{3}\right]$ excess, DME, $23{ }^{\circ} \mathrm{C}, 3 \mathrm{~h}$; d) MeI, $23{ }^{\circ} \mathrm{C}, 30 \mathrm{~min}$; e) $\mathrm{AgBF}_{4}$ (2.2 equiv.), THF, 
$-78{ }^{\circ} \mathrm{C}$ to $23{ }^{\circ} \mathrm{C}, 12 \mathrm{~h}$; f) $\mathrm{MeCO}_{2} \mathrm{H},-78{ }^{\circ} \mathrm{C}$; g) $\left[\mathrm{Ru}_{3}(\mathrm{CO})_{12}\right]$, DME, $18 \mathrm{~h}$; h) $\mathrm{LiAlH}_{4}, \mathrm{Et}_{2} \mathrm{O}, 0{ }^{\circ} \mathrm{C}$ to 23, $1 \mathrm{~h}$; i) $i \mathrm{Bu}_{2} \mathrm{AlH}, \mathrm{CH}_{2} \mathrm{Cl}_{2}, 0{ }^{\circ} \mathrm{C}, 2 \mathrm{~h}$; j) cat. 4- $\mathrm{MeC}_{6} \mathrm{H}_{4} \mathrm{SO}_{3} \mathrm{H}, \mathrm{C}_{6} \mathrm{H}_{6}, 60{ }^{\circ} \mathrm{C}, 2 \mathrm{~min}$; $\left.\mathrm{k}\right) \mathrm{KO} t \mathrm{Bu}$, DME, $\left.23{ }^{\circ} \mathrm{C}, 10 \mathrm{~min} ; 1\right)\left[\mathrm{W}(\mathrm{CO})_{3}(\mathrm{NCEt})_{3}\right]$, THF, $\left.23{ }^{\circ} \mathrm{C}, 12 \mathrm{~h} ; \mathrm{m}\right) \operatorname{LiN}\left(\mathrm{SiMe}_{3}\right)_{2}, \mathrm{THF},-78{ }^{\circ} \mathrm{C}, 5$ min; n) $\mathrm{NaNH}_{2}$, THF, $23{ }^{\circ} \mathrm{C}, 5 \mathrm{~min} ;$ o) $\left.\left[\operatorname{Re}(\mathrm{CO})_{3} \mathrm{Br}(\mathrm{THF})\right]_{2}, \mathrm{THF}, 23{ }^{\circ} \mathrm{C}, 1 \mathrm{~h} ; \mathrm{p}\right)$ $\left[\mathrm{Mo}(\mathrm{NCMe})_{3}(\mathrm{CO})_{3}\right]$, THF, $23{ }^{\circ} \mathrm{C}, 30 \mathrm{~min}$; q) $\left[\mathrm{Rh}(\mathrm{CO})_{2} \mathrm{Cl}\right]_{2}$, THF, $\left.23{ }^{\circ} \mathrm{C}, 1 \mathrm{~h} ; \mathrm{r}\right)\left[\mathrm{Mn}(\mathrm{CO})_{4} \mathrm{Br}\right]_{2}$, THF, $23{ }^{\circ} \mathrm{C}, 30 \mathrm{~min}$; s) $\mathrm{KOtBu}$, THF, $23{ }^{\circ} \mathrm{C}, 5 \mathrm{~min}$; t) $\left[\mathrm{W}(\mathrm{NCMe})_{3}(\mathrm{CO})_{3}\right]$, THF, $23{ }^{\circ} \mathrm{C}, 30 \mathrm{~min}$; u) $\mathrm{KH}$ excess, THF, 5 min; v) DIBAL-H, $\mathrm{CH}_{2} \mathrm{Cl}_{2}, 0{ }^{\circ} \mathrm{C}, 2 \mathrm{~h}$; $\mathrm{x}$ [ $\left[\mathrm{Rh}(\mathrm{CO})_{2} \mathrm{Cl}\right]_{2}$, THF, $1.5 \mathrm{~h}$.

It is possible to carry out the initial alkenylation of $\mathrm{Fv}$ dianion with selectivity for either series a ( $\alpha$-attack) or $\mathbf{b}$ ( $\beta$-attack). Thus, using dilithiofulvalene at $-78{ }^{\circ} \mathrm{C}$ in suspension in THF in step a) of Scheme 27 furnished almost exclusively only 116a, suggesting kinetic preference for $\alpha$ attack, even though more sterically encumbered. Such selectivity would be consistent with frontier orbital control in this process. ${ }^{63}$ On the other hand, employment of the much less reactive 3-ethoxy- rather than 3-chlorocyclopentenone as the reagent, led to exclusive formation of $116 \mathbf{b}{ }^{64}$

The second strategy stitches the $\mathrm{Cp}$ rings together one at a time and is therefore advantageous in the metal sequence specific assembly of heterotrimetallic arrays. Thus, for example, $\mathbf{8 1}$ (made as described in Section 2.2.1. according to Scheme 19 or by Pd coupling methodology) can be further elaborated via the reaction of its anion with 3-chlorocyclopentenone (Scheme 28) to 129a, b. Both regioisomers can then be subjected to a final metallation sequence, ${ }^{62,64}$ as shown for 129a in Scheme 28, providing 130 and $131 .{ }^{62}$ 


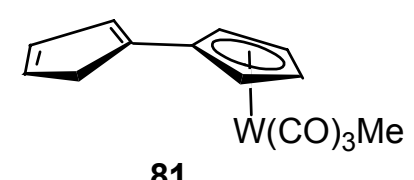

81

$\downarrow a-c$

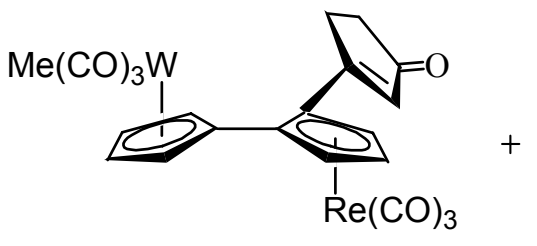

$129 a$

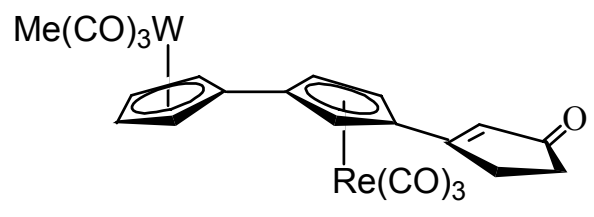

$129 b$

$1: 1$

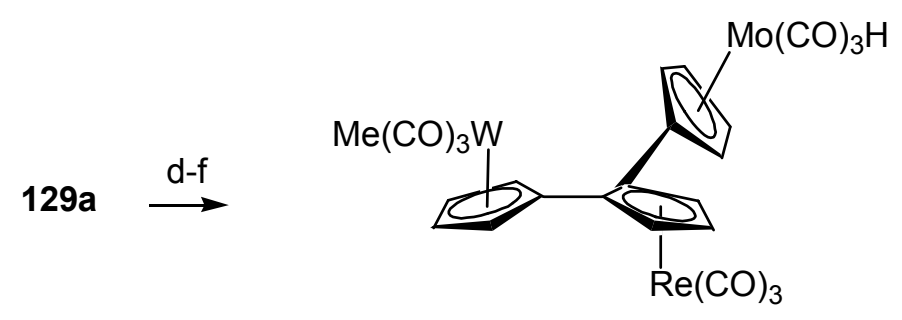

130

$\stackrel{\mathrm{g}, \mathrm{h}}{\longrightarrow}$

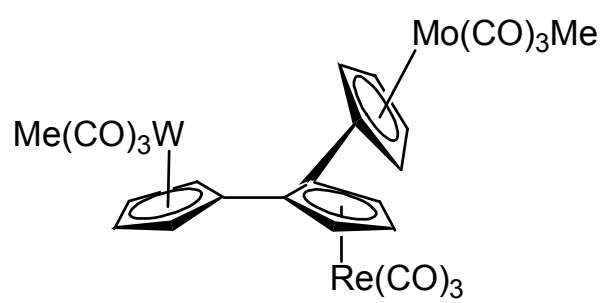

131

Scheme 28 a) $\mathrm{NaH}$ (3 equiv), THF, $0{ }^{\circ} \mathrm{C}, 20 \mathrm{~min}$; b) 3-chloro-2-cyclopentenone, $0{ }^{\circ} \mathrm{C}, 1.5 \mathrm{~h}$, then $23{ }^{\circ} \mathrm{C}, 30 \mathrm{~min}$; c) $\left[\mathrm{Re}(\mathrm{CO})_{3} \mathrm{Br}(\mathrm{THF})\right]_{2}$, THF, $4.5 \mathrm{~h}$; d) $i \mathrm{Bu}_{2} \mathrm{AlH}, \mathrm{CH}_{2} \mathrm{Cl}_{2}, 0{ }^{\circ} \mathrm{C}, 2 \mathrm{~h}$; e) 4$\mathrm{MeC}_{6} \mathrm{H}_{4} \mathrm{SO}_{3} \mathrm{H}, \mathrm{C}_{6} \mathrm{H}_{6}, 60{ }^{\circ} \mathrm{C}, 2 \mathrm{~min}$; f) [Mo(NCMe) $\left.)_{3}(\mathrm{CO})_{3}\right]$, THF, $23{ }^{\circ} \mathrm{C}, 19 \mathrm{~h}$; g) $\mathrm{KO} t \mathrm{Bu}, \mathrm{THF}$, $23{ }^{\circ} \mathrm{C}, 40 \mathrm{~min}$; h) MeI, $23{ }^{\circ} \mathrm{C}, 2.5 \mathrm{~h}$. 
Another complementary example illustrates an application in the $\beta$-terCp series, containing a $\mathrm{Fv}\left(\mathrm{M}^{1}-\mathrm{M}^{2}\right)$ fragment, and rests in part on the chemistry described in Scheme 23 (Scheme 29). ${ }^{64}$
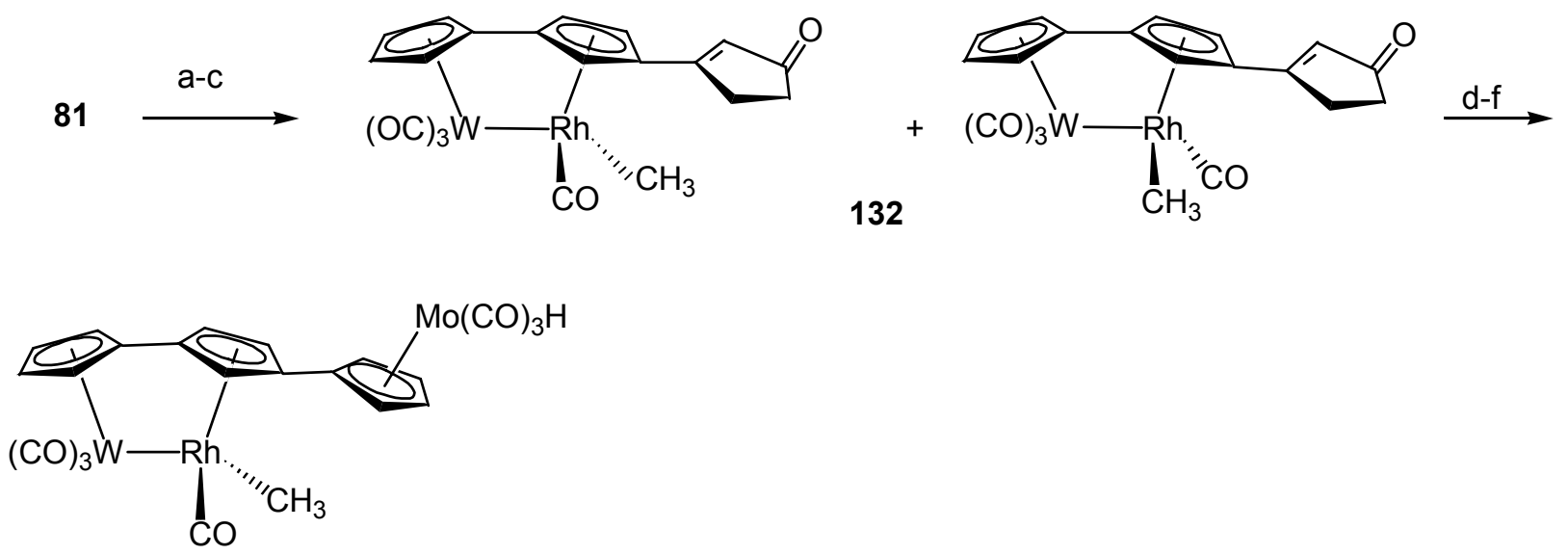

133

Scheme 29 a) $\mathrm{NaH}$; b) 3-chlorocyclopentenone; c) $\mathrm{NaH}$, THF, $\left[\mathrm{Rh}(\mathrm{CO})_{2} \mathrm{Cl}\right]_{2},-20{ }^{\circ} \mathrm{C}$ to reflux, column chromatography; d) $i \mathrm{BuAlH}$; e) $4-\mathrm{MeC}_{6} \mathrm{H}_{4} \mathrm{SO}_{3} \mathrm{H}$; f) $\mathrm{Mo}(\mathrm{NCEt})_{3}(\mathrm{CO})_{3}$.

Unlike 107, intermediate 132 can (and does) exist as two diastereomers, shown to interconvert on the NMR time scale, whereas only one isomer of $\mathbf{1 3 3}$ was observed. Structurally, the terCp ligand exists as two isomers that differ only in the connectivity of the $\mathrm{Cp}$ rings. As already indicated, the central ring may be substituted in either 1',2' ( $\alpha$ isomer) or 1',3' fashion ( $\beta$ isomer). It is apparent from X-ray crystallographic studies that in the $\alpha$ isomer there is a steric interaction that is responsible for a relatively large twist angle between one of the terminal $\mathrm{Cp}$ rings and the attached $\mathrm{FvM}_{2}$ fragment. When there is a $\mathrm{Fv}(\mathrm{M}-\mathrm{M})$ bond (as, e.g., in 123a) ${ }^{62}$, the twist angle is larger than $90^{\circ}$, with the attached metal minimizing steric interactions with the $\mathrm{FvM}_{2}$ frame. In the absence of an M-M bond [as, e.g., in terCpMo $\left.\mathrm{pm}_{3}(\mathrm{CO})_{3} \mathrm{Cl}_{3}\right]^{64}$ one $\mathrm{Cp}$ is nearly perpendicular to an almost coplanar $\mathrm{Fv}$ unit with the metals in the anti configuration, again, a sterically most accommodating arrangement. In the $\beta$ isomer, the terCp array is nearly coplanar, although some twisting and bending is visible, as already noted for simple $\mathrm{FvM}_{2}$ systems (Section 2.1.1.).

The synthesis of the terCp trimetals allowed their preliminary exploration as potentially cooperating trinuclear constructs.

\subsection{Reactivity}

\subsubsection{Anionic charge transfer}

Evidence for charge transfer along the trimetallic chain, a process of fundamental importance, ${ }^{60}$ was gleaned from several experiments. Thus, for example, the cyclopentadiene substituent in 
119 was readily perdeuterated $\left(\mathrm{D}_{2} \mathrm{O}, \mathrm{NEt}_{3}\right.$, acetone- $\left.d_{6}\right)$ and the resulting species converted to 122- $\boldsymbol{d}_{\mathbf{4}}$ as in Scheme 27. Remarkably, 122b- $\boldsymbol{d}_{\mathbf{4}}$ exhibited complete scrambling of the label over
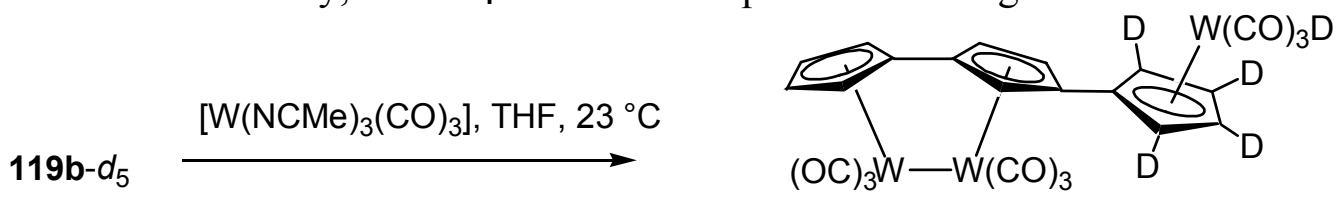

134
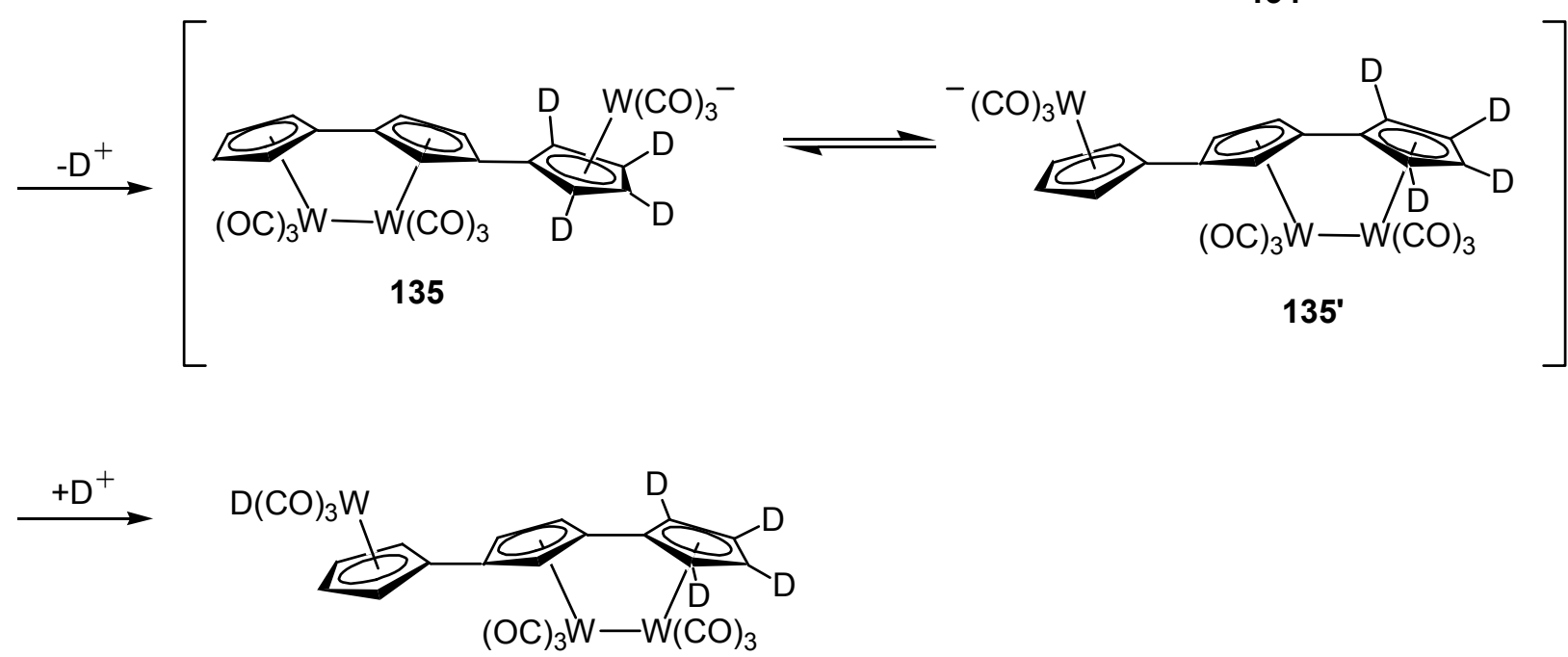

134

\section{Scheme 30}

the two terminal $\mathrm{Cp}$ rings, whereas 122a- $\boldsymbol{d}_{4}$ showed retention. ${ }^{62}$ Following the course of the reaction of $119 \mathrm{~b}-\boldsymbol{d}_{5}$ with $\left[\mathrm{W}(\mathrm{NCMe})_{3}(\mathrm{CO})_{3}\right]$ by ${ }^{1} \mathrm{H}$ NMR indicated that the initial metal deuteride 134 was generated label-specifically, but that it underwent equilibration with regioisomer 134', (Scheme 30). This process was accelerated by base, retarded by acid. A plausible mechanism for the label scrambling is the reversible formation of the anion 135, rapidly isomerizing to $\mathbf{1 3 5}^{\prime}$ (Scheme 30 ), as the $\mathrm{p} K_{\mathrm{a}}$ of $\mathbf{1 3 4}$ would be expected to be comparable to that of 45 (Section 2.1.2.) (24a $^{24}$ and $\mathrm{CpW}(\mathrm{CO})_{3} \mathrm{H}(\sim 16) .{ }^{65}$ The degenerate isomerization of 135 is unique in its simplicity and constitutes an intramolecular variant of the known and mechanistically complex nucleophilic attack by anionic metal centers on dinuclear complexes. ${ }^{66}$ As such it provides an opportunity to study this process was under potentially less complicated circumstances, currently in progress, thus perhaps pinpointing one of the three most reasonable pathways for exchange: ${ }^{60}$ electron transfer via nucleophilic attack directly at the metal with concomitant ring slippage of the central $\mathrm{Cp}$ or $\mathrm{CO}$ dissociation; direct nucleophilic attack at a central CO ligand; and one-electron transfer, followed by decay of the radical anion, and finally combination of the resulting 17 electron radicals.

Why should the rate of such an equilibration be less in the $\alpha$-isomer of 135? It appears that steric encumbrance to (normally fast) ${ }^{67}$ rotation of the $\mathrm{CpM}^{-}$unit is to blame, thus preventing the perhaps required (near) coplanarization of the terCp ligand and therefore sufficient proximity of the active centers. 


\subsubsection{Radical electron transfer}

A topologically very similar result to that described for $\mathbf{1 3 5}$, but presumably involving its radical counterpart, was obtained on treatment of regiopure 134 (or its $\alpha$-isomer) with $\mathrm{CCl}_{4}$ : complete scrambling (or retention) of label was evident in the resulting chloride 136 (Scheme 31). ${ }^{62}$

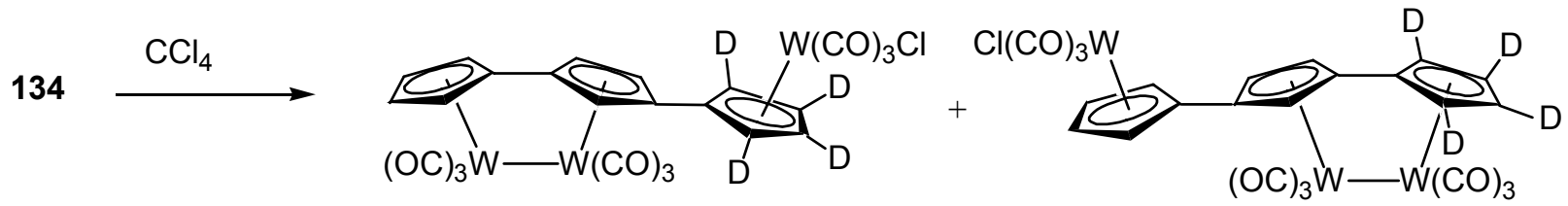

Scheme 31

136

\subsubsection{Methyl transfer}

One of the prerequisits for potentially synergistic catalysis by terCp trimetals is that intramolecular ligand transfer is facile. In this way, one can envisage metal specific activation of two organic substrates (especially in designed heterotrinuclear systems) and subsequent transformation of the resulting organic fragments. To probe the feasibility of such a process, complex 122b was scrutinized. However, the appropriately regiospecifically labeled $\mathbf{1 2 2} \mathbf{b}-\boldsymbol{d}_{\mathbf{4}}$ was stable towards rearrangement, even on irradiation.

On the other hand, reduction of the $\mathrm{W}-\mathrm{W}$ bond provided a dianion, ${ }^{\mathbf{1 3 7}}$ for which methyl migration to 138 was clearly visible by ${ }^{1} \mathrm{H}$ NMR spectroscopy and trapping with $\mathrm{CD}_{3} \mathrm{I}$ (Scheme 32). The 

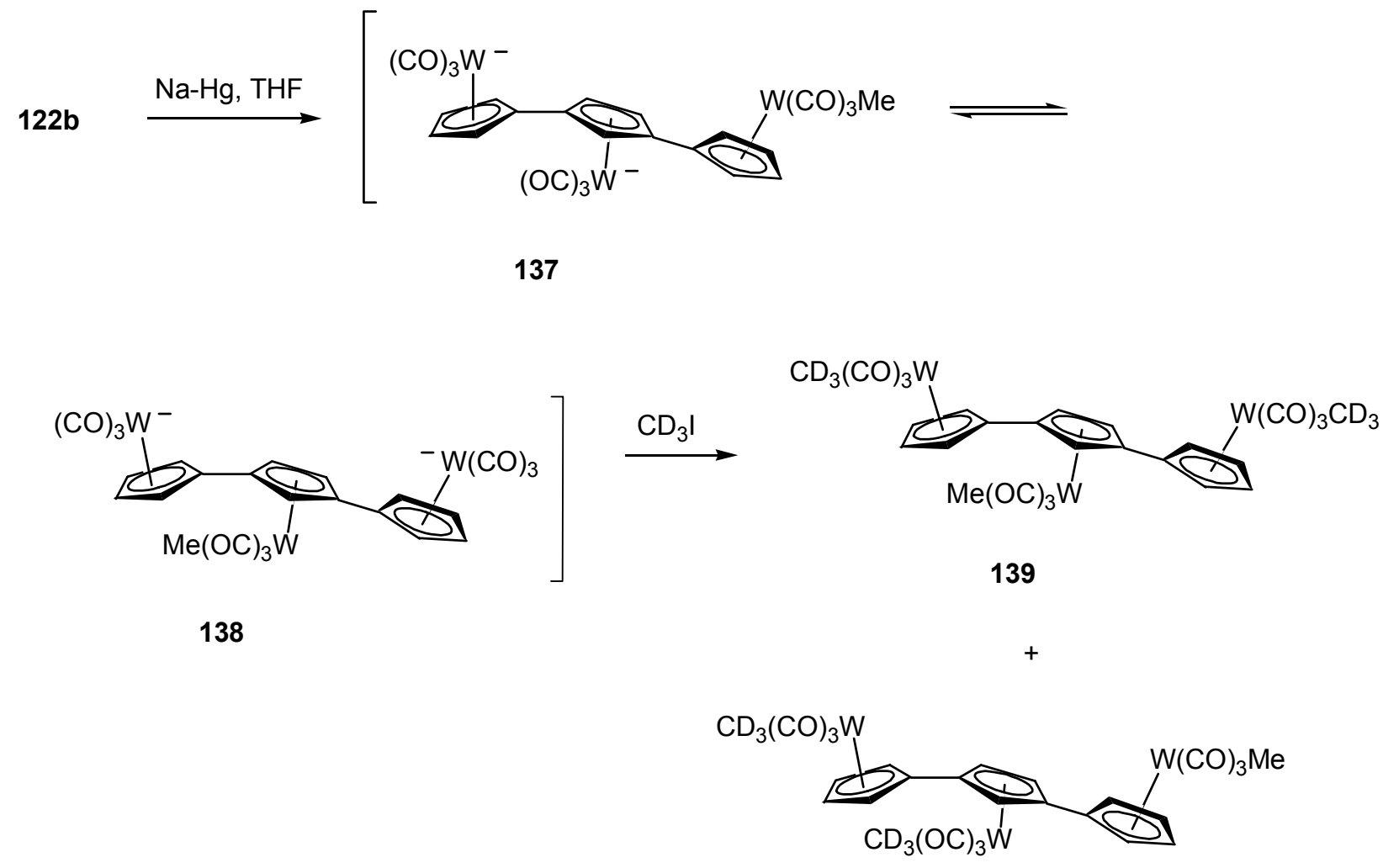

140

\section{Scheme 32}

equilibrium mixture of the dianion contained 138: 137 in a ratio of $2.7: 1$ initially, changing to 6:1. The thermodynamic dominance of $\mathbf{1 3 8}$ in this equilibrium might be expected on the basis of charge separation. The two isomeric dianions alkylate at comparable rates, as the methyl derivatives 139 and 140 were generated in a 2.4:1 ratio. Most significantly, a crossover experiment employing 122b and its $\left[\left(\eta^{5}-C_{5} D_{4}\right) W(C O)_{3}\left(C D_{3}\right)\right]$-substituted counterpart provided the final trimethylated products without any evidence for intermolecular label scrambling. In addition, an identical series of experiments starting with the $\alpha$-isomer 122a gave analogous results. It thus appears that in the latter, rescinding the conformational rigidity inherent in the Fv(M-M) part of the framework provides enough flexibility for the observed methyl transfers.

There is precedence for the intermolecular methyl (and alkyl) transfer from alkylmetals to metal ion complexes, and mechanistic studies reveal a more complex picture than might be envisaged on the basis of the analogy to the organic $\mathrm{S}_{N} 2$ process. ${ }^{68}$ Again, further mechanistic scrutiny of the terCp system in this regard might prove fruitful because of its strictly intramolecular constraints and ease of analysis.

\subsubsection{Some tantalizing photochemical experiments}

Preliminary experiments provide a glimpse of potentially rewarding photochemistry of the terCp trimetallic array. ${ }^{64}$ These experiments were carried out on systems for which the reactivity of the individual subunits under similar conditions had been well established (vide supra). Examples 
are shown in Scheme 33, in which the potential effect of the $\mathrm{FvRu}_{2}(\mathrm{CO})_{4}$ core on the dynamics of the appended CpM unit was probed. Thus, irradiation of $\mathbf{1 2 3 a}$ or $\mathbf{b}$ reproduced the analogous

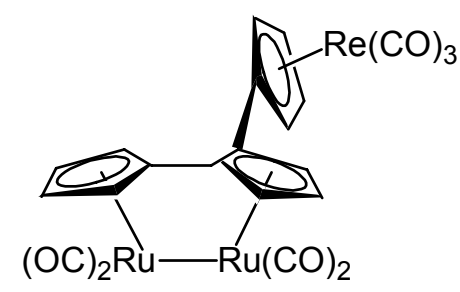

123a

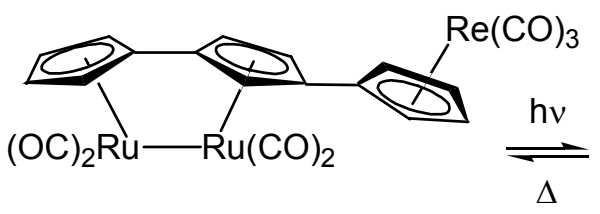

$123 b$

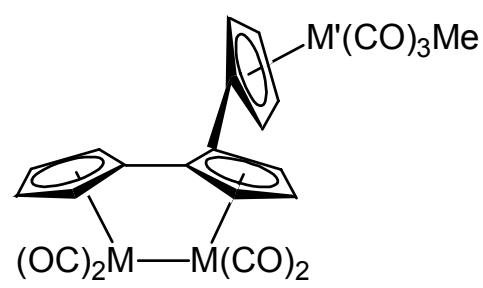

127a, $M=R u, M^{\prime}=W$
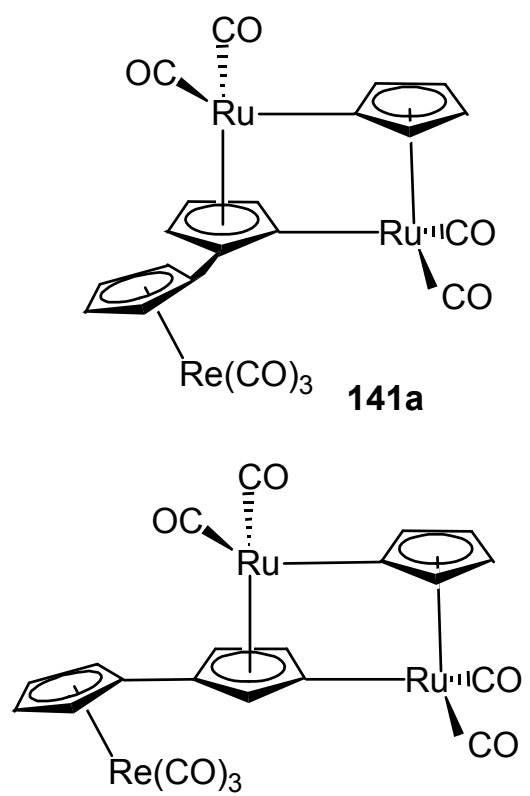

$141 b$

\section{Scheme 33}

isomerization of 3 (Schemes 15-17) faithfully. The resulting 141a and b underwent clean thermal reversal with activation parameters very similar to those of $\mathbf{5 5}$ (Scheme 17). Therefore, the excited state of this system appears to chemically transform according to the component chromophore of 3 . In contrast, the $\mathrm{W}$ analog $\mathbf{1 2 7}$ a shows the chemistry typical of the

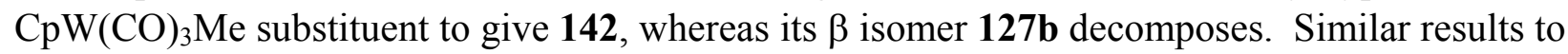
those with 127 were obtained with 122a and $\mathbf{b}$. The electronic spectra of the terCp complexes seem to be a composite of those of the individual chromophores, but the absorptions are bathochromically shifted, more so for the $\beta$ than the $\alpha$ isomers, perhaps a reflection of the 
difference in effective $\pi$ overlap along the chain. For 122 and 127, the electronic absorptions of the substructures overlap conderably, ${ }^{35 a, 40}$ and the selective photoreactivity at the $\mathrm{CpW}(\mathrm{CO})_{3} \mathrm{Me}$ end is interesting. Such also occurred in the presence of alkynes (Scheme 34), resulting in the typical $^{35 \mathrm{~d}, 69}$ insertion products 143 - 146, even in the presence of excess added ligand, remarkable, in light of the multitude of imaginable products.

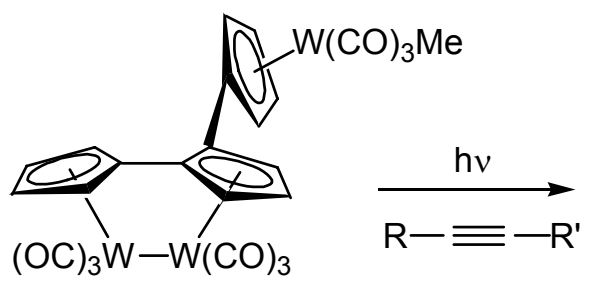

$122 \mathrm{a}$

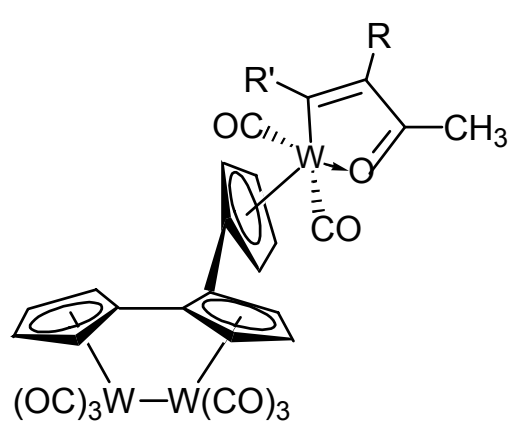

143, $R=E t, R^{\prime}=P h$

$144, R=R^{\prime}=M e$

$145, R=H, R^{\prime}=P h$

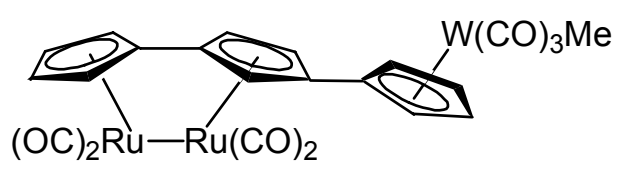

$127 b$

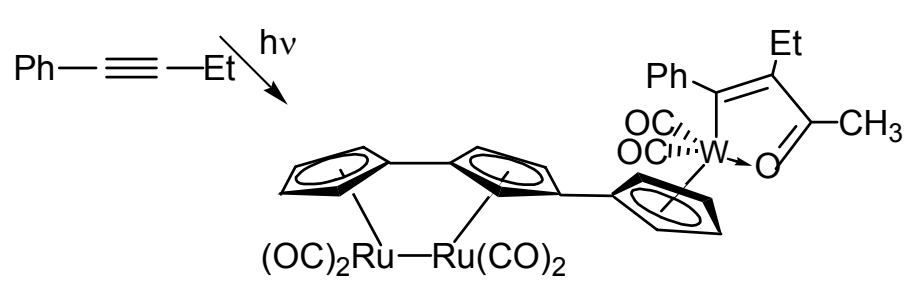

Scheme 34

146

\subsubsection{Conclusions}

It is clear that our methodology provides ready access to terCp trimetals with extensive, if not complete, control of metal, loco-, and ligand regioselectivity. The chemistry of the plethora of complexes now available is only in its infancy, but the preliminary data do show extensive intrachain communication, the possibility of intramolecular ligand migration, and the possibility of selective transformations in good yields, despite the multifunctional nature of the substrates. We hope to exploit these findings in the specific construction of trimetallic sequences whose identity may be conducive to synergistic catalysis.

\section{Quatercyclopentadienyl Metal Complexes}


The strategies employed in the assembly of the terCp ligand (Schemes 27 and 28) are, in principle, readily adaptable to its higher cyclopentadienologs. However, there are two facets of these approaches that render them it increasingly difficult to realize. One has the drawback that is inherent to any interactive sequence to oligomers: if the yield of each step is not close to quantitative, the efficiency of the scheme rapidly decreases to the point of impracticability. The second is built into the topology of the disubstituted internal CpM unit of the growing chain: it is stereogenic and may give rise to stereoisomers, in addition to the possibility of $\alpha$ and $\beta$ structural isomers already encountered in terCpM $\mathrm{pM}_{3}$. For the next higher oligomer, homonuclear quaterCpM 4 , this translates into the possibility of six isomers. This number rapidly increases if one considers M-M bonded isomers and heteronuclear analogs. Thus, one can readily envisage formidable synthetic obstacles.

In the event (and to quantify the above), Scheme 35 was executed, ${ }^{70}$ in a manner completely analogous to that for $\mathbf{1 2 2}$ in Scheme 27, but adjusting for the changed stoichiometry of the oxocyclopentenylation step. The results reveal that the initial double cyclopentenylation sequence to give isomers 147 avoids the generation of the two $\alpha, \alpha^{\prime}$ - regioisomers.

While this selectivity limits the number of isomers of 147 to four, continued execution of the Scheme doubles it, because of the possibility of M-M bond isomers, as in 148 and 149. (Partial) separation of isomers along the sequence was possible at various stages by column or preparative thin layer chromatography and by fractional crystallization. The structural assignments were made on the basis of X-ray analysis (147a and $\mathbf{b})$ and extensive ${ }^{1} \mathrm{H}$ NMR experiments. The final products 148 and 149 were isolated in milligram quantities, representing low overall yields from fulvalene dianion. However, while these results seem forbidding, it should be possible to improve on them by increasing the regioselectivity of the first step (see Section 3.1.) and by avoiding the possibility of M-M bond isomerism through a judicious choice of the conditions for the final step in Scheme 35.

Because of the only minute quantities available of the quaterCpW 4 isomers 148 and 149 , no chemistry could be executed on these complexes. Such would be interesting, as it is clear that their precursor dianions are equilibrating by a combination of the electron transfer and ligand migration steps described in Sections 3.2.1. - 3.2.3. for the terCpM $\mathrm{pM}_{3}$ system. 


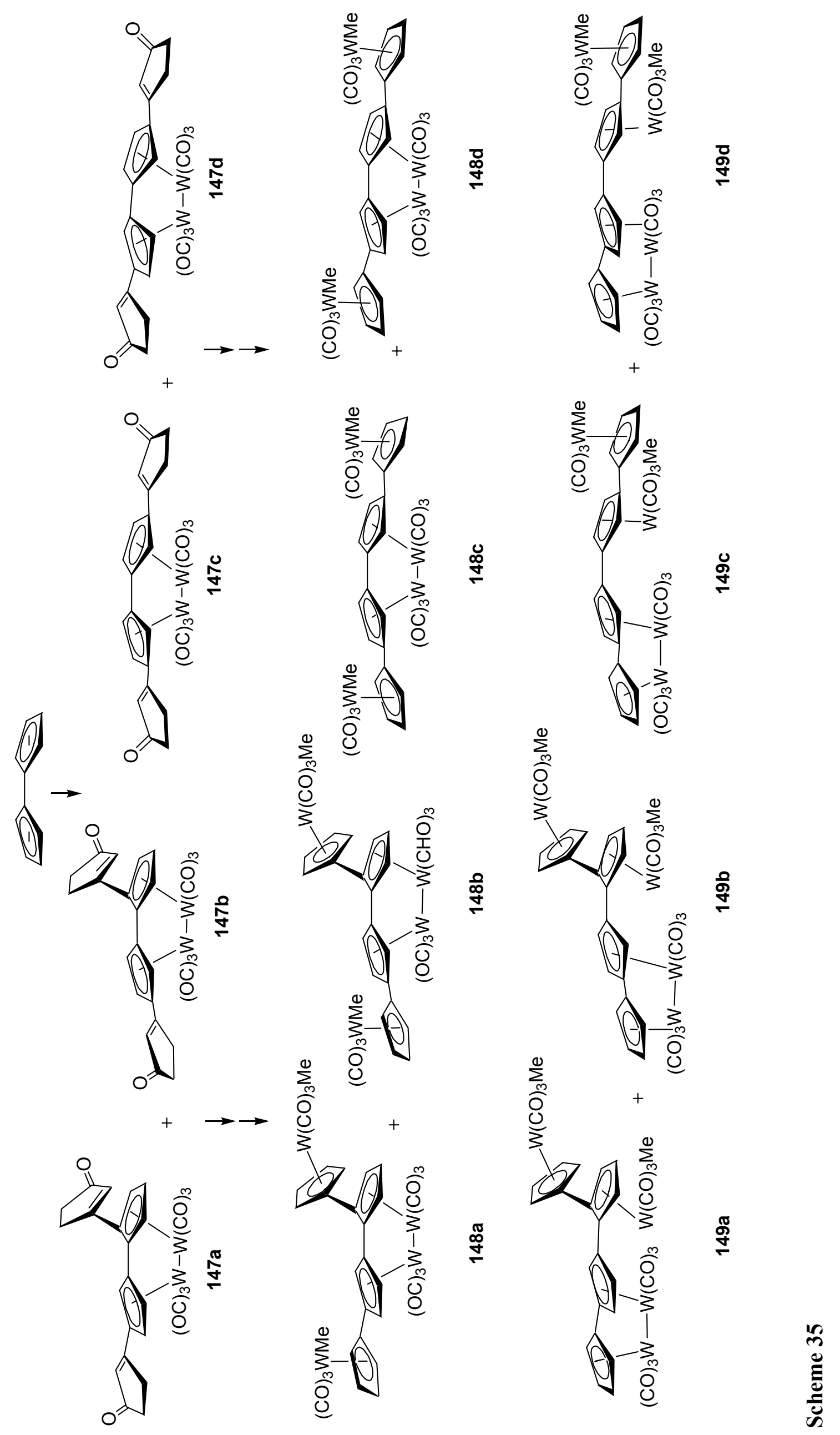




\section{Penta(cyclopentadienyl)- $\eta^{5}$-cyclopentadienyl Metal Complexes}

\subsection{Synthesis and structural characterization}

A rather dramatic observation was made during the application of the Pd catalyzed

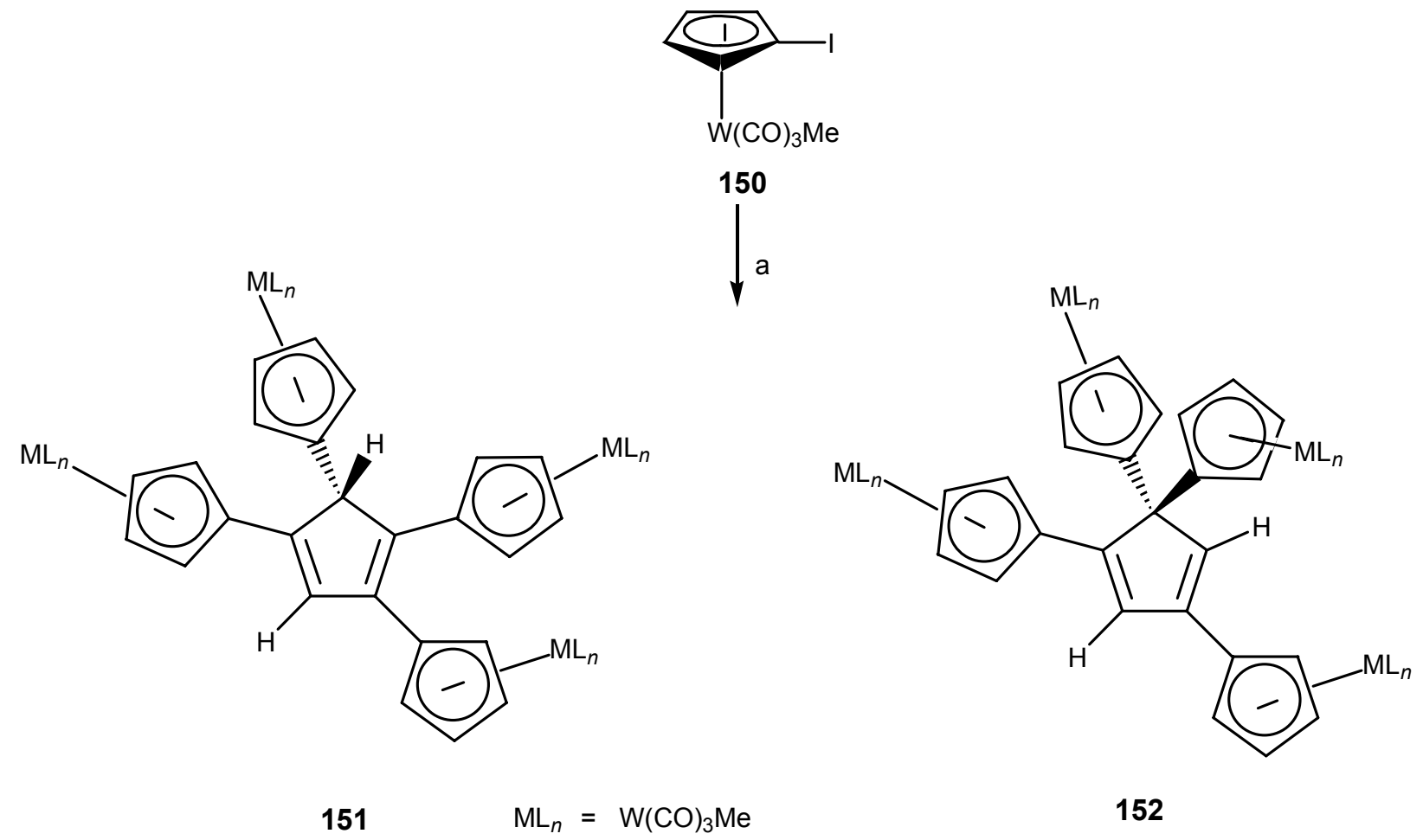

Scheme 36 a) $\mathrm{CpSnMe}_{3}$ (0.3 equiv), 3\% [Pd(OAc) $)_{2}$, $\mathrm{NaOAc}$ (15 equiv), $\mathrm{PhCH}_{2} \mathrm{Et}_{3} \mathrm{~N}^{+} \mathrm{Cl}^{-}(5$ equiv.), DMF, $23^{\circ} \mathrm{C}, 52 \mathrm{~h}$.

cyclopentadienylation of the iodide 150 to give $\mathbf{8 1}$ (Section 2.2.1.). Thus, using $\mathbf{1 5 0}$ in excess resulted directly in the tetracyclopentadienylated diene substrates 151 and 152 (Scheme 36)! ${ }^{47 c}$

Even better, this oligocyclopentadienylation could be carried out on cyclopentadiene itself, avoiding the unattractive (and cumbersome) use of the stannylated version. Similar results were obtained for $\mathrm{ML}_{n}=\mathrm{Mn}(\mathrm{CO})_{3}$ and $\mathrm{Fe}(\mathrm{CO})_{2} \mathrm{Me}^{47 \mathrm{c}}$ The facile generation of $\mathbf{1 5 1}$ immediately presented as a seemingly reachable target pentacyclopentadienyl(cyclopentadienyl) [pentaCp $(\mathrm{Cp})]$ complexes. This "star" like oligoCp topology is intrinsically theoretically interesting, has the potential of anchoring six metals (if clustered) in a completely novel constellation of a hexanuclear "minisurface" or (if metallocene like) a "Ferris wheel" array, and contains the topography of the elusive "buckybowl" semibuckminsterfullerene, $\mathrm{C}_{30} \mathrm{H}_{10} \mathbf{1 5 6}$ (see Scheme 38). ${ }^{71}$

Unfortunately, attempts to outfit $\mathbf{1 5 1}$ with a fifth $\mathrm{CpML}_{n}$ substituent failed by this method, very likely for steric reasons. Indeed an X-ray structure of 152 already shows severe congestion around the core five-membered ring. To get around this problem, an inverse strategy was employed which proved successful (Scheme 37). Thus, pentaiodocymanthrene 153 was 
persubstituted to $\mathbf{1 5 4}$, which could then be deprotonated to the highly symmetrical pentaanion 155. In solution, $\mathbf{1 5 4}$ exists as eight equilibrating double bond isomers (with all possible combinations of 1,3- and 1,4-cyclopentadienyl substituent sequences), one of which (shown in drawing 154) crystallizes to allow for an X-ray analysis. ${ }^{72}$ The substituent cyclopentadiene rings

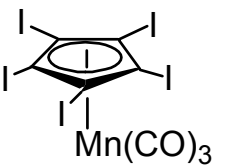

153

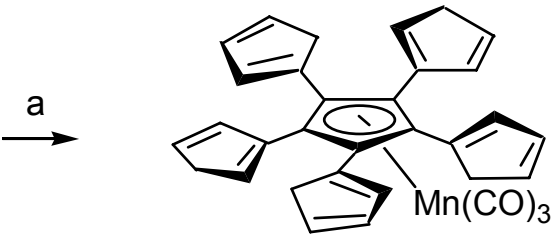

154

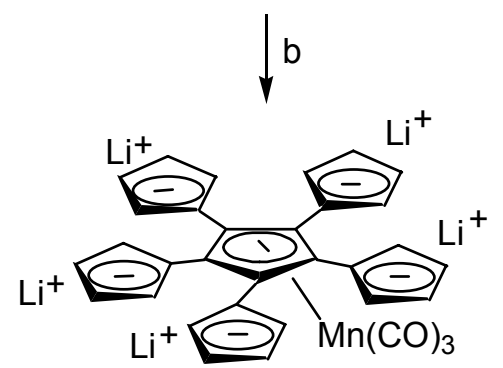

155

Scheme 37 a) $\mathrm{CpSnMe}_{3}$ (10 equiv), 30\% $\left[\mathrm{Pd}\left(\mathrm{CH}_{3} \mathrm{CN}\right)_{2} \mathrm{Cl}_{2}\right]$, DMF, $90{ }^{\circ} \mathrm{C}, 15 \mathrm{~min}$; b) $\mathrm{BuLi}(5$ equiv), THF, $23^{\circ} \mathrm{C}, 10 \mathrm{~min}$.

adopt a propeller-like arrangement to minimize steric interactions, with dihedral angles ranging from $42.2^{\circ}$ to $46.4^{\circ}$.

\subsection{Reactivity}

Consistent with the crowded environment around the central ring, all attempts at effecting transition metallation of $\mathbf{1 5 4}$ or $\mathbf{1 5 5}$ have failed so far. Instead, electron transfer (in the case of 155) seems to dominate. However, very interesting coalescence phenomena were observed on laser desorption/ionization (LDI) of 154. ${ }^{72}$ The aim of this experiment was to exploit the connectivity in the starting material to generate 156, as such (Scheme 38), or as a metal complex. Surprisingly, LDI-mass spectrometry at low laser power revealed initial fragmentation by not only successive loss of $\mathrm{CO}$ and eventually the metal, but also loss of one $\mathrm{Cp}$ ring. However, no signal for $\mathrm{C}_{30} \mathrm{H}_{10}$ was evident. At higher laser power, fullerenes (mostly $\mathrm{C}_{48}-\mathrm{C}_{74}$ ) appeared, with a dominant $\mathrm{C}_{50}{ }^{+}$ion peak, in addition to a relatively abundant $\mathrm{C}_{60}$ signal. An attempt to generate 156 by flash vacuum pyrolysis failed. Perhaps modified analogs of 154 (or 155) will produce the desired chemistry. 


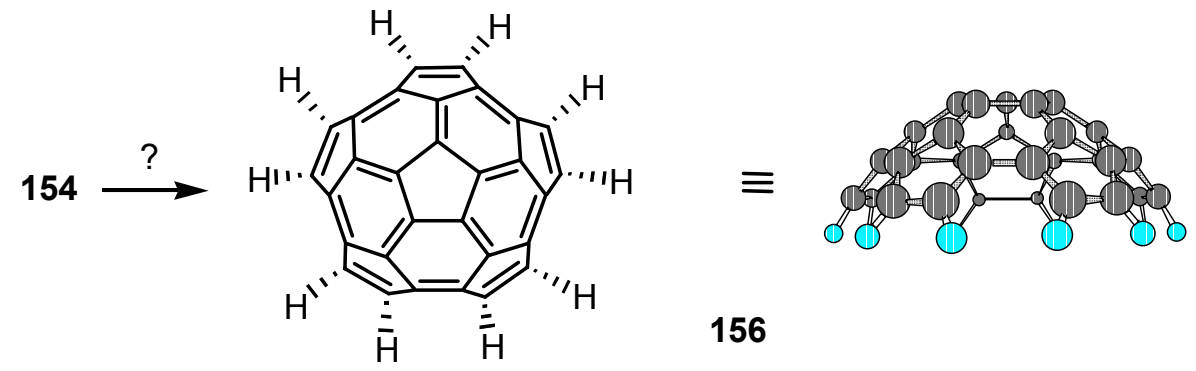

Scheme 38

\subsection{Conclusions}

While the pentaCp $(\mathrm{Cp})$ framework as present in $\mathbf{1 5 4}$ and $\mathbf{1 5 5}$ has proven to be difficult to harness, its rapid method of production clearly points the way to applications to other systems. ${ }^{73}$ In our group, these currently include functionalized cyclopentadienyls and their attachment to extended $\pi$ systems, metal-complexed and not.

\section{Outlook}

Since our first foray into the chemistry of fulvalene dimetals, ${ }^{14 a}$ we have come a long way. The field has blossomed and the ligand has become a standard staple of the synthetic organometallic chemist. One can anticipate that with the variety of methods developed to extend fulvalene to higher oligocyclopentadienyls, these ligands may find their way into the literature with increasing frequency. Many fascinating possibilities remain to be tested, and some of them are indicated in the body of this Account. In our group, the aim will remain the uncovery of new organic reactions mediated by these assemblies, perhaps in a catalytic fashion, and the construction of novel clusters with unprecedented physical and chemical properties.

\section{Acknowledgments}

This work was supported by the Director, Office of Energy Research, Office of Basic Energy Sciences, Chemical Sciences Division, of the U.S. Department of Energy, under Contract DEAC03-76SF00098. The Center for New Directions in Organic Synthesis is supported by BristolMyers Squibb as Sponsoring Member. C. G. A. is grateful to Fundação para a Ciência e Tecnologia (Lisbon, Portugal) for financial support. K. P. C. V. was blessed by the presence of an intellectually superb and experimentally highly gifted group of coworkers.

\section{References and Notes}

(1) Permanent address: Centro de Química Estrutural, Instituto Superior Técnico, Av. Rovisco Pais, 1049-001 Lisboa, Portugal. E-mail: cristina.azevedo@ist.utl.pt

(2) For selected pertinent reviews, see inter alia: a) Heck, J.; Dabek, S.; Meyer-Friedrichsen, T.; Wong, H. Coord. Chem. Rev. 1999, 190, 1217. b) Van den Beuken, E. K.; Feringa, B. 
L. Tetrahedron 1998, 54, 12985. c) Beck, W.; Niemer, B.; Wieser, M. Angew. Chem., Int. Ed. Engl. 1993, 32, 923. d) Casey, C. P. J. Organomet. Chem. 1990, 400, 205. e) Knox, S. A. R. J. Organomet. Chem. 1990, 400, 255. f) Stephan, D. W. Coord. Chem. Rev. 1989, 95, 41. g) Winter, M. J. Adv. Organomet. Chem. 1989, 29, 101. h) Muetterties, E. L.; Rhodin, R. N.; Band, E.; Brucker, C. F.; Pretzer, W. R. Chem. Rev. 1979, 79, 91. For a comprehensive monograph, see: i) Metal Clusters in Catalysis; Braunstein, P.; Oro, L. A.; Raithby, P. R. Eds.; Wiley-VCH: Weinheim, 1999; Vol. 1, 2.

(3) a) Jacobson, D. B.; Freiser, B. S. J. Am. Chem. Soc. 1985, 107, 7399. b) Skinner, H. A.; Connor, J. A. Pure Appl. Chem. 1985, 57, 79. c) Hoff, C. D. J. Organomet. Chem. 1985, 282, 201. d) Connor, J. A. Top. Curr. Chem. 1976, 71, 71. e) Ryan, M. F.; Eyler, J. R.; Richardson, D. E. J. Am. Chem. Soc. 1992, 114, 8611. f) Hoff, C. D. Prog. Inorg. Chem. 1992, 40, 503.

(4) a) For a review, see: Delville M.-H. Inorg. Chem. Acta 1999, 291, 1. b) Marcos, M. L.; Moreno, C.; Medina, R. M.; Macazaga, M. J.; Delgado, S.; Gonzalez-Velasco, J. J. Organomet. Chem. 1998, 568, 185. c) Moreno, C.; Marcos, M. L.; Macazaga, M. J.; Medina, R. M.; Farrar, D. H.; Gonzalez-Velasco, J.; Delgado, S. Organometallics 1998, 17, 4657. d) Hilbig, H.; Hudeczek, P.; Köhler, F. H.; Xie, X.; Bergerat, P.; Kahn, O. Inorg. Chem. 1998, 37, 4246.

(5) a) Dong, T.-Y.; Ho, P.-H.; Lai, X.-Q.; Lin, Z.-W.; Lin, K.-J. Organometallics 2000, 19, 1096 and references therein. b) Chin, T. T.; Grimes, R. N.; Geiger, W. E. Inorg. Chem. 1999, 38, 93 and references therein. c) Hendrickson, D. N.; Oh, S. M.; Dong, T.-Y.; Kambara, T.; Cohn, M. J.; Moore, M. F. Comments Inorg. Chem. 1985, 4, 329.

(6) Mueller-Westerhoff, U. T. Angew. Chem., Int. Ed. Engl. 1986, 25, 702.

(7) For some recent references, see: a) Heck, J.; Körnich, J. J. Organomet. Chem. 1999, 586, 111. b) Fröhlich, R.; Gimeno, J.; González-Cueva, M.; Lastra, E.; Borge, J.; GarcíaGranda, S. Organometallics 1999, 18, 3008. c) Bitterwolf, T. E.; Haener, J. L.; Shade, J. E.; Rheingold, A. L.; Yap, G. P. A. J. Organomet. Chem. 1997, 547, 23 and references therein. d) Van den Berg, W.; Boot, L.; Joosen, H.; van der Linden, J. G. M.; Bosman, W. P.; Smits, J. M. M.; de Gelder, R.; Beurskens, P. T.; Heck, J.; Gal, A. W. Inorg. Chem. 1997, 36, 1821. e) Zhou, X.; Zhang, Y.; Xu, S.; Tian, G.; Wang, B. Inorg. Chim. Acta 1997, 262, 109.

(8) a) Davis, J. H., Jr.; Sinn, E.; Grimes, R. N. J. Am. Chem. Soc. 1989, 111, 4784. b) Smart, J. C.; Curtis, C. J. Inorg. Chem. 1977, 16, 1788.

(9) a) Süss-Fink, G.; Meister, G. Adv. Organomet. Chem. 1993, 35, 41. b) Surprisingly, such perceived strain, while lengthening the M-M bonds, may not necessarily weaken them: Vollhardt, K. P. C.; Cammack, J. K.; Matzger, A. J.; Bauer, A.; Capps, K. B.; Hoff C. D. Inorg. Chem. 1999, 38, 2624.

(10) Churchill, M. R.; Wormald, J. Inorg. Chem. 1969, 8, 1970.

(11) Smart, J. C.; Pinsky, B. L.; Frederich, M. F.; Day, V. W. J. Am. Chem. Soc. 1979, 101, 4371.

(12) Drage, J. S.; Vollhardt, K. P. C. Organometallics 1986, 5, 280.

(13) Abrahamson, H. B.; Heeg, M. J. Inorg. Chem. 1984, 23, 2281.

(14) a) Vollhardt, K. P. C.; Weidman, T. W. J. Am. Chem. Soc. 1983, 105, 1676. See also ref. 40.

b) Vollhardt, K. P. C.; Weidman, T. W. Organometallics 1984, 3, 82. c) Curtis, C. J.; Haltiwanger, R. C. Organometallics 1991, 10, 3220 and references therein. d) Boese, R.; 
Tolman, W. B.; Vollhardt, K. P. C. Organometallics 1986, 5, 582.

(15) McGovern, P. A.; Vollhardt, K. P. C. J. Chem. Soc., Chem. Commun. 1996, 1593.

(16) a) Adams, R. D.; Collins, D. M.; Cotton, F. A. J. Am. Chem. Soc. 1974, 96, 749. b) Adams, R. D.; Collins, D. M.; Cotton, F. A. Inorg. Chem. 1974, 13, 1086. c) Mills, O. S.; Nice, J. P. J. Organomet. Chem. 1967, 9, 339.

(17) For illustrative recent examples of the variety of Fv dimetallic constructs and reactivity, see a) Royo, E.; Royo, P.; Cuenca, T.; Galakhov, M. Organometallics 2000, 19, 5559. b) Royo, E.; Galakhov, M.; Royo, P.; Cuenca, T. Organometallics 2000, 19, 3347. c) Kayser, B.; Eichberg, M. J.; Vollhardt, K. P. C. Organometallics 2000, 19, 2389. d) Kovács, I.; Shaver, A. J. Organomet. Chem. 1999, 586, 31. e) Watanabe, M.; Sato, M.; Takayama, T. Organometallics 1999, 18, 5201. f) Kovács, I.; Pearson, C.; Shaver, A. J. Organomet. Chem. 1999, 584, 347. g) Reference 4b. h) Moreno, C.; Macazaga, M.-J.; Medina, R.-M.; Farrar, D. H.; Delgado, S. Organometallics 1998, 17, 3733.

(18) McGovern, P. A.; Vollhardt, K. P. C. Synlett 1990, 493.

(19) This effort is to be viewed within the context of the growing interest in the properties of "linear" oligometals. For selected recent references, see : a) Tanase, T.; Begum, R. A.; Toda, H.; Yamamoto, Y. Organometallics 2001, 20, 968. b) Clérac, R.; Cotton, F. A.; Daniels, L. M.; Dunbar, K. R.; Kirschbaum, K.; Murillo, C. A.; Pinkerton, A. A.; Schultz, A. J.; Wang, X. J. Am. Chem. Soc. 2000, 122, 6226. c) Clérac, R.; Cotton, F. A.; Dunbar, K. R.; Lu, T.; Murillo, C. A.; Wang, X. J. Am. Chem. Soc. 2000, 122, 2272. d) AbuYoussef, M. A. M.; Escuer, A.; Goher, M. A. S.; Mautner, F. A.; Rei $\beta$, G. J.; Vicente, R. Angew. Chem. Int. Ed. 2000, 39, 1624. e) Adams, R. D.; Qu, B. Organometallics 2000, 19, 2411. f) Dubé, T.; Gambarotta, S.; Yap, G. P. A. Organometallics 2000, 19, 115. g) Cotton, F. A.; Daniels, L. M.; Murillo, C. A.; Wang, X. Chem. Commun. 1999, 2461. h) Tejel, C.; Bordonaba, M.; Ciriano, M. A.; Lahoz, F. J.; Oro, L. A. Chem. Commun. 1999, 2387. i) Murahashi, T.; Mochizuki, E.; Kai, Y.; Kurosawa, H. J. Am. Chem. Soc. 1999, 121, 10660. j) Prater, M. E.; Pence, L. E.; Clérac, R.; Finniss, G. M.; Campana, C.; Auban-Senzier, P.; Jérome, D.; Canadell, E.; Dunbar, K. R. J. Am. Chem. Soc. 1999, 121, 8005.

(20) For review, see : a) Peckham, T. J.; Gómez-Elipe, P.; Manners, I. In Metallocenes; Togni, A.; Halterman, R. L., Eds.; Wiley-VCH : Weinheim, 1998; Vol. 2, Chapter 12, p 723. b) For early work, see: Gmelin Handbook of Inorganic Chemistry; Springer-Verlag: Berlin, 1977; Vol.41, Pt. A. Ferrocene 6.

(21) a) Bister, H.-J.; Butenschön, H. Synlett 1992, 22. b) Jutzi, P.; Schnittger, J. Chem. Ber. 1989, $122,629$.

(22) a) Haines, R. J.; du Pereez, A. L.; Marais, I. L. J. Organomet. Chem. 1971, 28, 97. b)

Barnett, K. W.; Treichel, P. M. Inorg. Chem. 1967, 6, 294.

(23) a) Tyler, D. R. Prog. Inorg. Chem. 1988, 36, 125. b) Philbin, C. E.; Golman, A. S.; Tyler, D. R. Inorg. Chem. 1986, 25, 4434. c) Stiegman, A. E.; Tyler, D. R. J. Am. Chem. Soc., 1985, 107,967 and references therein.

(24) a) Tilset, M.; Vollhardt, K. P. C.; Boese, R. Organometallics 1994, 13, 3146. For related work on $\mathrm{FvMo}_{2-}$ and $\mathrm{FvW}_{2}$-systems, see, e.g.: ref. 4c, $17 \mathrm{f}, \mathrm{h}$ and b) Bitterwolf, T. E. Coord. Chem. Rev. 2000, 206-207, 419. c) Delgado, S.; Macazaga, M.-J.; Medina, R. M.; Moreno, C. Organometallics 1996, 15, 5416. d) Kovács, I.; Baird, M. C. Organometallics 1995, 14, 4074, 4084.

(25) Whiteley, M. W. In Comprehensive Organometallic Chemistry 2; Abel, E. W.; Stone, F. G. A.; Wilkinson, G., Eds.; Pergamon: New York; Vol. 5, Chapter 6, p 331. 
(26) a) Volland, M. A. O.; Kudis, S.; Helmchen, G.; Hyla-Kryspin, I.; Rominger, F.; Gleiter, R. Organometallics 2001, 20, 227. b) Klahn, A. H.; Oelckers, B.; Godoy, F.; Garland, M. T.; Vega, A.; Perutz, R. N.; Higgitt, C. L. J. Chem. Soc., Dalton Trans. 1998, 3079 and references therein. c) Rau, D.; Behrens, U. J. Organomet. Chem. 1990, 387, 219 and references therein.

(27) Treichel, P. M.; Shubkin, R. L. Inorg. Chem. 1967, 6, 1328.

(28) For selected recent references, see a) Matsuzaka, H.; Ichikawa, K.; Ishioka, T.; Sato, H.; Okubo, T.; Ishii, T.; Yamashita, M.; Kondo, M.; Kitagawa, S. J. Organomet. Chem. 2000, 596, 121. b) Baxter, R. J.; Knox, G. R.; Moir, J. H.; Pauson, P. L.; Spicer, M. D. Organometallics 1999, 18, 197, 206. c) Adams, K. J.; Barker, J. J.; Knox, S. A. R.; Orpen, A. G. J. Chem. Soc., Dalton Trans. 1996, 975 and references therein. d) See also: Diercks, R.; Eaton, B. E.; Gürtzgen, S.; Jalisatgi, S.; Matzger, A. J.; Radde, R. H.; Vollhardt, K. P. C. J. Am. Chem. Soc. 1998, 120, 8247 and references therein.

(29) Drage, S. J.; Tilset, M.; Vollhardt, K. P. C.; Weidman, T. W. Organometallics 1984, 3, 812.

(30) a) El Amouri, H.; Vaissermann, J.; Besace, Y.; Vollhardt, K. P. C.; Ball, G. E. Organometallics 1993, 12, 605. b) El Amouri, H.; Besace, Y. Organometallics 1996, 15, 3102. c) El Amouri, H.; Besace, Y. Organometallics 1996, 15, 1514.

(31) a) Piper, T. S.; Wilkinson, G. J. Inorg. Nucl. Chem. 1956, 3, 104. b) King, R. B.; Fronzaglia, A. J. Am. Chem. Soc. 1966, 88, 709.

(32) a) De Sanctis, Y.; Arce, A. J.; Machado, R.; Capparelli, M. V.; Atencio, R.; Deeming, A. J.; Manzur, J. Organometallics 1997, 16, 1520. b) Rausch, M. D.; Spink, W. C.; Conway, B. G.; Rogers, R. D.; Atwood, J. L. J. Organomet. Chem. 1990, 383, 227. b) Rittinger, S.; Buchholz, D.; Delville-Desbois, M.-H.; Linares, J.; Varret, F.; Boese, R.; Zsolnai, L.; Huttner, G.; Astruc, D. Organometallics 1992, 11, 1454. c) Meng, X.; Sabat, M.; Grimes, R. N. J. Am. Chem. Soc. 1993, 115, 6143.

(33) Tilset, M.; Vollhardt, K. P. C. Organometallics 1985, 4, 2230.

(34) For example, see : a) Yu, P.; Murphy, E. F.; Roesky, H. W.; Lubini, P., Schmidt, H.-G.; Noltemeyer, M. Organometallics 1997, 16, 313. b) Ni, J.; Qiu, Y.; Cox, T. M.; Jones, C. A.; Berry, C.; Melon, L.; Bott, S. Organometallics 1996, 15, 4669. c) Thewalt, U.; Wöhrle, T. J. Organomet. Chem. 1996, 506, 331 and references therein.

(35) a) Samuel, E.; Rausch, M. D.; Gismondi, T. E.; Mintz, E. A.; Gianotti, C. J. Organomet. Chem. 1979, 172, 309. b) Rausch, M. D.; Gismondi, T. E.; Alt, H. G.; Schwärzle, J. A. Z. Naturforsch., B: Anorg. Chem., Org. Chem. 1977, 32B, 998. c) Tyler, D. R. Inorg. Chem. 1981, 20, 2257. d) Alt, H. G. Angew. Chem., Int. Ed. Engl. 1984, 96, 752.

(36) Nataro, C.; Thomas, L. M.; Angelici, R. J. Inorg. Chem. 1997, 36, 6000.

(37) For $\left(\mathrm{CpML}_{3}\right)_{2}{ }^{2+}, \mathrm{M}=\mathrm{Mo}, \mathrm{W}$, see : Alvarez, M. A.; García, G.; García, M. E.; Riera, V.; Ruiz, M. A.; Lanfranchi, M.; Tiripicchio, A. Organometallics 1999, 18, 4509.

(38) Dyke, A. F.; Knox, S. A. R.; Naish, P. J.; Taylor, G. E. J. Chem. Soc., Dalton Trans. 1982, 1297 and references therein.

(39) Bloyce, P. E.; Campen, A. K.; Hooker, R. H.; Rest, A. J.; Thomas, N. R.; Bitterwolf, T. E.; Shade, J. E. J. Chem. Soc., Dalton Trans. 1990, 2833.

(40) Boese, R.; Cammack, J. K.; Matzger, A. J.; Pflug, K.; Tolman, W. B.; Vollhardt, K. P. C.; Weidman, T. W. J. Am. Chem. Soc. 1997, 119, 6757 and references therein.

(41) See, inter alia: a) Godoy, F.; Higgitt, C. L.; Klahn, A. H.; Oelckers, B.; Parsons, S.; Perutz, R. N. J. Chem. Soc., Dalton Trans. 1999, 2039. b) Alvarez, M. A.; Alvarez, C.; García, M. 
E.; Riera, V.; Ruiz, M. A. Organometallics 1997, 16, 2581 and references therein. c) Briggs, P. M.; Young, V. G. Jr.; Wigley, D. E. Chem. Commun. 1997, 791.

(42) For a pertinent recent diruthenium case, see : Ohki, Y.; Suzuki, H. Angew. Chem. Int. Ed. 2000, 39, 3463.

43) Perhaps most relevant are: a) Wielstra. Y.; Gambarotta, S.; Spek, A. L.; Smeets, W. J. J. Organometallics 1990, 9, 2142. b) Berry, M.; Cooper, N. J.; Green, M. L. H.; Simpson, S. J. J. Chem. Soc., Dalton Trans. 1980, 29. c) Barral, M. C.; Green, M. L. H.; Jimenez, R. J. Chem. Soc., Dalton Trans. 1982, 2495. d) Green, M. L. H.; Mtetwa, V. S. B.; Sella, A.; Chernega, A. N. J. Chem. Soc., Dalton Trans. 1994, 201.

(44) A topologically tantalizingly close, but mechanistically different manifold involving bridged $(\mathrm{CpM})_{2}$ complexes of $\mathrm{Fe}$ and $\mathrm{Ru}$ has been extensively investigated, see : a) Sun, H.; Teng, X.; Huang, X.; Hu, Z.; Pan, Y. J. Organomet. Chem. 2000, 595, 268. b) Zhang, Y.; Wang, B.; Xu, S.; Zhou, X.; Sun, J. J. Organomet. Chem. 1999, 584, 356. c) Xie, W.; Wang, B.; Dai, X.; Xu, S.; Zhou, X. Organometallics 1998, 17, 5406. d) Burger, P. Angew. Chem. Int. Ed. 2001, 40, 1917. e) Bitterwolf, T. E. Coord. Chem. Rev. 2001, 211, 235.

(45) For recent extensive reviews, see a) Gade, L. H. Angew. Chem. Int. Ed. 2000, 39, 2658. b) Gade, L. H.; Memmler, H.; Kauper, U.; Schneider, A.; Fabre, S.; Bezougli, I.; Lutz, M.; Galka, C.; Scowen, I. J.; McPartlin, M. Chem. Eur. J. 2000, 6, 692. c) Wheatley, N.; Kalck, P. Chem. Rev. 1999, 99, 3379. d) Braunstein, P.; Rosé, J. In Metal Clusers in Catalysis; Braunstein, P.; Oro, L. A.; Raithby, P. R. Eds.; Wiley-VCH : Weinheim, 1999; Vol. 2, p 616 and references therein.

(46) For recent references, see : a) Kang, Y. K.; Shin, K. S.; Lee, S.-G.; Lee, I. S.; Chung, Y. K. Organometallics 1999, 18, 180. b) Schottenberger, H.; Buchmeiser, M.; Rieker, C.; Jaitner, P.; Wurst, K. J. Organomet. Chem. 1997, 541, 249. c) Begley, M. J.; Mountford, P.; Stewart, P. J.; Swallow, D.; Wan, S. J. Chem. Soc., Dalton Trans. 1996, 1323. d) Scott, P.; Rief, U.; Diebold, J.; Brintzinger, H. H. Organometallics 1993, 12, 3094. e) Bauer, A.; Hilbig, H.; Hiller, W.; Hinterschwepfinger, E.; Köhler, F. H.; Neumayer, M. Synthesis 2001, 778. f) Hilbig, H.; Köhler, F. H.; Mörtl, K. J. Organomet. Chem. 2001, 627, 71.

(47) a) Huffman, M. A.; Newman, D. A.; Tilset, M.; Tolman, W. B.; Vollhardt, K. P. C. Organometallics 1986, 5, 1926. b) Kahn, A. P.; Newman, D. A.; Vollhardt, K. P. C. Synlett 1990, 141. c) Boese, R.; Bräunlich, G.; Gotteland, J.-P.; Hwang, J.-T.; Troll, C.; Vollhardt, K. P. C. Angew. Chem., Int. Ed. Engl. 1996, 35, 995.

(48) Lo Sterzo, C.; Miller, M. M.; Stille, J. K. Organometallics 1989, 8, 2331.

(49) Tolman, W. B.; Vollhardt, K. P. C. unpublished results.

(50) Kahn, A. P.; Vollhardt, K. P. C. unpublished results.

(51) Boese, R.; Huffman, M. A.; Vollhardt, K. P. C. Angew. Chem., Int. Ed. Engl. 1991, 30, 1463.

(52) For mononuclear examples of alkyne-vinylidene isomerizations, see, inter alia : a) Bartlett, I. M.; Connelly, N. G.; Martín, A. J.; Orpen, A. G.; Paget, T. J.; Rieger, A. L.; Rieger, P. H. J. Chem. Soc., Dalton Trans. 1999, 691. b) Peréz-Carreño, E.; Paoli, P.; Ienco, A.; Mealli, C. Eur. J. Inorg. Chem. 1999, 1315. c) Bruce, M. I.; Hall, B. C.; Zaitseva, N. N.; Skelton, B. W.; White, A. H. J. Chem. Soc., Dalton Trans. 1998, 1793 and references therein. d) Oliván, M.; Clot, E.; Eisenstein, O.; Caulton, K. G. Organometallics 1998, 17, 3091.

(53) For homodinuclear analogs, see, inter alia : a) King, P. J.; Knox, S. A. R.; Mc Cormick, G. J.; Orpen, A. G. Dalton 2000, 2975. b) Ishii, Y.; Ogio, K.; Nishio, M.; Retbøll, M.; Kuwata, S.; Matsuzaka, H.; Hidai, M. J. Organomet. Chem. 2000, 599, 221. c) Kuncheria, 
J.; Mirza, H. A.; Vittal, J. J.; Puddephatt, R. J. J. Organomet. Chem. 2000, 593, 77 and references therein.

(54) For related heterodinuclear systems, see, inter alia : a) Beckhaus, R.; Oster, J.; Wang, R.; Böhme, U. Organometallics 1998, 17, 2215. b) George, D. S. A.; Mc Donald, R.; Cowie, M. Organometallics 1998, 17, 2553. c) Beckhaus, R. J. Chem. Soc., Dalton Trans. 1997, 1991.

(55) Kahn, A. P.; Boese, R.; Blümel, J.; Vollhardt, K. P. C. J. Organomet. Chem. 1994, 472, 149.

(56) For $\mathrm{CpW}(\mathrm{CO})_{3} \mathrm{Me}$, see : a) Virrels, I. G.; George, M. W.; Johnson, F. P. A.; Turner, J. J.; Westwell, J. R. Organometallics 1995, 14, 5203 and references therein. For $\mathrm{CpMo}(\mathrm{CO})_{3} \mathrm{CH}_{3}$, see : b) Solodovnikov, S.; Tumanskii, B. L.; Bubnov, N. N.; Kabacknik, M. I. Izv. Akad. Nauk. SSSR, Ser. Khim. 1986, 2147. See also Section 2.1.2. and reference 35. For $\mathrm{CpRh}(\mathrm{CO})_{2}$, see : c) Dunwoody, N.; Sun, S.-S.; Lees, A. J. Inorg. Chem. 2000, 39, 4442 and references therein. d) Asbury, J. B.; Ghosh, H. N.; Yeston, J. S.; Bergman, R. G.; Lian, T. Organometallics 1998, 17, 3417 and references therein. For a relevant earlier review, see : e) Alt, H. G. Angew. Chem., Int. Ed. Engl. 1984, 23, 766.

(57) Moulton R.; Weidman, T. W.; Vollhardt, K. P. C.; Bard, A. J. Inorg. Chem. 1986, 25, 1846.

(58) a) Brown, D. S.; Delville-Desbois, M.-H.; Vollhardt, K. P. C.; Astruc, D. New J. Chem. 1992, 16, 899. b) Delville-Desbois, M.-H.; Brown, D. S.; Vollhardt, K. P. C.; Astruc, D. J. Chem. Soc., Chem. Commun. 1991, 1355.

(59) a) Brown, D.; Delville-Desbois, M.-H.; Vollhardt, K. P. C.; Astruc, D. Organometallics 1996, 15, 2360. b) Brown, D. S.; Delville-Desbois, M.-H.; Boese, R.; Vollhardt, K. P. C.; Astruc, D. Angew. Chem., Int. Ed. Engl. 1994, 33, 661.

(60) Astruc, D. Electron Transfer and Radical Processes in Transition-Metal Chemistry; VCH : New York, 1995; Chapter 4.

(61) For recent relevant publications, see, inter alia : a) Cammell, E. J.; Andersen, J.-A. M. J. Organomet. Chem. 2000, 604, 7. b) Cao, Z.; Niu, S.; Hall, M. B. J. Phys. Chem. 2000, 104, 7324. c) Derecskei-Kovacs, A.; Marynick, D. S. J. Am. Chem. Soc. 2000, 122, 2078. d) Oke, O.; McDonald, R.; Cowie, M. Organometallics 1999, 18, 1629 and references therein.

(62) Boese, R.; Myrabo, R. L.; Newman, D. A.; Vollhardt, K. P. C. Angew. Chem., Int. Ed. Engl. 1990, 29, 549.

(63) Coulson, C. A.; Streitwieser, A., Jr.; Poole, M. D.; Brauman, J. I. Dictionary of $\pi$-Electron Calculations; Pergamon Press: London, 1965.

(64) Baryza, J.; Cammack, J. K.; Gooßen, L. J.; Myrabo, R. L.; Vollhardt, K. P. C. unpublished results.

(65) Moore, E. J.; Sullivan, J. M.; Norton, J. R. J. Am. Chem. Soc. 1986, 108, 2257.

(66) Most relevant studies are a) Corraine, M. S.; Atwood, J. D. Organometallics 1991, 10, 2315. b) Corraine, M. S.; Atwood, J. D. Inorg. Chem. 1989, 28, 3781.

(67) See, e.g. : Chin, T. T.; Geiger, W. E.; Rheingold, A. L. J. Am. Chem. Soc. 1996, 118, 5002.

(68) For selected relevant studies, see : a) Wang, P.; Atwood, J. D. Organometallics 1993, 12, 4247. b) Schwarz, C. L.; Bullock, R. M.; Creutz, C. J. Am. Chem. Soc. 1991, 113, 1225. c) Lai, C.-K.; Feighery, W. G.; Zhen, Y.; Atwood, J. D. Inorg. Chem. 1989, 28, 3929. d) Baxter, S. M.; Ferguson, G. S.; Wolczanski, P. T. J. Am. Chem. Soc. 1988, 110, 4231 and references therein. e) Casey, C. P.; Cyr, C. R.; Anderson, R. L.; Marten, D. F. J. Am. Chem. Soc. 1975, 97, 3053. 
(69) a) Alt, H. G. J. Organomet. Chem. 1985, 288, 149. b) Alt, H. G.; Engelhardt, H. E.; Thewalt, U.; Riede, J. J. Organomet. Chem. 1985, 288, 165.

(70) Azevedo, C. G.; Boese, R.; Newman, D. A.; Vollhardt, K. P. C. Organometallics 1995, 14 , 4980.

(71) See, inter alia : a) Sygula, A.; Zbigniew, M.; Ilia, G.; Rabideau, P. W.; Franczek, F. R. Chem. Commun. 2000, 2439. b) Scott, L. T. Pure Appl. Chem. 1996, 68, 291. c) Rabideau, P. W.; Sygula, A. Acc. Chem. Res. 1996, 29, 235.

(72) Barrow, M. P.; Cammack, J. K.; Goebel, M.; Wasser, I. M.; Vollhardt, K. P. C.; Drewello, T. J. Organomet. Chem. 1999, 572, 135.

(73) For a recent adaptation of this method to the preparation of pentaarylcyclopentadienes, see : Dyker, G.; Heiermann, J.; Muira, M.; Inoh, J.-I.; Pivsa-Art, S.; Satoh, T.; Nomura, M. Chem. Eur. J. 2000, 6, 3426. 
Graphic Abstract

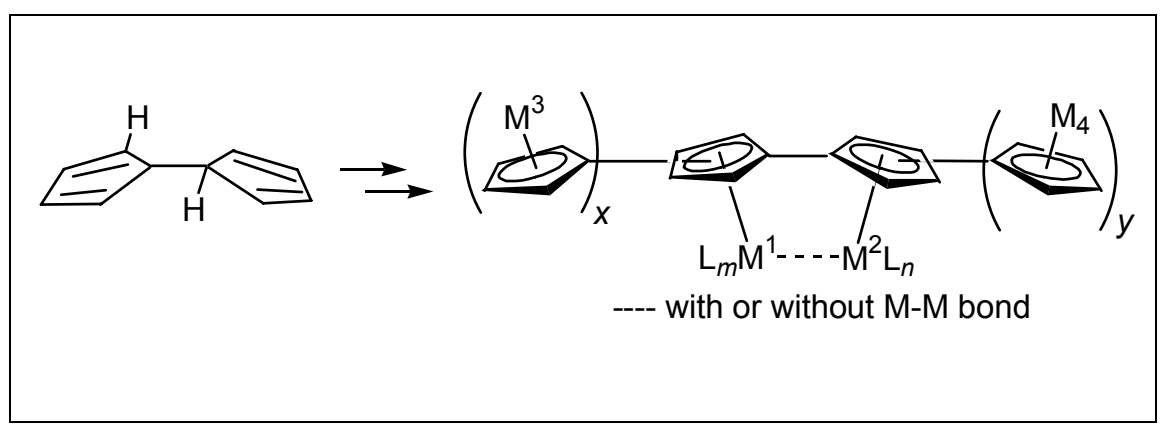




\section{Biographical Sketches}

Cristina G. de Azevedo was born in 1958 in Portugal. She studied at the Instituto Superior Técnico, Lisbon, where she graduated and received both her Msc. and Ph.D. in Chemical Engineering with Professor Carlos Romão. She carried out experimental work at the Max-Planck Institut für Kohlenforschung, Germany, in collaboration with Prof. P. W. Jolly. After a postdoctoral year at the University of California at Berkeley with Prof. K. Peter C. Vollhardt on quatercyclopentadienyl transition metal complexes, she returned to the Instituto Superior Técnico, where she is an Assistant Professor. Her research interests are organometallic chemistry, in particular the synthesis, characterization, and reactivity of group 4 and 6 transition metal complexes bearing ligands with $\mathrm{N}$ and P-donor atoms.

K. Peter C. Vollhardt was born in Madrid, raised in Buenos Aires and Munich, studied at the University of Munich, got his Ph.D. with Professor Peter Garratt at the University College London, and was a postdoctoral fellow with Professor Bob Bergman (then) at the California Institute of Technology. He moved to Berkeley in 1974, when he began his efforts towards the development of organocobalt reagents in organic synthesis, the preparation of theoretically interesting hydrocarbons, the assembly of novel transition metal arrays with potential in catalysis, and the discovery of a parking space. Among other pleasant experiences, he was a Studienstiftler, Adolf Windaus medallist, Humboldt Senior Scientist, ACS Organometallic Awardee, Otto Bayer Prize Awardee, and A. C. Cope Scholar. Among his over 250 publications, he treasures especially his textbook on Organic Chemistry, translated into seven languages. He is the Chief Editor of this journal. The photograph shows him gratuitously at the center of the (extended) Thieme family of Synlett and Synthesis. 


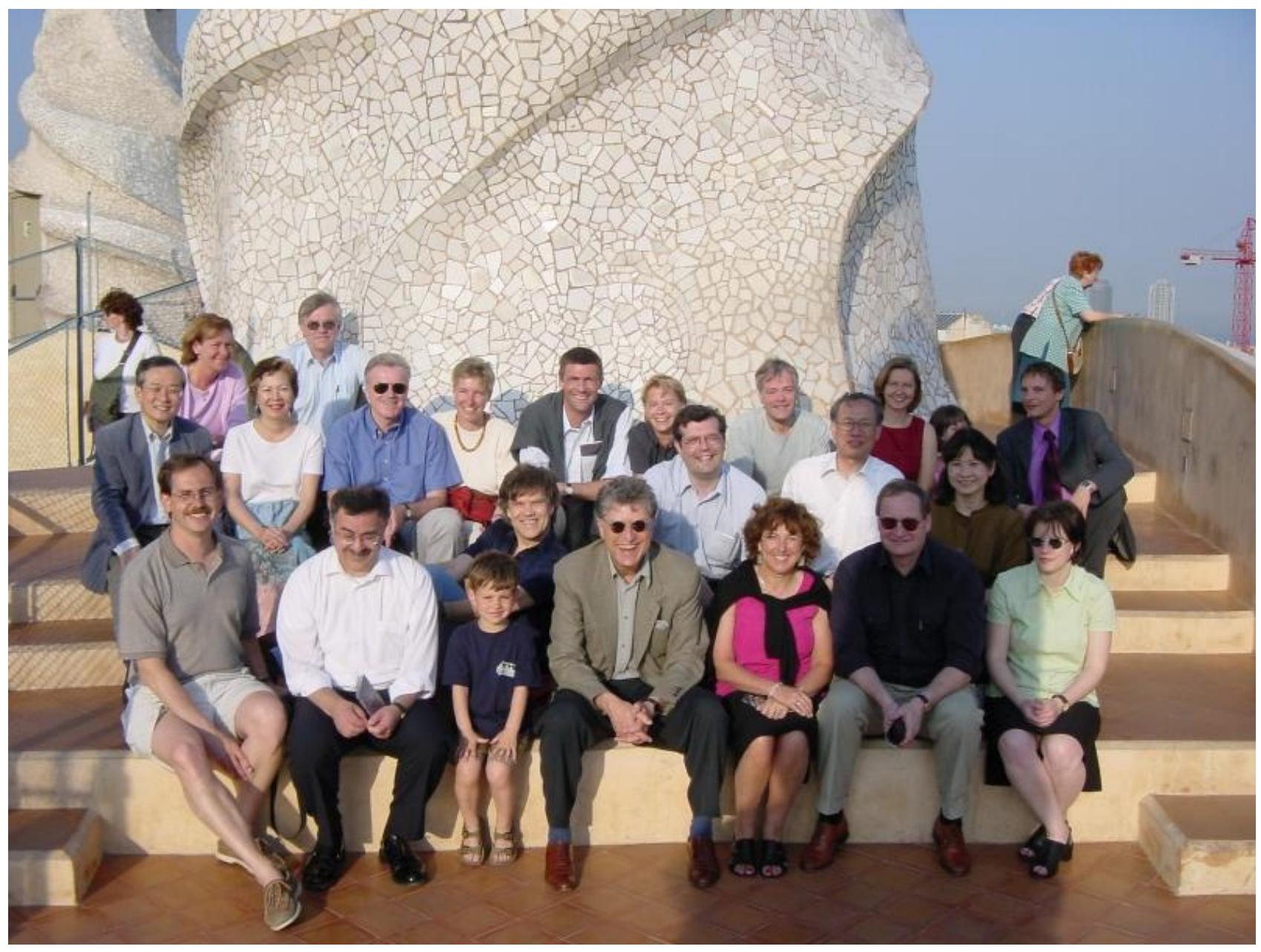

From left, 4th row: Mechthild Enders, Dieter Enders; 3rd row: Hisashi Yamamoto, Michiyo Yamamoto, Bernd Giese, Anne

Giese, Thorsten Bach, Martina Otten, Laurence Harwood, Kristina Kurz, Margot Lautens, Thomas Krimmer; 2nd row:

Victor Snieckus, Paul Knochel, Tohru Fukuyama, Yuri Fukuyama; 1st row: Mark Lautens, Philip Kocienski, Nathan Lautens, Peter Vollhardt, Rose Ley, Steve Ley, Susanne Haak. 


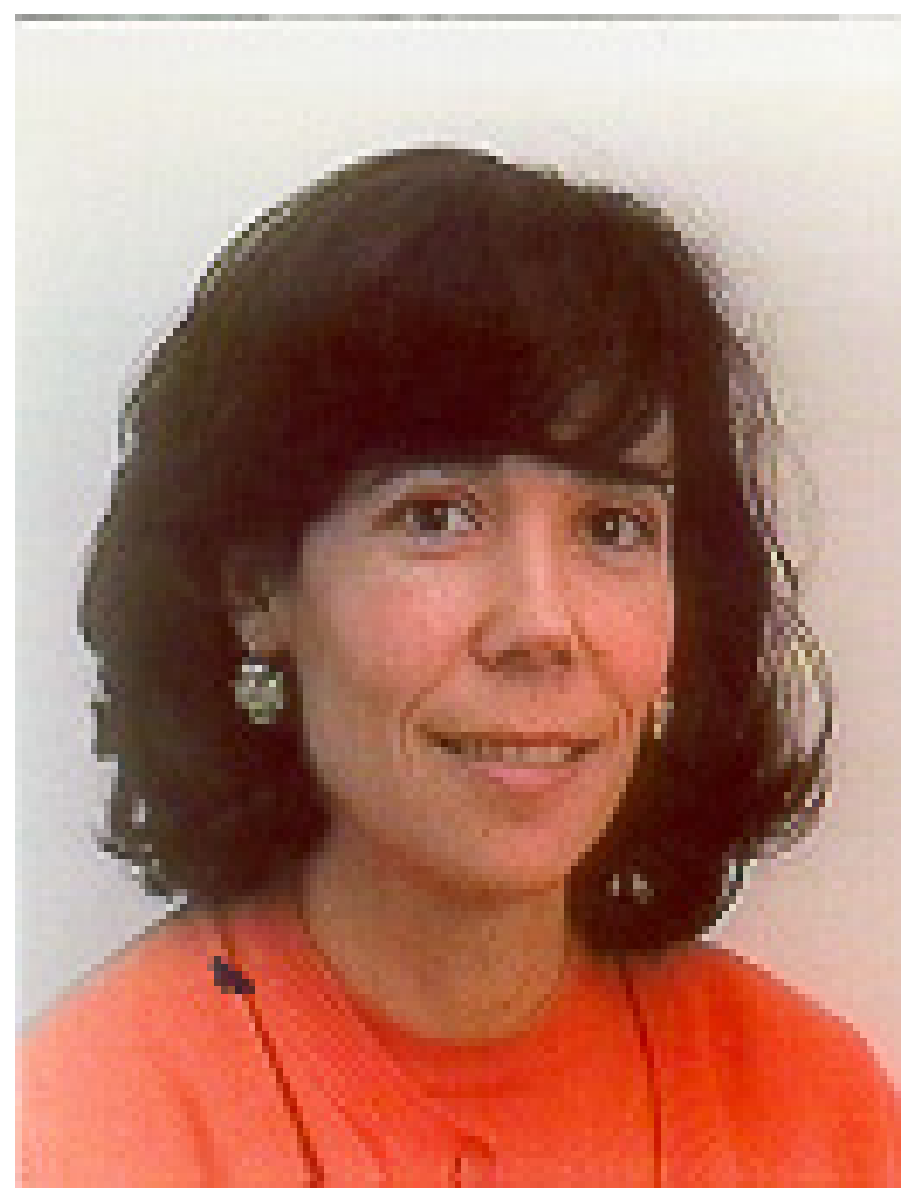

Dr. Cristina G. de Azevedo 